Article

\title{
Application of Mode-Adaptive Bidirectional Pushover Analysis to an Irregular Reinforced Concrete Building Retrofitted via Base Isolation
}

\author{
Kenji Fujii ${ }^{1, *}$, Takumi Masuda ${ }^{2}$ \\ 1 Department of Architecture, Faculty of Creative Engineering, Chiba Institute of Technology; Chiba 275- \\ 0016, Japan; kenji.fujii@p.chibakoudai.jp \\ 2 Graduate School of Creative Engineering, Chiba Institute of Technology; Chiba 275-0016, Japan; \\ s16b1147bq@s.chibakoudai.jp \\ * Correspondence: kenji.fujii@p.chibakoudai.jp
}

Featured Application: Seismic response evaluation of a base-isolated building; seismic rehabilitation design for Reinforced Concrete buildings using the base-isolation technique.

\begin{abstract}
In this article, the main building of the former Uto City Hall, which was severely damaged in the 2016 Kumamoto earthquake, is investigated as a case study for the retrofitting of an irregular Reinforced Concrete building using the base-isolation technique. Its peak response is predicted via mode-adaptive bidirectional pushover analysis (MABPA), which was originally proposed by the authors. In the prediction step of MABPA, the peaks of the first and second modal responses are predicted considering the energy balance during a half cycle of the structural response. The numerical analysis results show that the peak relative displacement can be properly predicted by MABPA. The results also show that the performance of the retrofitted building models is satisfactory for the ground motion considered in this study, including the recorded motions in the 2016 Kumamoto earthquake.
\end{abstract}

Keywords: seismic isolation; asymmetric building; mode-adaptive bidirectional pushover analysis (MABPA); seismic retrofit; momentary energy input

\section{Introduction}

\subsection{Background}

Seismic isolation is widely applied to buildings for earthquake protection in earthquake-prone countries [1]. Unlike in the case of traditional (non-isolated) earthquake-resistant structures, seismic isolation ensures that the behaviors of building structures are within the elastic range and reduces acceleration in buildings during large earthquakes [2]. Therefore, this technique is applied to not only new buildings but also existing reinforced concrete and masonry buildings, including historical structures [3-11].

In general, there is some degree of irregularity in building structures, whether they are newly designed or preexisting. Therefore, the problem of torsional response due to plan irregularities needs to be studied for base-isolated structures as well as non-isolated structures. Several researchers have investigated the seismic behavior of base-isolated buildings with plan irregularities [12-25]; these include fundamental parametric studies using idealized models [12-16], as well as studies using more realistic frame building models [17-25]. Most of these studies are based on nonlinear time-history analyses [1224]. However, there are a few investigations that examine the applicability of nonlinear static procedures to base-isolated buildings with asymmetry. Kilar and Koren [25] had examined the applicability of the extended N2 method [26,27], which is one of the variants 
of the nonlinear static procedures, to the base-isolated asymmetric buildings. They found the nonlinear peak response of base-isolated asymmetric building can be predicted by the extend N2 method. However, they have examined only those whose superstructure is regular in elevation. Therefore, further investigations are needed for the applicability of the nonlinear static procedures, especially for base-isolated building with plan and elevation irregularities.

\subsection{Motivation}

There are two main motivations for this study. The first is to extend nonlinear static analyses to base-isolated buildings with irregularities, and the second is to predict the nonlinear peak responses of base-isolated buildings according to the concept of energy input.

With respect to the first motivation, the authors have proposed mode-adaptive bidirectional pushover analysis (MABPA) [28-33]. This is a variant of nonlinear static analysis and was originally proposed for the seismic analysis of non-isolated asymmetric buildings subjected to horizontal bidirectional excitation. The first version of MABPA was proposed for non-isolated asymmetric buildings with regular elevation [28]; it was then updated following the development of displacement-based mode-adaptive pushover (DB-MAP) analysis [29]. This version has been applied to reinforced concrete asymmetric frame buildings with buckling-restrained braces [30] and to building models with bidirectional setbacks [31]. The applicability of MABPA has been discussed and evaluated based on the effective modal mass ratio of the first two modes [32]. The seismic capacity of an existing irregular building severely damaged in the 2016 Kumamoto earthquake (the former Uto City Hall) has been evaluated using MABPA [33]. Looking back on the development of MABPA, the logical next step should be to extend the method to base-isolated buildings with irregularities. Considering the case in which the seismic isolation period is well separated from the natural period of a superstructure, the behavior of the superstructure may be considered to be that of a rigid body, as discussed by several researchers, e.g., [16]. In such cases, the effective modal mass ratio of the first and second modes is close to unity, provided that the torsional resistance at the isolation layer is sufficient. It is expected that the seismic response of such a base-isolated building with plan irregularities will be accurately predicted by MABPA.

In the nonlinear static analysis shown in the American Society of Civil Engineers ASCE/SEI 41-17 document [3], the reduced spectrum considering the effective damping is used to predict the target displacement for a nonlinear static analysis. Similarly, as shown in Notification No. 2009 of the Ministry of Construction of Japan [34], the equivalent linearization technique can be used for target displacement evaluations of base-isolated buildings. However, several researchers have examined the responses of long-period building structures subjected to pulse-like ground motions, e.g., Mazza examined a base-isolated building [18, 20] and Güneş and Ulucan studied a tall reinforced concrete building [35]. Because the effective damping is calculated based on a steady response having the same displacement amplitude in the positive and negative directions, the use of effective damping for the prediction of the peak responses of base-isolated structures subjected to pulselike ground motion is questionable. From this viewpoint, an alternative concept for predicting the peak response is required. Accordingly, the second motivation of this study is to investigate the use of the energy concept.

The concept of energy input was introduced by Akiyama in the 1980s [36] and is implemented in the design recommendation for seismically isolated buildings presented by the Architectural Institute of Japan [2]. In Akiyama's theory, the total input energy is considered to be a suitable seismic intensity parameter to access the cumulative response of a structure. Instead of the total input energy, Inoue et al. proposed the maximum momentary input energy [37-39] as an intensity parameter related to the peak displacement; the nonlinear peak displacement can be predicted by equating the maximum momentary input energy and the cumulative hysteresis energy during a half cycle of the structural 
response. Following the work of Inoue et al., the authors investigated the relationship between the maximum momentary input energy and the total input energy of an elastic single-degree-of-freedom (SDOF) model [40]. In addition, the concept of the momentary input energy was extended to consider bidirectional horizontal excitation [41, 42]. Specifically, the time-varying function of the momentary energy input has been formulated for unidirectional [40] and bidirectional [41] excitation: this function can be calculated from the transfer function of the model and the complex Fourier coefficients of the ground acceleration. Using the time-varying function, both energy parameters, the total and the maximum momentary input energy, can be accurately calculated. In a previous study [42], it was shown that the nonlinear peak displacement and the cumulative energy of the isotropic two-degree-of-freedom model representing a reinforced concrete building can be properly predicted using a time-varying function. Therefore, the use of a time-varying function of the momentary energy input is promising for seismic response predictions for base-isolated buildings.

\subsection{Objectives}

Based on the above discussion, the following questions are addressed in this paper.

- Is MABPA capable of predicting the peak response of irregular base-isolated buildings?

- The prediction of the peak equivalent displacement of the first two modal responses is an essential step in MABPA. For this, the relationship between the maximum momentary input energy and the peak displacement needs to be properly evaluated. How can this relationship be evaluated from the pushover analysis results?

- In the prediction of the maximum momentary input energy of the first two modal responses, the effect of simultaneous bidirectional excitation needs to be considered. Can the upper bound of the peak equivalent displacement of the first two modal responses be predicted using the bidirectional maximum momentary input energy spectrum [41]?

In this study, the main building of the former Uto City Hall [33] is investigated as a case study of an irregular reinforced concrete building retrofitted using the base-isolation technique. The nonlinear peak responses of two retrofitted building models subjected to bidirectional excitation are investigated via a time-history analysis using artificial and recorded ground motion datasets. Then, their peak responses are predicted by MABPA to evaluate its accuracy.

The rest of paper is organized as follows. Section 2 briefly presents information concerning the original building. Then, two retrofitted building models using the base-isolation technique are presented, as well as the ground motion data. Section 3 presents an outline of MABPA. Then, the prediction procedure of the maximum equivalent displacement is conducted using the maximum momentary input energy. The validation of the prediction of the peak response is discussed in Section 4. Discussions focused on (i) the relationship between the maximum equivalent displacement and the maximum momentary input energy, (ii) the predictability of the largest maximum momentary input energy from the bidirectional momentary input energy spectrum, and (iii) the accuracy of the upper bound of the maximum equivalent displacement of the first two modes are presented in Section 5. Conclusions and future directions of study are discussed in Section 6.

\section{Building and Ground Motion Data}

\subsection{Original Building}

Figure 1 shows a simplified structural plan and the elevation of the main building of the former Uto City Hall [33]. This five-story reinforced concrete irregular building was constructed in 1965. Details concerning this building can be found in the literature [33]. 


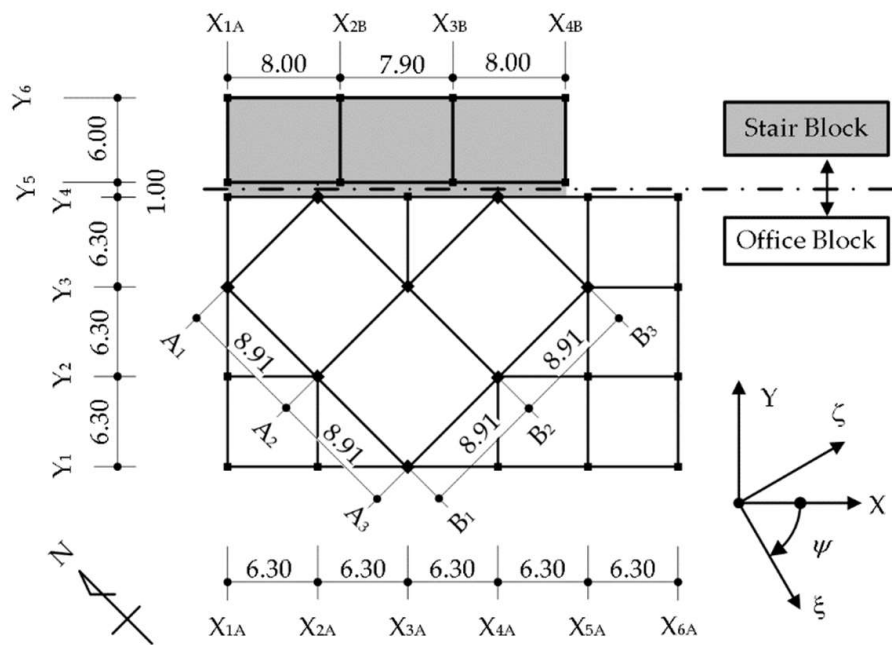

(a)

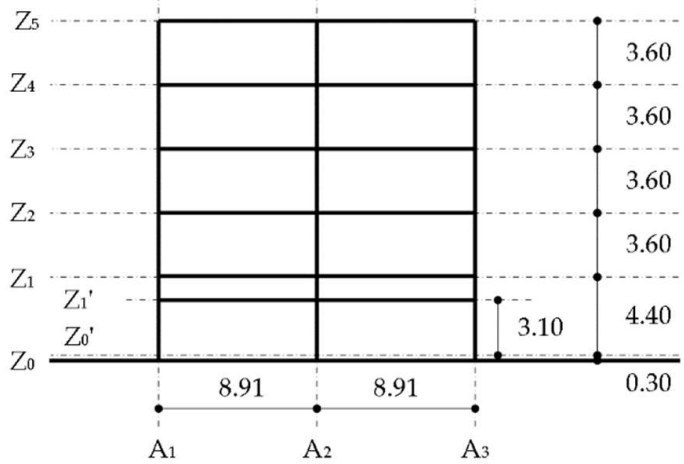

(Unit: m)

(b)

Figure 1. Simplified structural plan and elevation of the main building of the former Uto City Hall [33]: (a) structural plan (Level $\mathrm{Z}_{0}$ ) and (b) simplified plan elevation (frame $\mathrm{B}_{1}$ ).

\subsection{Properties of the Isolation Layer}

Two retrofitted building models are examined in this study to consider different seismic isolation periods $\left(T_{f}\right)$. The properties of the isolation layer were determined as follows based on the energy-balanced design method introduced in the design recommendation [2].

First, the mass and the moment of inertia of each floor were calculated. Table 1 shows the floor mass $\left(m_{j}\right)$, moment of inertia $\left(I_{j}\right)$, and the radius of gyration of the floor mass ( $r_{j}$ ) for the $j$ th floor. Here, the values of the floor mass and the moment of inertia above level 1 are taken from a previous study [33], while the weight per unit area at level 0 is assumed to be $24 \mathrm{kN} / \mathrm{m}^{2}$ for the calculation of the floor mass and the moment of inertia of each floor. Therefore, the calculated total mass $(M)$ is $5412 \mathrm{t}$.

Table 1. Floor mass, moment of inertia, and radius of gyration of the floor mass of each floor level.

\begin{tabular}{cccc}
\hline $\begin{array}{c}\text { Floor level } \\
\boldsymbol{j}\end{array}$ & $\begin{array}{c}\text { Floor mass } \\
\boldsymbol{m}_{\boldsymbol{j}}(\mathbf{t})\end{array}$ & $\begin{array}{c}\text { Moment of Inertia } \\
\mathbf{I}_{\boldsymbol{j}}\left(\mathbf{\times} \mathbf{1 0}^{\mathbf{3}} \mathbf{t m}^{\mathbf{2}}\right)\end{array}$ & $\begin{array}{c}\text { Radius of gyration of } \\
\text { floor mass } \boldsymbol{r}_{\boldsymbol{j}}(\mathbf{m})\end{array}$ \\
\hline 5 & 677.8 & 77.37 & 10.75 \\
4 & 548.5 & 62.85 & 10.70 \\
3 & 543.0 & 62.50 & 10.73 \\
2 & 581.0 & 67.12 & 10.75 \\
1 & 1208.1 & 199.0 & 12.83 \\
0 & 1853.7 & 274.9 & 12.18 \\
\hline
\end{tabular}

Figure 2 shows the horizontal response spectra of the recorded ground motions of the first (April 14, 2016: UTO0414) and second (April 16, 2016: UTO0416) earthquakes observed at the K-NET Uto station. Note that the spectral acceleration $\left(S_{A}\right)$ and velocity $\left(S_{V}\right.$ ) shown in Figures 2(a) and 2(b) are calculated as the absolute (vector) value of the two horizontal components. The total input energy spectrum (the $V_{I}$ spectrum) is also calculated considering the simultaneous input of the two horizontal components. The viscous damping ratio is set to 0.05 for the calculations of $S_{A}$ and $S_{V}$, while it is set to 0.10 for the calculation of $V_{I}$ following the work done by Akiyama [36]. 

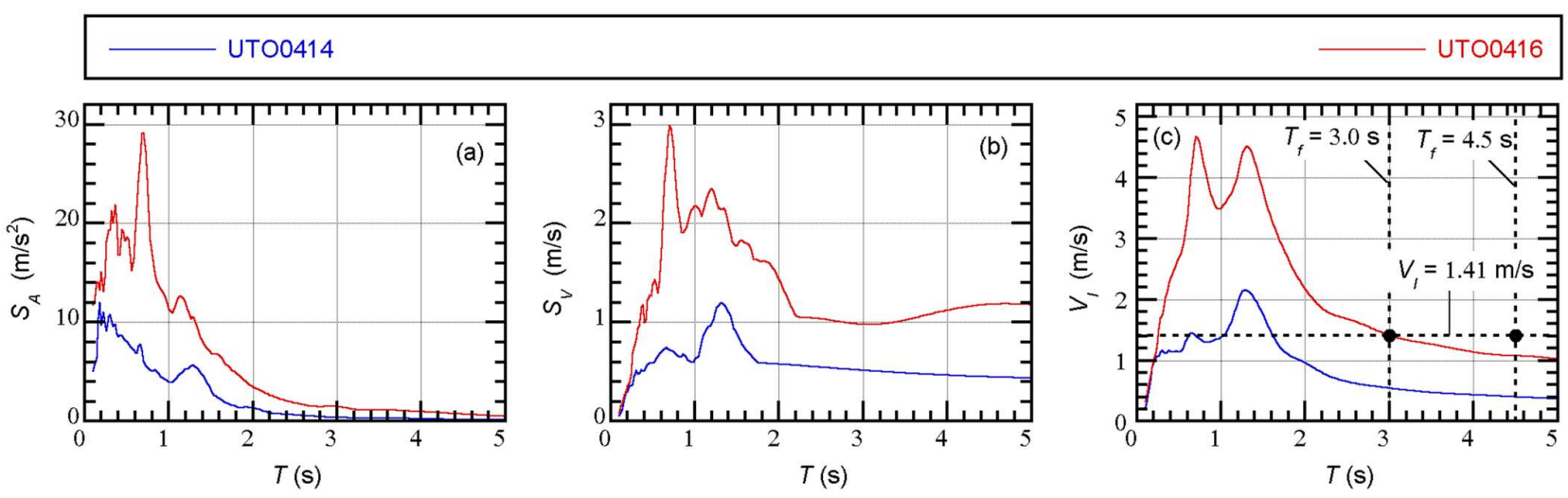

Figure 2. Horizontal response spectra of the recorded ground motions at the K-NET Uto station: (a) elastic acceleration response spectrum (damping ratio: 0.05); (b) elastic velocity response spectrum (damping ratio: 0.05); and (c) elastic total input energy spectrum (damping ratio: 0.10 ).

In this study, the range of the seismic isolation period $\left(T_{f}\right)$ is considered to be from $3 \mathrm{~s}$ to $4.5 \mathrm{~s}$ when determining the properties of the isolation layer. Based on Figure 2(c), the equivalent velocity of the total input energy $\left(V_{I}\right)$ is set to $1.41 \mathrm{~m} / \mathrm{s}$ to determine the properties of the isolation layer.

Assuming that the superstructure is a rigid body, the equation of the energy balance is expressed as

$$
\frac{1}{2} K_{f} \delta_{\max }^{2}+4_{s} n_{s} Q_{y} \delta_{\max }=\frac{1}{2} M V_{I}^{2} .
$$

In Eq. (1), $\delta_{\max }$ is the maximum horizontal displacement, ${ }_{s} n$ is the equivalent number of repetitions, $K_{f}$ is the total horizontal stiffness of the flexible element, and ${ }_{s} Q_{y}$ is the total yield strength of the rigid-plastic element. Equation (1) can be rewritten as

$$
\begin{gathered}
\left(\frac{2 \pi}{T_{f}}\right)^{2} \delta_{\max }{ }^{2}+8_{s} n_{s} \alpha_{y} g \delta_{\max }=V_{I}^{2}, \\
K_{f}=M\left(\frac{2 \pi}{T_{f}}\right)^{2},{ }_{s} \alpha_{y}=\frac{{ }_{s} Q_{y}}{M g} .
\end{gathered}
$$

In Eq. (3), $g$ is the acceleration due to gravity, assumed to be $9.8 \mathrm{~m} / \mathrm{s}^{2}$, and ${ }_{s} \alpha_{y}$ is the yielding shear strength coefficient. In this study, the design-allowable horizontal displacement $\left(\delta_{a}\right)$ is set to $0.40 \mathrm{~m}$, while the value of ${ }_{s} n$ is set to 2 following the design recommendation [2]. Then, the two parameters of the isolation layer, $T_{f}$ and ${ }_{s} \alpha_{y}$, are adjusted such that the following condition is satisfied:

$$
\left(\frac{2 \pi}{T_{f}}\right)^{2} \delta_{a}^{2}+16_{s} \alpha_{y} g \delta_{a} \geq V_{I}^{2} .
$$

The isolation layer below level 0 comprises natural rubber bearings (NRBs), elastic sliding bearings (ESBs), and steel dampers. Figure 3 shows the layout of the isolators and dampers in the isolation layer of the two retrofitted building models: Model-Tf34, shown in Figure 3(a), and Model-Tf44, shown in Figure 3(b). As shown in the figure, the steel dampers are placed at the perimeter frames to provide torsional resistance. The point $G$ shown in this figure is the center of mass of the superstructure, the point $\mathrm{S}_{0}$ is the center 
of stiffness of the isolation layer calculated according to the initial stiffness of the isolators and dampers, while the point $S_{1}$ is the center of stiffness of the isolation layer calculated according to the secant stiffness of the isolators and dampers considering their displacement $(\delta)$ of $0.40 \mathrm{~m}$.

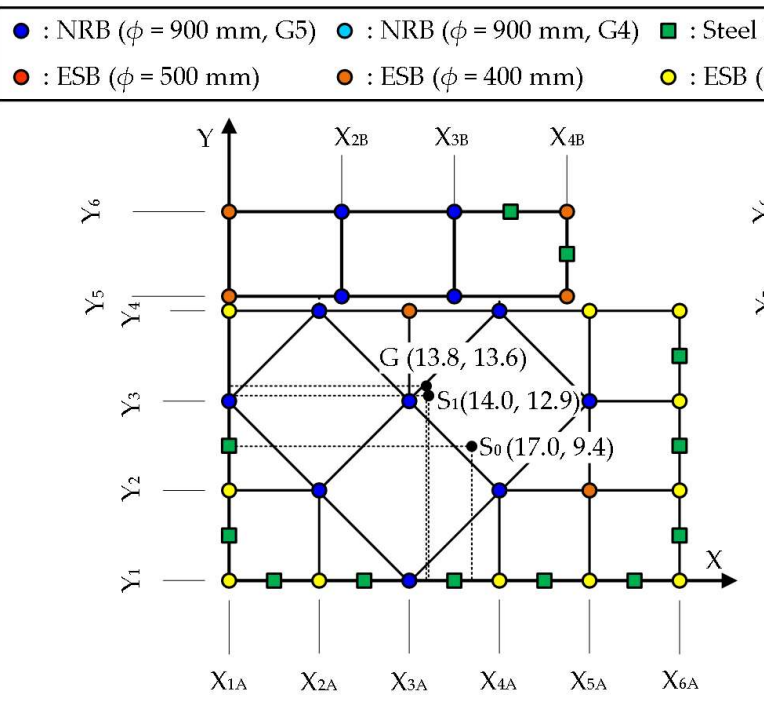

(a)
G : Center of Mass $S_{0}:$ Center of Stiffness (Initial) $\mathrm{S}_{1}:$ Center of Stiffness (Secant Stiffness, $\delta=0.40 \mathrm{~m}$ )

Figure 3. Layout of the isolators and dampers in the isolation layer: (a) Model-Tf34 and (b) Model-Tf44.

For Model-Tf34, $T_{f}=3.38 \mathrm{~s}$ and ${ }_{s} \alpha_{y}=0.0448$, while for Model-Tf44, $T_{f}=4.40 \mathrm{~s}$ and ${ }_{s} \alpha_{y}=0.0396$. Note that $T_{f}$ is calculated according to the horizontal stiffness of the NRBs, while ${ }_{s} \alpha_{y}$ is calculated according to the yield shear strength of the ESBs and steel dampers.

As shown Figure 3, the eccentricity at the isolation layer is non-negligible in both models. The eccentricity indices [34] of Model-Tf34 calculated according to the initial stiffnesses in the $\mathrm{X}$ - and Y-directions are $R_{e X}=0.285$ and $R_{e Y}=0.216$, respectively, while those calculated according to the secant stiffnesses in the $X$ - and $Y$-directions are $R_{e X}=0.014$ and $R_{e Y}=0.054$, respectively. Similarly, the eccentricity indices of ModelTf44 calculated according to initial stiffnesses in the X-and Y-directions are $R_{e X}=0.155$ and $R_{e Y}=0.126$, respectively, while those calculated according to the secant stiffnesses in the X-and Y-directions are $R_{e X}=0.233$ and $R_{e Y}=0.015$, respectively. In this study, the perimeter frames $\mathrm{X}_{1 \mathrm{~A}}$ and $\mathrm{Y}_{6}$ are referred as the "flexible-side frames," while the frames $\mathrm{X}_{6 \mathrm{~A}}$ and $\mathrm{Y}_{1}$ are referred to as the "stiff-side frames." Note that no optimization to minimize the torsional response has been made to choose the dampers in this study because such optimization is beyond the scope of this study.

Figure 4 shows envelopes of the force-deformation relationship for the isolators and dampers. The behavior of the NRBs is assumed to be linear elastic, while that of the ESBs and dampers is assumed to be bilinear.

All of the isolators were chosen from a catalog provided by the Bridgestone Corporation $[43,44]$, considering that the ultimate horizontal deformation is larger than $150 \%$ of $\delta_{a}(1.5 \times 0.40 \mathrm{~m}=0.60 \mathrm{~m})$. Meanwhile, the steel dampers were chosen from a catalog provided by Nippon Steel Corporation Engineering Co. Ltd. [45]. Tables 2-4 list the properties of the isolators and dampers used in the two models. 


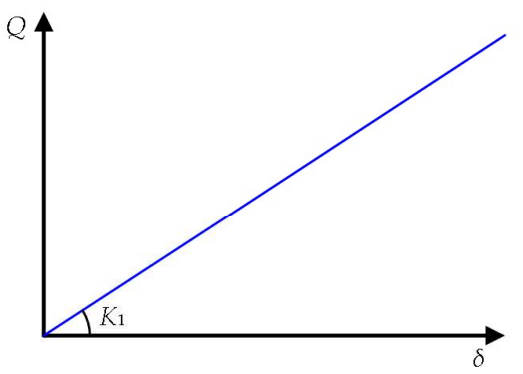

(a)

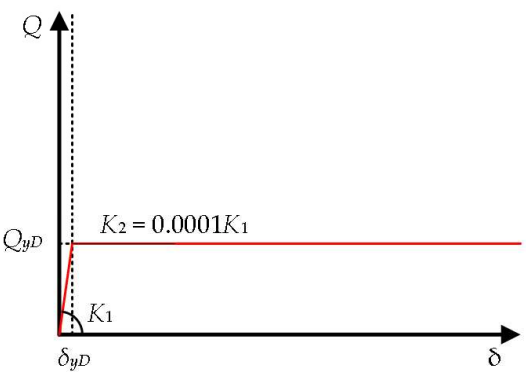

(b)

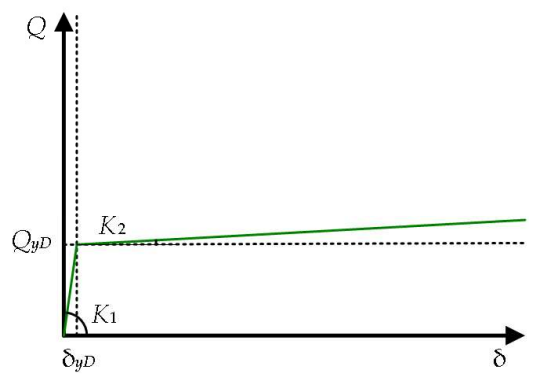

(c)

Figure 4. Envelope of the force-deformation relationship for the isolators and dampers: (a) natural rubber bearings (NRBs); (b) elastic sliding bearings (ESBs); (c) and steel dampers.

Table 2. Properties of the selected natural rubber bearings (NRBs).

\begin{tabular}{cccccc}
\hline Type & $\begin{array}{c}\text { Outer } \\
\text { Diameter } \\
(\mathbf{m m})\end{array}$ & $\begin{array}{c}\text { Total } \\
\text { rubber } \\
\text { thickness } \\
\mathbf{( m m )}\end{array}$ & $\begin{array}{c}\text { Shear } \\
\text { modulus } \\
\mathbf{( M P a )}\end{array}$ & $\begin{array}{c}\text { Horizontal } \\
\text { stiffness }\end{array}$ & $\begin{array}{c}\text { Vertical } \\
\text { stiffness }\end{array}$ \\
\hline NRB $(\phi=900 \mathrm{~mm} / \mathrm{m})$ & $\left.\boldsymbol{K}_{V} \mathbf{( M N} / \mathbf{m}\right)$ \\
NRB $(\phi=900 \mathrm{~mm}, \mathrm{G} 4)$ & 900 & 180 & 0.441 & 1.56 & 3730 \\
\hline
\end{tabular}

Table 3. Properties of the selected elastic sliding bearings (ESBs).

\begin{tabular}{cccccc}
\hline Type & $\begin{array}{c}\text { Outer } \\
\text { Diameter } \\
(\mathbf{m m})\end{array}$ & $\begin{array}{c}\text { Shear } \\
\text { modulus } \\
\mathbf{( M P a )}\end{array}$ & $\begin{array}{c}\text { Friction } \\
\text { coefficient } \\
\text { (M) }\end{array}$ & $\begin{array}{c}\text { Initial } \\
\text { horizontal } \\
\text { stiffness } \\
\left.K_{\mathbf{1}} \mathbf{( M N} / \mathbf{m}\right)\end{array}$ & $\begin{array}{c}\text { Vertical } \\
\text { stiffness } \\
K_{V}(\mathbf{M N} / \mathbf{m})\end{array}$ \\
\hline ESB $(\phi=300 \mathrm{~mm})$ & 300 & 0.392 & 0.010 & 0.884 & 1380 \\
ESB $(\phi=400 \mathrm{~mm})$ & 400 & 0.392 & 0.010 & 1.48 & 2270 \\
ESB $(\phi=500 \mathrm{~mm})$ & 500 & 0.392 & 0.010 & 2.40 & 3710 \\
\hline
\end{tabular}

Table 4. Properties of the selected steel dampers.

\begin{tabular}{ccc}
\hline $\begin{array}{c}\text { Initial stiffness } \\
K_{\mathbf{1}}(\mathbf{M N} / \mathbf{m})\end{array}$ & $\begin{array}{c}\text { Yield Strength } \\
Q_{y d}(\mathbf{k N})\end{array}$ & $\begin{array}{c}\text { Post yield stiffness } \\
K_{2}(\mathbf{M N} / \mathbf{m})\end{array}$ \\
\hline 7.60 & 184 & 0.128 \\
\hline
\end{tabular}

The yield strength of an ESB is calculated as

$$
Q_{y D}=\mu P_{V} .
$$

In Eq. (5), $P_{V}$ is the vertical load of the ESB due to gravity.

\subsection{Structural Modeling}

The two building models are modeled as three-dimensional spatial frames, wherein the floor diaphragms are assumed to be rigid in their own planes without an out-of-plane stiffness. Figure 5 shows the structural modeling. For the numerical analyses, a nonlinear analysis program for spatial frames developed by the authors in a previous study [46] was used. The structural models are based on Model-RuW4-100 from a previous study [33]. As shown in Figures 5(b) and 5(c), all the vertical and rotational springs in the basement of the original model were replaced by isolators and dampers were installed in the isolation layer. The shear behavior of the isolators is modeled using the multi-shear-spring model proposed by Wada and Hirose [47], while their axial behavior is modeled using a linear elastic spring, as shown in Figure 5(d). The shear behavior of the steel dampers is 
also modeled using the multi-shear-spring model, as shown in Figure 5(e). No bending stiffness is considered in either the isolators or the dampers. The hysteresis rules of the ESBs and steel dampers are modeled following the normal bilinear rule for simplicity of analysis. Details of the structural modeling of the superstructure can be found in the literature [33]. The damping matrix of the superstructure was then assumed to be proportional to the tangent stiffness matrix of the superstructure, with $2 \%$ of the critical damping of the first mode. The damping of the isolators and dampers was not considered, assuming that their energy absorption effects are already included in the hysteresis rules. Note that the force-displacement relationships of all members, including those in the superstructures and in the isolation layers, are assumed to be symmetric in the positive and negative loading directions, as in previous studies [33, 46].

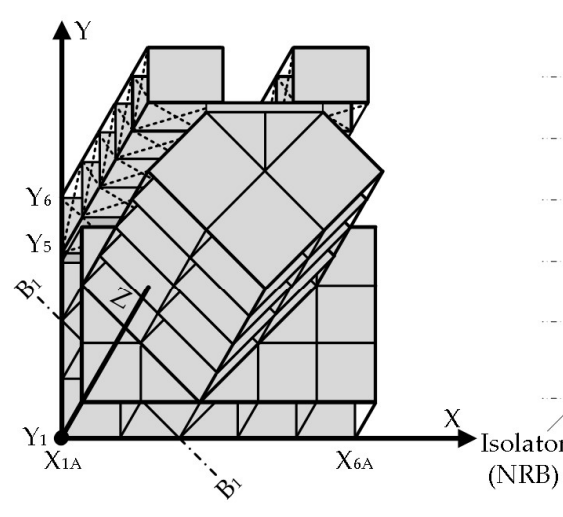

(a)

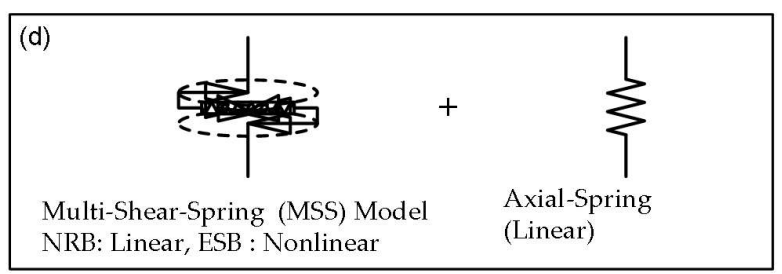

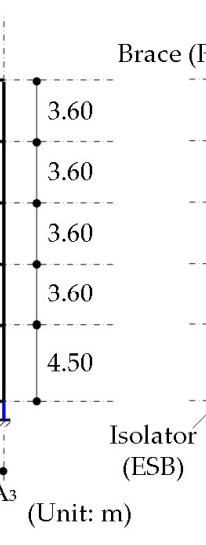

(b)

Column (Pin-end in both sides)

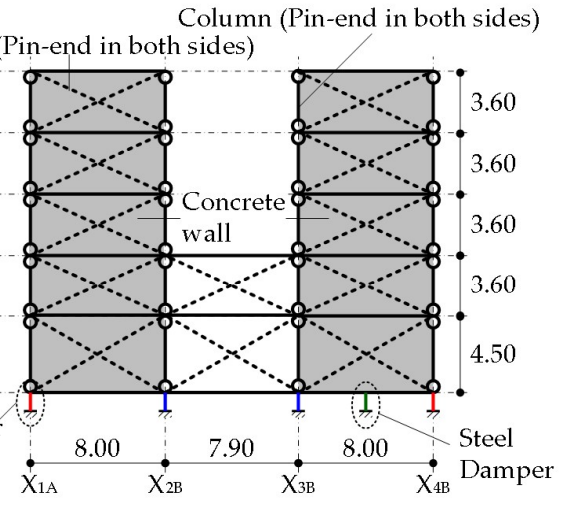

(c)

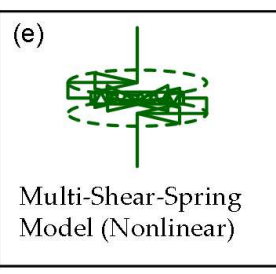

Note:

The slabs connecting the office and stair blocks are considered as rigid.

Figure 5. Structural modeling: (a) overview of the structural model; (b) frame $B_{1} ;(\mathbf{c})$ frame $\mathrm{Y}_{6}$; (d) modeling of the isolators (NRBs and ESBs); and (e) modeling of the steel dampers.

Figures 6 and 7 show the first three natural modes of Model-T34 and Model-T44 in the elastic range. Here, $T_{i e}$ is the natural period of the $i$ th mode in the elastic range $(i=$ $1-3), m_{i e}^{*}$ is the effective modal mass ratio of the $i$ th mode with respect to its principal direction in the elastic range, $\psi_{i e}$ is the incidence of the principal direction of the $i$ th modal response in the elastic range, and $R_{\rho i e}$ is the torsional index of the $i$ th mode in the elastic range. The values of $m_{i e}{ }^{*}, \psi_{i e}$, and $R_{\rho i e}$ are calculated according to the $i$ th elastic mode vector $\left(\varphi_{\mathrm{ie}}\right)$ as follows:

$$
m_{i e}^{*}=\frac{1}{M} \frac{\left(\sum_{j=0}^{5} m_{j} \phi_{X j i e}\right)^{2}+\left(\sum_{j=0}^{5} m_{j} \phi_{Y j i e}\right)^{2}}{\sum_{j=0}^{5} m_{j} \phi_{X j i e}{ }^{2}+\sum_{j=0}^{5} m_{j} \phi_{Y j i e}{ }^{2}+\sum_{j=0}^{5} I_{j} \phi_{\Theta j i e}{ }^{2}},
$$




$$
\begin{aligned}
& \tan \psi_{i e}=-\sum_{j=0}^{5} m_{j} \phi_{Y j i e} / \sum_{j=0}^{5} m_{j} \phi_{X j i e}, \\
& R_{\rho i e}=\sqrt{\sum_{j=0}^{5} I_{j} \phi_{\theta j i e}{ }^{2} /\left(\sum_{j=0}^{5} m_{j} \phi_{x j i e}{ }^{2}+\sum_{j=0}^{5} m_{j} \phi_{\gamma j i e}{ }^{2}\right)}, \\
& \varphi_{\mathrm{ie}}=\left\{\begin{array}{lllllllll}
\phi_{X 0 i e} & \cdots & \phi_{X 5 i e} & \phi_{Y 0 i e} & \cdots & \phi_{Y 5 i e} & \phi_{\Theta 0 i e} & \cdots & \phi_{\Theta 5 i e}
\end{array}\right\}^{\mathrm{T}} .
\end{aligned}
$$

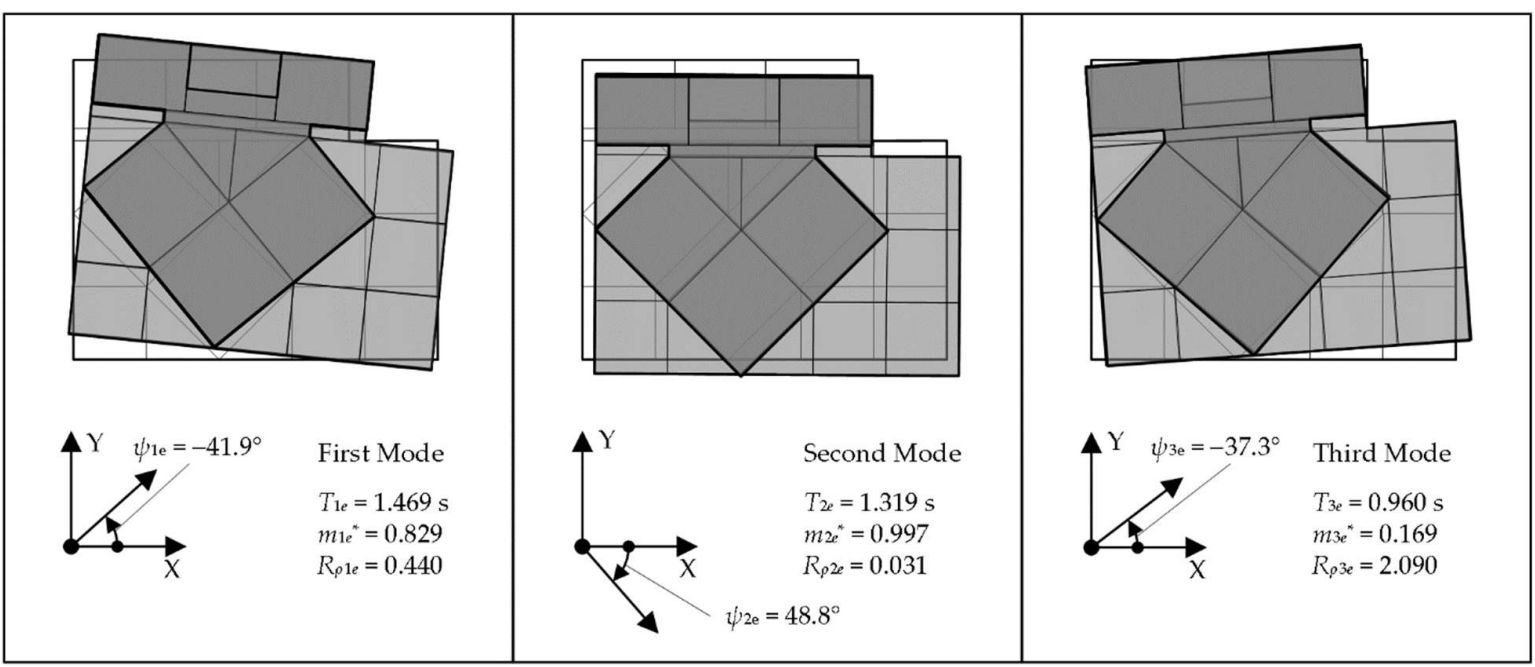

Figure 6. Shape of the first three natural modes of Model-Tf34 in the elastic range.

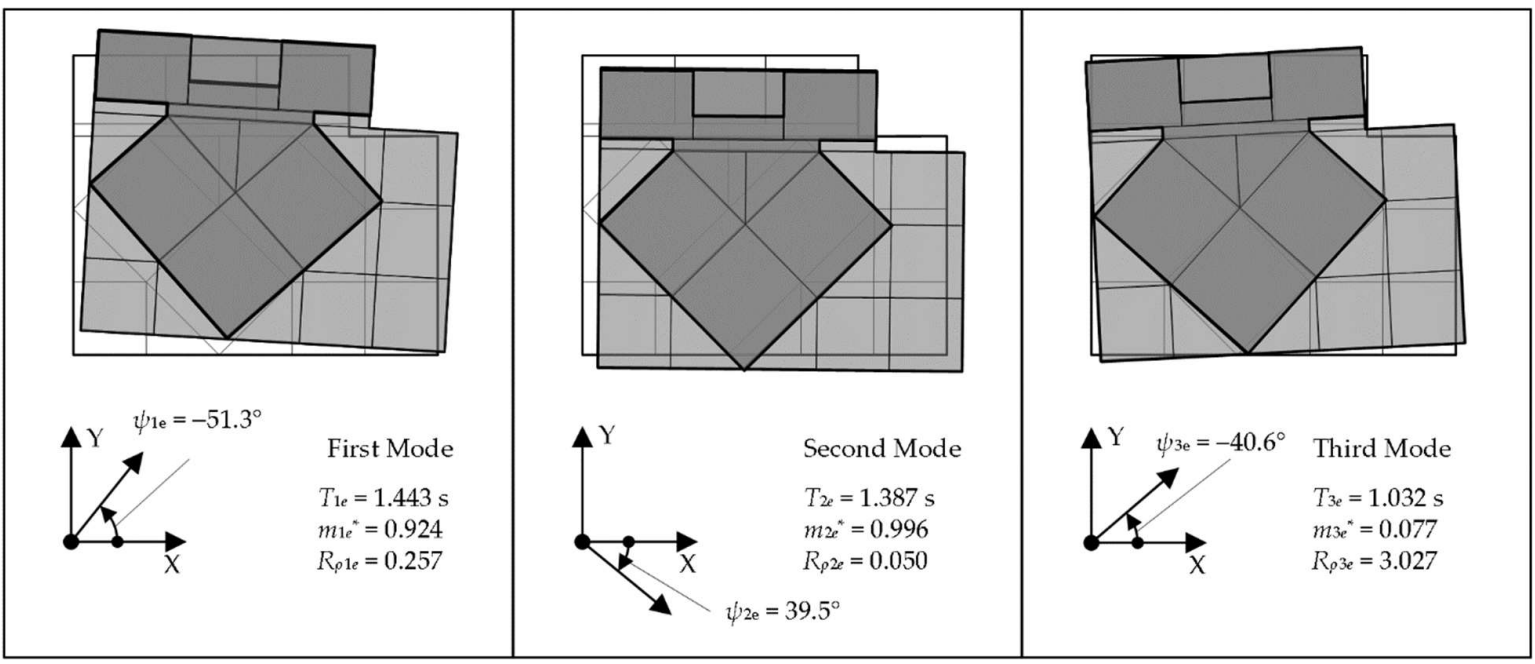

Figure 7. Shape of the first three natural modes of Model-Tf44 in the elastic range.

The behavior of the superstructure can be considered as a rigid body in the first three modes in the elastic range, as observed from Figures 6 and 7. In both building models, the effective modal mass ratios of the first two modes are close to 1 . In addition, the first mode is predominantly translational $\left(R_{\rho 1 e}<1\right)$, the second mode is nearly purely translational ( $\left.R_{\rho 2 e}<<1\right)$, and the third mode is predominantly torsional $\left(R_{\rho 3 e}>1\right)$. In addition, the angles between the principal directions of the first two modes are close to $90^{\circ}\left(90.7^{\circ}\right.$ for Model- 
Tf34 and $90.8^{\circ}$ for Model-Tf44). Therefore, both building models are classified as torsionally stiff buildings: in a previous study [32], the conditions for classification as a torsionally stiff building are $R_{\rho 1}, R_{\rho 2}<1$, and $R_{\rho 3}>1$.

The natural periods of the superstructure in the elastic range, assuming that the entire basement is supported by pins, are $0.373 \mathrm{~s}$ (first mode), $0.342 \mathrm{~s}$ (second mode), and 0.192 $\mathrm{s}$ (third mode). Therefore, the natural period of the superstructure is well separated from the seismic isolation period in both models.

\subsection{Ground motion data}

In this study, the seismic excitation is bidirectional in the $\mathrm{X}-\mathrm{Y}$ plane and both artificial ground motions and recorded ground motions are considered.

\subsubsection{Artificial ground motions}

In this study, two series of artificial ground motion datasets (the Art- 1 and Art-2 series) were generated. As noted in Section 2.2, the equivalent velocity of the total input energy $\left(V_{I}\right)$ was set to $1.41 \mathrm{~m} / \mathrm{s}$ to determine the properties of the isolation layer. Therefore, the artificial ground motion datasets were generated such that their bidirectional $V_{I}$ spectrum fit the predetermined target $V_{I}$ spectrum as follows.

The target bidirectional $V_{I}$ spectrum with a damping ratio of 0.10 was determined such that

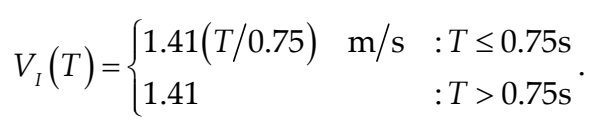

To generate each horizontal component, it was assumed that the intensity of $V_{I}$ in both orthogonal components ( $\xi$ - and $\zeta$ - components) was identical. The target equivalent velocities of the total input energy of the $\xi$ - and $\zeta$-components, $V_{I \xi}(T)$ and $V_{I \zeta}(T)$, respectively, were calculated as

$$
V_{I \xi}(T)=V_{I \zeta}(T)=V_{I}(T) / \sqrt{2} .
$$

The phase angle is given by a uniform random value, and to consider the time-dependent amplitude of the ground motions, a Jenning-type envelope function $(e(t))$ is assumed. In this study, two envelope functions were considered. In Art-1-00, the envelope function was set as in Eq. (12), while in Art-2-00 the envelope function was set as in Eq. (13).

$$
\begin{gathered}
e(t)= \begin{cases}(t / 5)^{2} & : 0 s \leq t \leq 5 s \\
1 & : 5 s \leq t \leq 25 s \\
\exp \{-0.066(t-25)\} & : 25 s \leq t \leq 60 s\end{cases} \\
e(t)= \begin{cases}(t / 2.5)^{2} & : 0 s \leq t \leq 2.5 s \\
1 & : 2.5 s \leq t \leq 12.5 s \\
\exp \{-0.132(t-12.5)\} & : 12.5 s \leq t \leq 30 s\end{cases}
\end{gathered}
$$

Figures 8 and 9 show the time-histories of the two components and the orbits of Art1-00 and Art-2-00, respectively. Because the same target $V_{I}$ spectrum is applied while the duration of Art-2-00 is the half that of Art-1-00, the peak ground acceleration of Art-200 is larger than that of Art-1-00. 

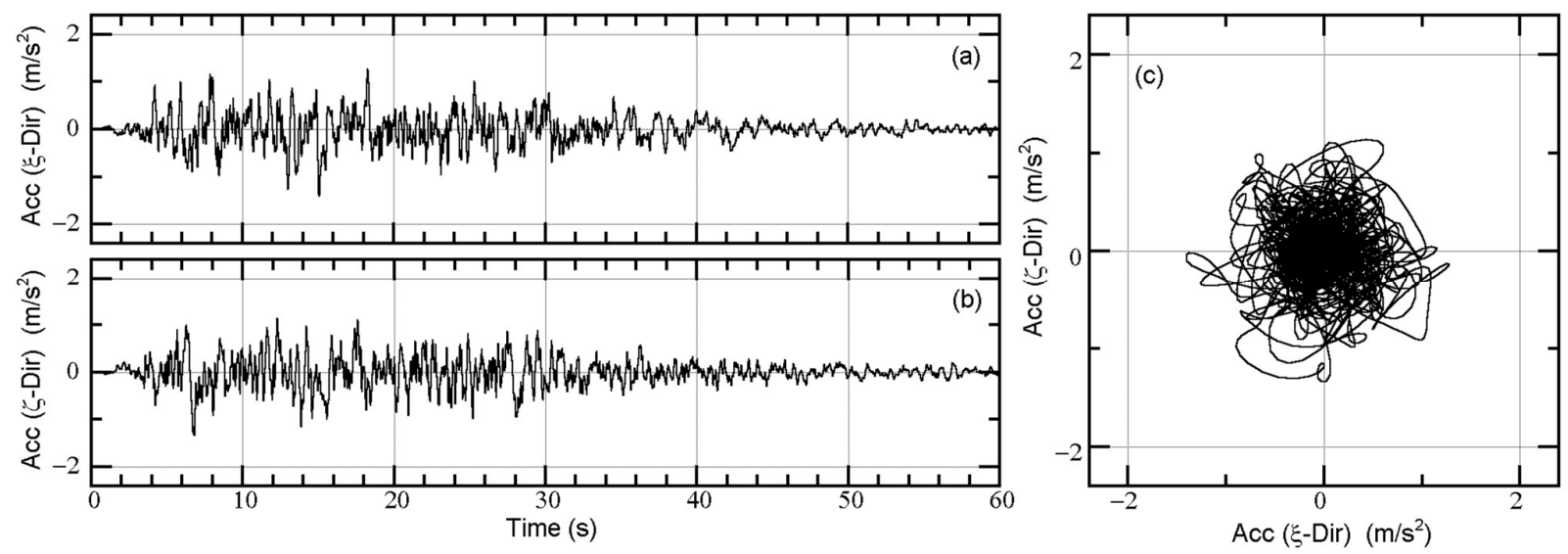

Figure 8. Two components of the generated artificial ground motion (Art-1-00): (a) $\xi$-direction; (b) $\zeta$-direction; and (c) orbit.
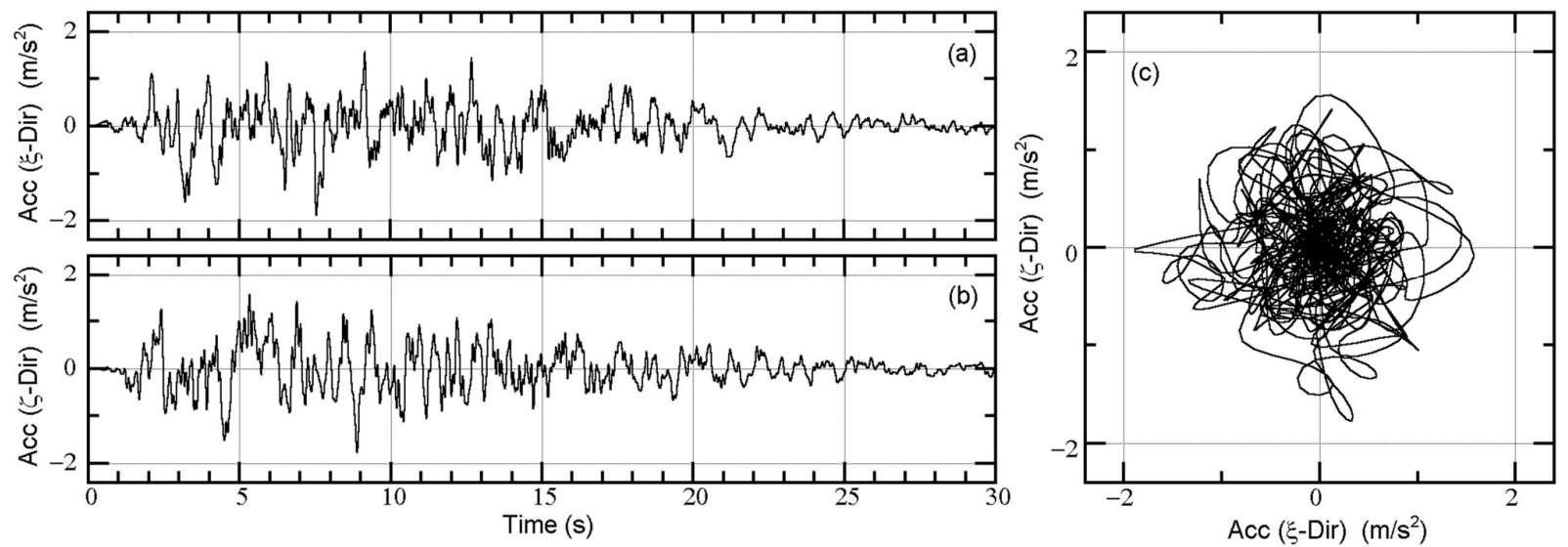

Figure 9. Two components of the generated artificial ground motion (Art-2-00): (a) $\xi$-direction; (b) $\zeta$-direction; and (c) orbit.

Note that the artificial ground motions used in this study were generated independently. The correlation coefficients of Art-1-00 and Art-2-00 are close to zero, even though the envelope functions of the two components are the same; therefore, the two components can be considered independently of each other.

Next, 11 artificial ground motion datasets were generated from Art-1-00 and Art-200 by shifting the phasing angle. The generated artificial ground motion vector $\left(\mathbf{a}_{\mathbf{g}}\left(t, \Delta \phi_{0}\right)\right.$ ) is expressed as

$\mathbf{a}_{\mathbf{g}}\left(t, \Delta \phi_{0}\right)=\left\{\begin{array}{c}a_{g \xi}\left(t, \Delta \phi_{0}\right) \\ a_{g \zeta}\left(t, \Delta \phi_{0}\right)\end{array}\right\}=\sum_{n=-N}^{N}\left\{\begin{array}{c}c_{\xi, n} \\ c_{\zeta, n}\end{array}\right\} \exp \left[i\left\{\omega_{n} t-\operatorname{sgn}\left(\omega_{n}\right) \Delta \phi_{0}\right\}\right]$.

In Eq. (14), $c_{\xi, n}$ and $c_{\zeta, n}$ are the complex Fourier coefficients of the $n^{\text {th }}$ harmonics of $a_{g \xi}(t)$ and $a_{g s}(t)$, respectively, $\omega_{n}$ is the circular frequency of the $n^{\text {th }}$ harmonic, and $\Delta \phi_{0}$ is the constant used to shift the phase angle of all the harmonics. As in previous studies [40,42], the constant $\Delta \phi_{0}$ was set from $\pi / 12$ to $11 \pi / 12$ with an interval of $\pi / 12$. Notably, the phase difference of each ground motion component does not change when shifting the phase angle. In addition, the total input energy spectrum (the $V_{I}$ spectrum) is independent of the shifting phase angle $\left(\Delta \phi_{0}\right)$. This is because the shifting phase angle does not affect the absolute value of the complex Fourier coefficient, and the total input energy 
per unit mass can be calculated from the Fourier amplitude spectrum without the phase characteristics of the ground motion, as shown by Ordaz [48]. The generated artificial ground motion datasets are numbered from 01 to 11 depending on $\Delta \phi_{0}$, with a total of 2 $\times 12=24$ artificial ground motion datasets generated and used in this study.

Figures 10 and 11 show the horizontal response spectra of the generated ground motion datasets. As shown in these figures, the spectral acceleration $\left(S_{A}\right)$ and the spectral velocity $\left(S_{V}\right)$ differs slightly because of the shift in the phase angle. A comparison of Figures 10 and 11 reveals that $S_{A}$ and $S_{V}$ of the Art-2 series are larger than those of the Art1 series, even though the target $V_{I}$ spectrum is identical.
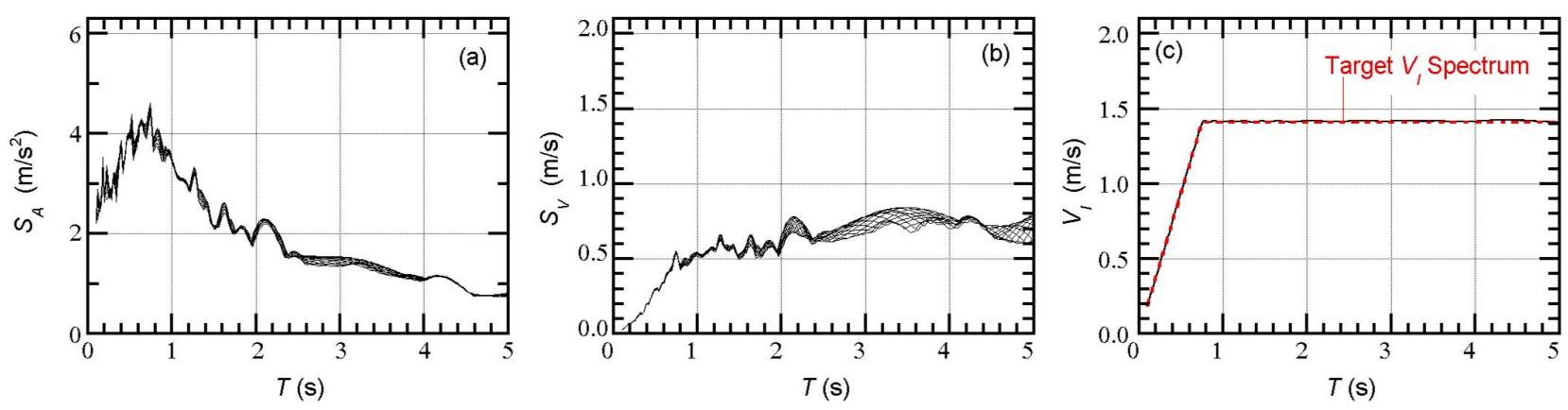

Figure 10. Horizontal response spectra of the artificial ground motion (Art-1 series): (a) elastic acceleration response spectrum (damping ratio: 0.05); (b) elastic velocity response spectrum (damping ratio: 0.05); and (c) elastic total input energy spectrum (damping ratio: 0.10$)$.
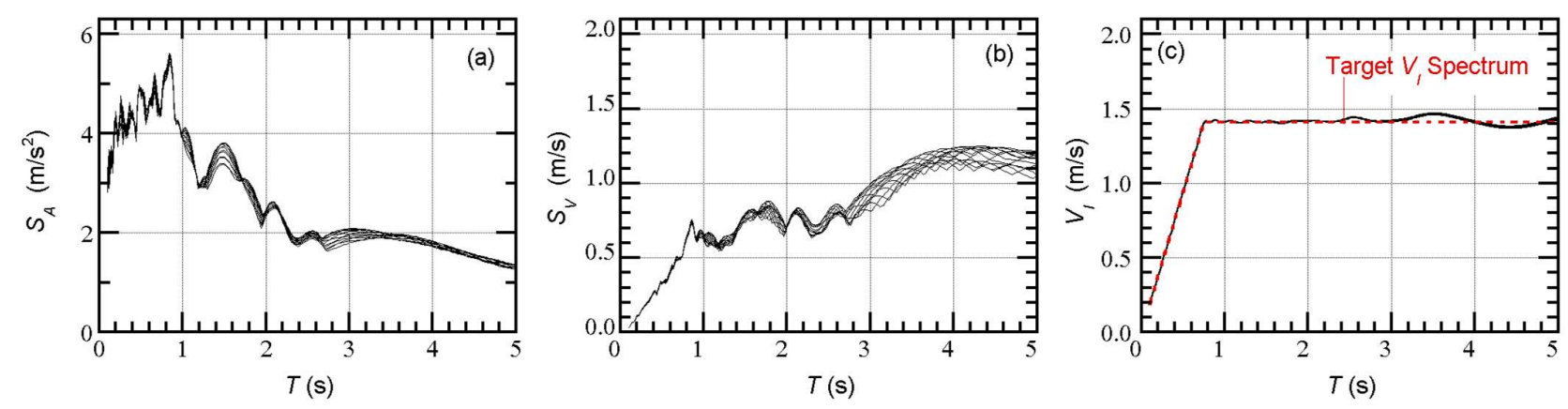

Figure 11. Horizontal response spectra of the artificial ground motion (Art-2 series): (a) elastic acceleration response spectrum (damping ratio: 0.05); (b) elastic velocity response spectrum (damping ratio: 0.05); and (c) elastic total input energy spectrum (damping ratio: 0.10 ).

\subsubsection{Recorded ground motions}

Table 5 lists the four datasets of recorded ground motions used in this study. Details concerning the original ground motions can be found in the Appendix. Figure 12 shows the horizontal response spectra of the unscaled recorded ground motion datasets.

One of the motivations of this analysis is to evaluate the seismic performance of the two retrofitted models under the ground motions recorded during the 2016 Kumamoto earthquake. Therefore, the two recorded ground motion datasets (UTO0414 and UTO0416) were used without scaling. A further two datasets of ground motions, TCU and YPT, were chosen as examples of long-period pulse-like ground motions, as investigated by Güneş and Ulucan [35]. These two ground motion datasets were scaled such that the equivalent velocity of the total energy input $\left(V_{I}\right)$ at the isolation period $\left(T_{f}\right)$ equals 1.41 $\mathrm{m} / \mathrm{s}$, which is consistent with the intensity considered in the determination of the properties of the isolation layer, as discussed in Section 2.2. 
Table 5. List of the recorded ground motion datasets used in this study.

\begin{tabular}{cccc}
\hline Earthquake of & \multirow{2}{*}{ Ground Motion ID } & \multicolumn{2}{c}{ Scale Factor } \\
\cline { 3 - 4 } the Original Record & & Model-Tf34 & Model-Tf44 \\
\hline Kumamoto, 2016/04/14 & UTO0414 & 1.000 & 1.000 \\
Kumamoto, 2016/04/16 & UTO0416 & 1.000 & 1.000 \\
Chichi, 1999 & TCU & 0.5540 & 0.5718 \\
Kocaeli, 1999 & YPT & 0.4293 & 0.5057 \\
\hline
\end{tabular}
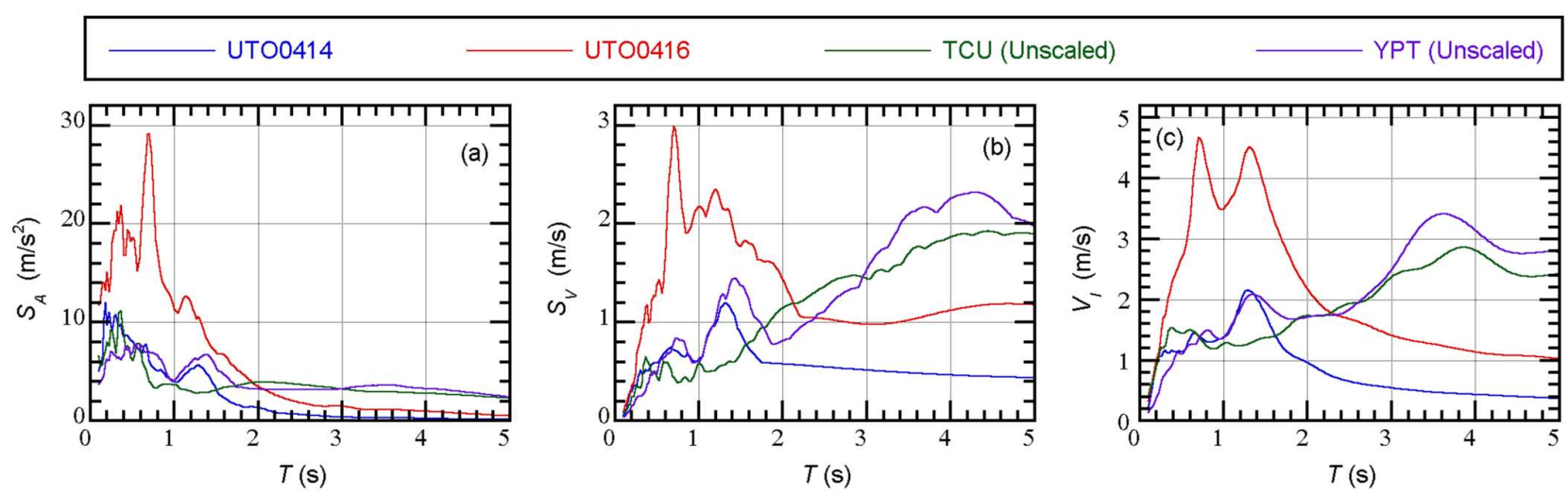

Figure 12. Horizontal response spectra of the recorded ground motions: (a) elastic acceleration response spectrum (damping ratio: 0.05); (b) elastic velocity response spectrum (damping ratio: 0.05); and (c) elastic total input energy spectrum (damping ratio: 0.10$)$.

\section{Description of MABPA}

\subsection{Outline of $M A B P A$}

Figure 13 shows the flow of the updated MABPA. Here, the U-axis is the principal axis of the first modal response, while the $\mathrm{V}$-axis is the axis perpendicular to the $\mathrm{U}$-axis, following previous studies $[28,30]$. In this study, the predictions of the peak responses of the first and second modes (steps 2 and 4) were updated as follows.

- The bidirectional momentary input energy proposed in the previous study is applied as the seismic intensity parameter.

- The peak response of each mode is predicted from the energy balance in a half cycle of the structural response.

It is assumed that the upper bound of the unidirectional maximum momentary input energy considering the various directions of the seismic input is approximated by the bidirectional maximum momentary input energy. For the prediction of the peak equivalent displacements of the first and second modal responses, the bidirectional maximum momentary input energy spectrum (bidirectional $V_{\Delta E}$ spectrum) is used. This is because the influences of the simultaneous input of two horizontal components are included in the bidirectional $V_{\triangle E}$ spectrum, as discussed in previous studies [41, 42]. Note that the maximum momentary input energy of each modal response varies depending on the angle of incidence of the horizontal ground motion. The assumption that the maximum momentary input energy of each modal response can be predicted from the bidirectional $V_{\Delta E}$ spectrum can lead to conservative predictions. The validation of this assumption is discussed in Section 5. 

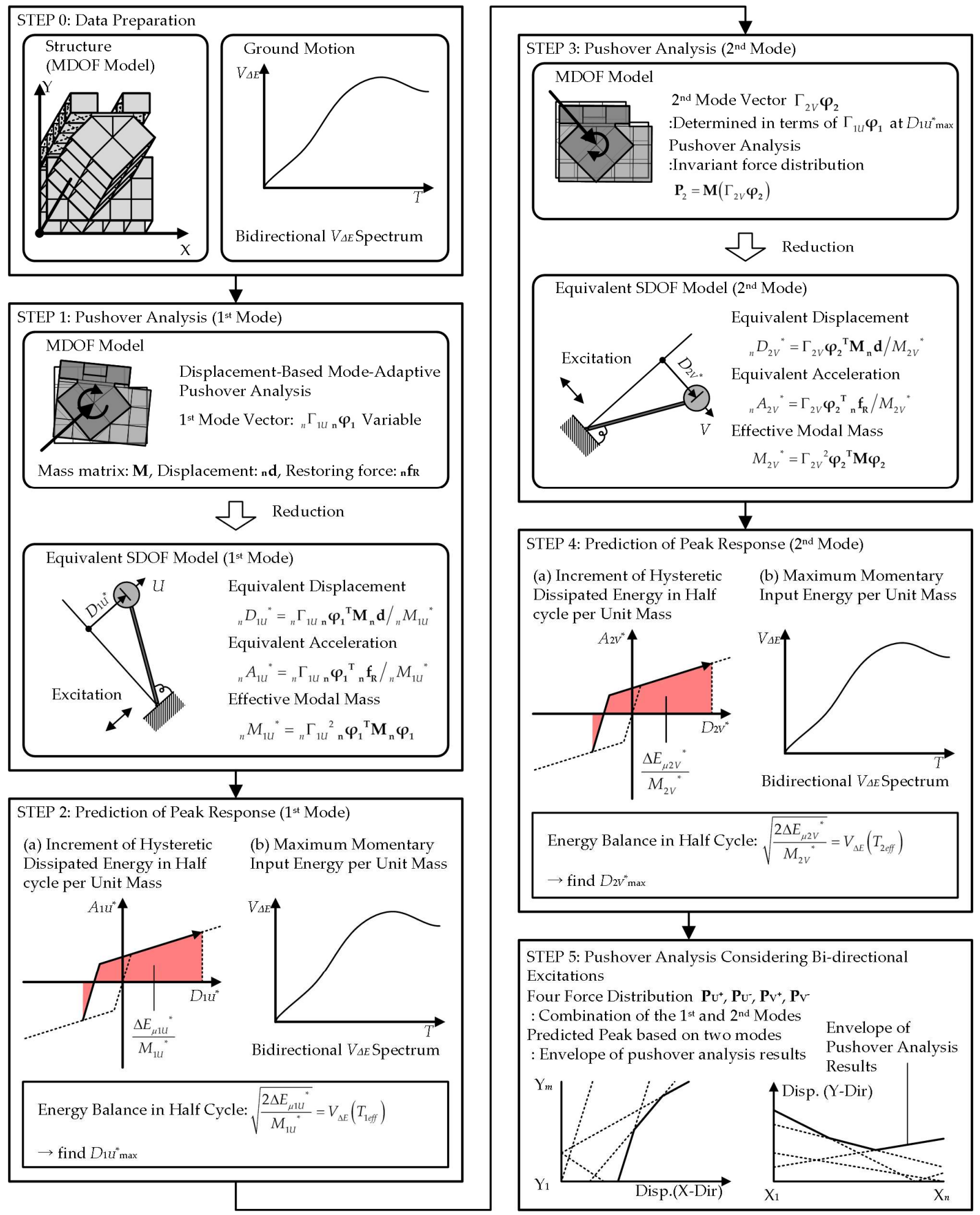

STEP 4: Prediction of Peak Response (2 $2^{\text {nd }}$ Mode)

(a) Increment of Hysteretic Dissipated Energy in Half cycle per Unit Mass

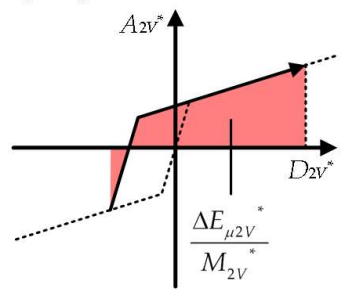

(b) Maximum Momentary Input Energy per Unit Mass

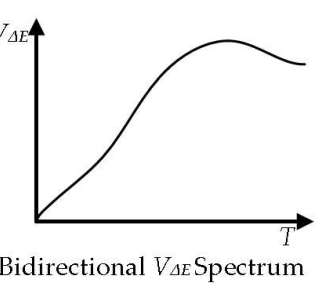

$$
\begin{aligned}
& \text { Energy Balance in Half Cycle: } \sqrt{\frac{2 \Delta E_{\mu 2 V}{ }^{*}}{M_{2 V}{ }^{*}}}=V_{\Delta E}\left(T_{2 e f f}\right) \\
& \rightarrow \text { find } D_{2 V^{*} \max }
\end{aligned}
$$

STEP 5: Pushover Analysis Considering Bi-directional Excitations

Four Force Distribution $\mathbf{P u}^{+}, \mathbf{P u}^{+}, \mathbf{P v}^{+}, \mathbf{P v}$

: Combination of the $1^{\text {st }}$ and $2^{\text {nd }}$ Modes

Predicted Peak based on two modes Envelope of

: Envelope of pushover analysis results Pushover Analysis

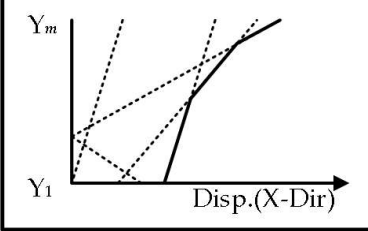

Results

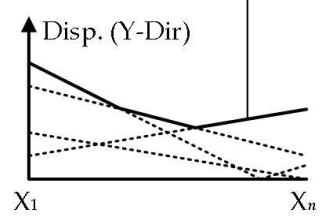

Figure 13. Flow of the updated mode-adaptive bi-directional pushover analysis (MABPA).

\subsection{Prediction of the peak response using the momentary energy input}

\subsubsection{Calculation of the bidirectional momentary input energy spectrum}

The bidirectional momentary input energy spectrum, which was proposed in previous studies [41, 42], is calculated as follows. 
First, the complex Fourier coefficient of the two horizontal components, $c_{\xi, n}$ and $c_{\zeta, n}$, can be calculated via the discrete Fourier transform of the two horizontal components $a_{g \xi}(t)$ and $a_{g \zeta}(t)$, respectively.

The displacement and velocity transfer function of the linear system with viscous and complex damping can be calculated as follows:

$$
H_{C V D}\left(i \omega_{n}\right)=\frac{1}{\omega_{0}^{2}-\omega_{n}^{2}+2 \omega_{0}\left\{h \omega_{n}+\beta \omega_{0} \operatorname{sgn}\left(\omega_{n}\right)\right\}}, H_{C V V}\left(i \omega_{n}\right)=i \omega_{n} H_{C V D}\left(i \omega_{n}\right) .
$$

In Eq. (15), $\omega_{0}(=2 \pi / T)$ is the natural circular frequency and $h$ and $\beta$ are the viscous and complex damping of the linear system, respectively. From the complex Fourier coefficients $\left(c_{\xi, n}\right.$ and $\left.c_{\zeta, n}\right)$ and the transfer functions of the linear system $\left(H_{C V D}\left(i \omega_{n}\right)\right.$ and $\left.H_{C V V}\left(i \omega_{n}\right)\right)$, the duration of a half cycle of response $(\Delta t)$ can be calculated as

$$
\Delta t=\pi \sqrt{\sum_{n=1}^{N}\left|H_{C V D}\left(i \omega_{n}\right)\right|^{2}\left\{\left|c_{\xi, n}\right|^{2}+\left|c_{\zeta, n}\right|^{2}\right\} / \sum_{n=1}^{N}\left|H_{C V V}\left(i \omega_{n}\right)\right|^{2}\left\{\left|c_{\xi, n}\right|^{2}+\left|c_{\zeta, n}\right|^{2}\right\}} .
$$

Then, the Fourier coefficient of the time-varying function of the momentary energy input can be calculated as follows:

$$
E_{\Delta B I, n}^{*}= \begin{cases}\frac{\sin \left(\omega_{n} \Delta t / 2\right)}{\omega_{n} \Delta t / 2} \sum_{n_{1}=n+1}^{N}\left\{H_{V}\left(i \omega_{n_{1}}\right)+H_{V}\left(-i \omega_{n_{1}-n}\right)\right\}\left\{c_{\xi, n_{1}} c_{\xi,-\left(n_{1}-n\right)}+c_{\zeta, n_{1}} c_{\zeta,-\left(n_{1}-n\right)}\right\} & : n>0 \\ 2 \sum_{n_{1}=1}^{N} \operatorname{Re}\left\{H_{V}\left(i \omega_{n_{1}}\right)\right\}\left\{\left|c_{\xi, n_{1}}\right|^{2}+\left|c_{\zeta, n_{1}}\right|^{2}\right\} & : n=0 . \\ \frac{E_{\Delta B I, n}^{*}}{} & : n<0\end{cases}
$$

The momentary input energy per unit mass at time $t$ can be calculated as follows:

$$
\frac{\Delta E_{B I}(t)}{m}=\int_{t-\Delta t / 2}^{t+\Delta t / 2} \sum_{n=-N+1}^{N-1} E_{\Delta B I, n}^{*} \exp \left(i \omega_{n} t\right) d t
$$

The maximum momentary input energy per unit mass $\left(\Delta E_{B I, \max } / m\right)$ can be evaluated as the maximum value calculated by Eq. (18) over the course of the seismic event. The bidirectional maximum momentary input energy spectrum (the bidirectional $V_{\Delta E}$ spectrum) is calculated as

$$
V_{\Delta E}=\sqrt{2 \Delta E_{B I, \max } / m}
$$

The bidirectional $V_{\Delta E}$ spectrum is prepared at the beginning of the MABPA (step 0). The range of the natural period ( $T$ ) needs to be properly considered. In this study, a range of $T$ from $0.1 \mathrm{~s}$ to $6.0 \mathrm{~s}$ (longer than the seismic isolation period) is considered. The assumption of damping is also important. Because only a hysteresis (displacement-dependent) damper is installed in the isolation layer, complex damping was chosen in this study. The complex damping ratios $(\beta)$ were set to $0.10,0.20$, and 0.30 .

3.2.2. Formulation of the effective period and the hysteretic dissipated energy in a half cycle

To predict the peak responses of the first two modes, bilinear idealization of the equivalent acceleration-equivalent displacement relationship was made as follows. In the following discussion, the formulations are made for the first modal response. Figure 14 shows the bilinear idealization procedure used in this study. 


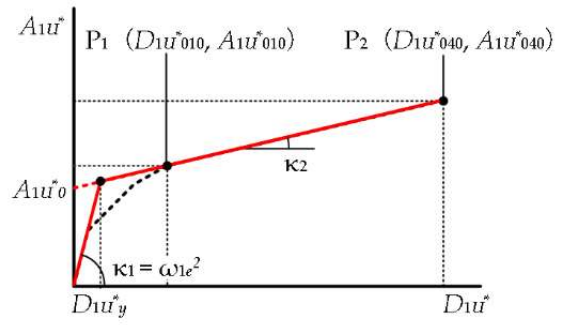

$$
\begin{aligned}
& \text { Idealized } A_{11 u^{*}}-D_{1 u} u^{*} \text { relationship: } \\
& A_{1 U}{ }^{*}\left(D_{1 U}{ }^{*}\right)= \begin{cases}\kappa_{1} D_{1 u^{*}}{ }^{*} & : D_{1 u}{ }^{*} \leq D_{1 U}{ }^{*}{ }^{*} \\
A_{1 u_{0}}{ }^{*}+\kappa_{2} D_{1 U}{ }^{*} & : D_{1 U}{ }^{*}>D_{1 U}{ }^{*}{ }^{*}\end{cases} \\
& \kappa_{2}=\frac{A_{1 U \text { 040 }}{ }^{*}-A_{1 U}{ }^{*} 010}{D_{1 U 040}{ }^{*}-D_{1 U}{ }^{*} 010} \\
& D_{1 U, y}{ }^{*}=A_{1 U i}{ }^{*} /\left(\kappa_{1}-\kappa_{2}\right), A_{1 U{ }_{0}}{ }^{*}=A_{1 U 010}{ }^{*}-\kappa_{2} D_{1 U}{ }^{*} 010
\end{aligned}
$$

Figure 14. Bilinear idealization of the equivalent acceleration-equivalent displacement relationship.

Then, the effective period $\left(T_{1 e f f}\right)$ and the hysteretic dissipated energy in the half cycle per unit mass $\left(\Delta E_{\mu 1 U}{ }^{*} / M_{1 U}{ }^{*}\right)$ are formulated. Figure 15 shows the modeling of the structural response in a half cycle used to predict the peak response. In Figure 15, the parameter $\eta$ is the displacement ratio in the positive and negative directions and is assumed to be in the range from 0 to 1 . In addition, the horizontal deformation of the isolation layer is assumed to be predominant in the first modal response.

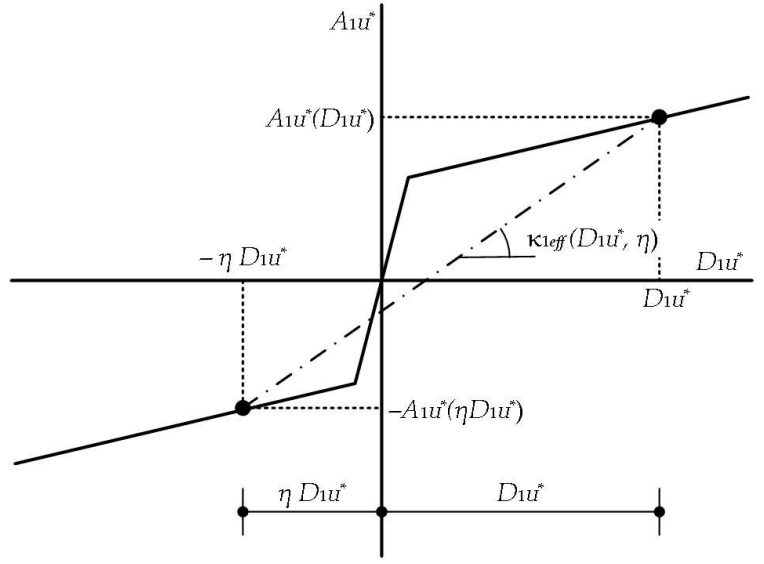

(a)

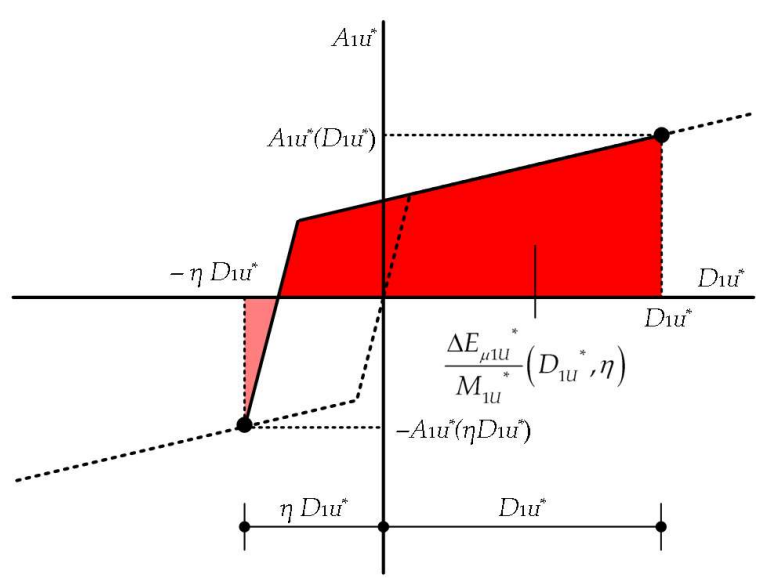

(b)

Figure 15. Modeling of the structural response in a half cycle used to predict the peak response: (a) the effective slope ( $\kappa 1$ eff) and (b) the hysteretic dissipated energy in a half cycle per unit mass $\left(\Delta E_{\mu 1 u} / M_{1} u^{*}\right)$.

In this study, the effective period of the first mode corresponding to $D_{1 U}{ }^{*}$ is calculated as

$$
T_{1 e f f}\left(D_{1 U}^{*}\right)=2 \pi / \sqrt{\kappa_{1 e f f}\left(D_{1 U}^{*}\right)} .
$$

In addition, the equivalent velocity of the hysteretic dissipated energy in a half cycle corresponding to $D_{1 U}{ }^{*}$ is calculated as

$$
V_{\Delta E \mu 1 U}{ }^{*}\left(D_{1 U}^{*}\right)=\sqrt{\frac{2 \Delta E_{\mu 1 U}^{*}}{M_{1 U}^{*}}\left(D_{1 U}^{*}\right)} .
$$

The effective slope corresponding to $D_{1 U}{ }^{*}$ is calculated as 


$$
\begin{aligned}
& \kappa_{1 \text { eff }}\left(D_{1 U}{ }^{*}\right)=\int_{0}^{1} \kappa_{1 \text { eff }}\left(D_{1 U}{ }^{*}, \eta\right) d \eta \\
& = \begin{cases}\kappa_{1} & : D_{1 u}{ }^{*} \leq D_{1 u}{ }^{*} y . \\
(2 \ln 2) \frac{A_{1 u}{ }^{*} 0}{D_{1 u}{ }^{*}}+\kappa_{2}-\left\{\ln \left(1+\frac{D_{1 u}{ }^{*} y}{D_{1 u}{ }^{*}}\right)\right\}\left(\frac{A_{1 u}{ }^{*} 0}{D_{1 u}{ }^{*}}+\kappa_{1}-\kappa_{2}\right)+\frac{D_{1 u y}{ }^{*}}{D_{1 u}{ }^{*}}\left(\kappa_{1}-\kappa_{2}\right) & : D_{1 u}{ }^{*}>D_{1 u}{ }^{*} y\end{cases}
\end{aligned}
$$

The hysteretic dissipated energy in a half cycle per unit mass corresponding to $D_{1 U}{ }^{*}$ is calculated as

$$
\begin{aligned}
& \frac{\Delta E_{\mu 1 U}{ }^{*}}{M_{1 U}{ }^{*}}\left(D_{1 U}{ }^{*}\right)=\int_{0}^{1} \frac{\Delta E_{\mu 1 U}{ }^{*}}{M_{1 U}{ }^{*}}\left(D_{1 U}{ }^{*}, \eta\right) d \eta
\end{aligned}
$$

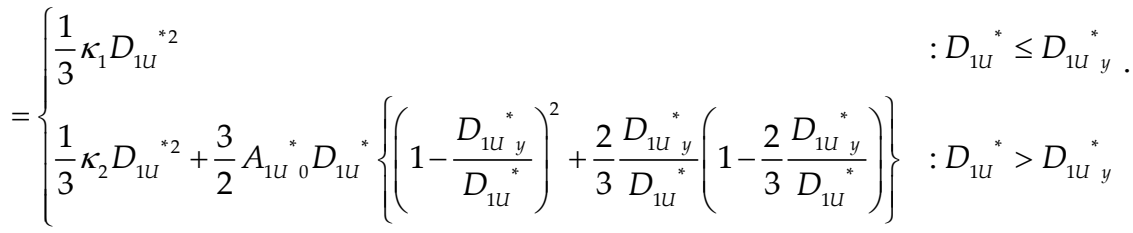

The predicted peak response $D_{1 U}{ }^{*}$ max is obtained from the following equation:

$$
V_{\Delta E \mu 1 U}{ }^{*}\left\{T_{\text {leff }}{ }^{*}\left(D_{1 U}{ }^{*} \max \right)\right\}=V_{\Delta E}\left\{T_{1 \text { leff }}{ }^{*}\left(D_{1 U}{ }^{*} \max \right)\right\} .
$$

Note that no viscous damping is considered because the isolation layer is assumed to have no viscous damping.

\section{Analysis Results}

The analysis results are split into two subsections. In the first subsection, an example of the prediction of the peak equivalent displacement using the updated MABPA is shown. In the second subsection, comparisons are made between the nonlinear time-history analysis results and the predicted results.

\subsection{Example of a prediction of the peak equivalent displacement}

The structural model shown here as an example is Model-Tf44. Figure 16 shows the nonlinear properties of the equivalent SDOF model calculated according to Section 3.2.2.
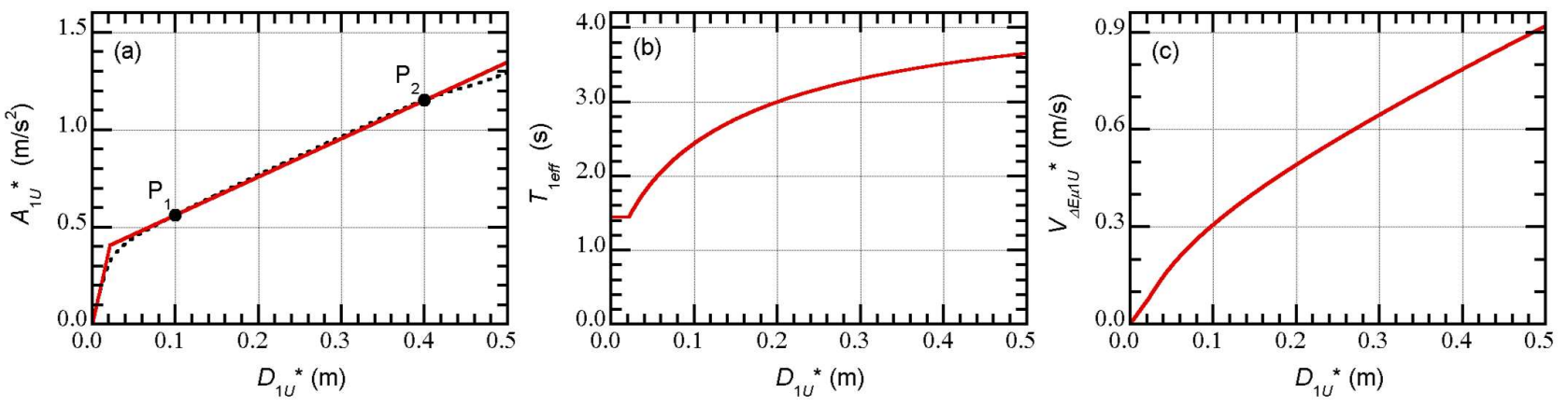

Figure 16. Nonlinear properties of the equivalent single-degree-of-freedom (SDOF) model representing the first modal response (Model-Tf44): (a) the $A_{1} u^{*}-D_{1} u^{*}$ relationship; (b) the $T_{1 e f f}{ }^{*}-D_{1} u^{*}$ relationship; and (c) the $V_{\Delta E \mu 1} u^{*}-D_{1} u^{*}$ relationship.

In the results shown in Figures 16(b) and 16(c), the $V_{\triangle E \mu 1 U}{ }^{*}-T_{\text {leff }}$ curve is constructed and overlaid with the bidirectional $V_{\Delta E}$ spectrum. Figure 17 shows the prediction of the peak equivalent displacements of the first two modes. 

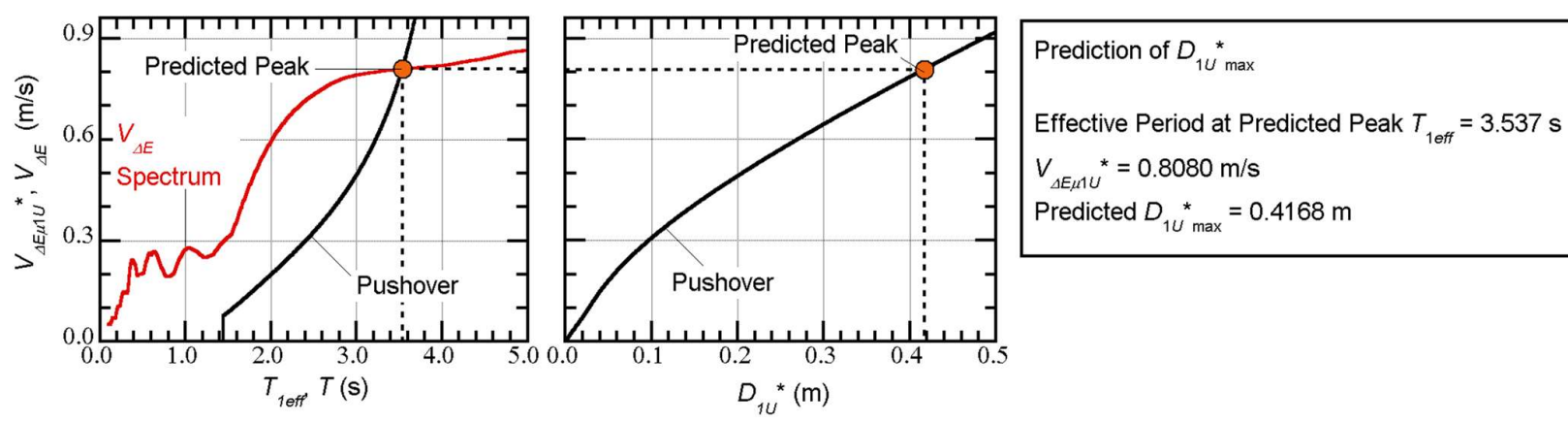

(a)
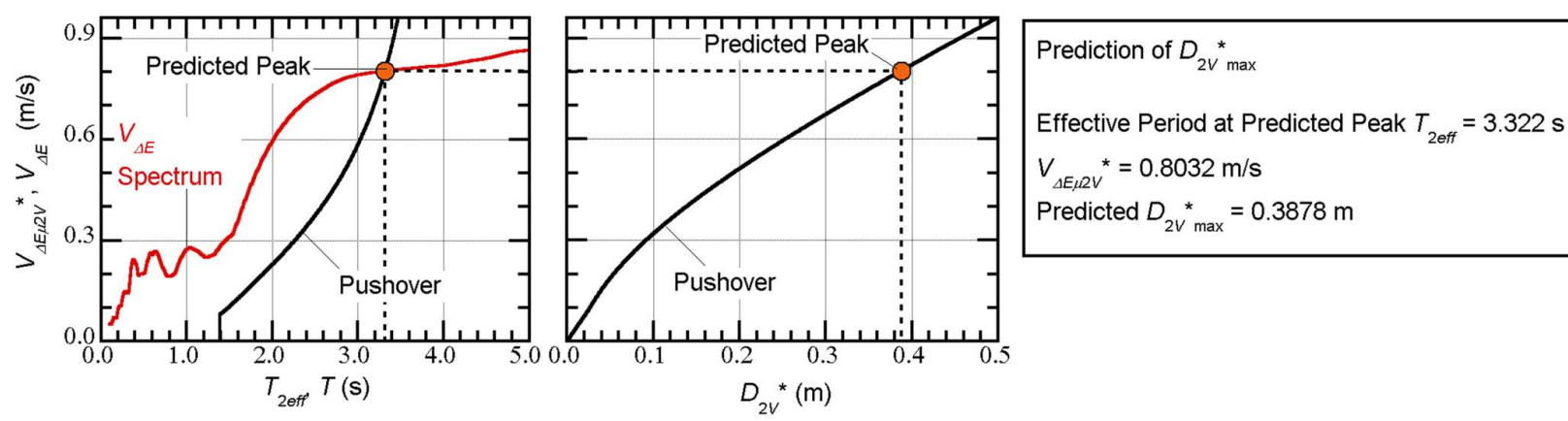

(b)

Figure 17. Prediction of the peak equivalent displacements (model: Model-Tf44, ground motion: TCU): (a) prediction of the peak of the first modal response and $(\mathbf{b})$ prediction of the peak of the second modal response.

The predicted peak was obtained as the intersection point of the $V_{\Delta E \mu 1 U}{ }^{*}-T_{1 e f f}$ curve according to the pushover analysis results and the bidirectional $V_{\Delta E}$ spectrum, as shown on the left side of Figure 17(a). Then, the peak equivalent displacement $D_{1 u}{ }^{*}{ }_{\max }$ was predicted from the $V_{\triangle E \mu 1 U}{ }^{*}-D_{1 U}{ }^{*}$ max curve. The prediction of the peak equivalent displacement of the second mode, $D_{2 V}{ }^{*}$ max , can be made using the same procedure as that of $D_{1 U}{ }^{*}{ }_{\max }$, as shown in Figure 17(b). Note that, for the predictions of $D_{1 U}{ }^{*}$ max and $D_{2 V}{ }^{*}{ }_{\max }$, the same $V_{\Delta E}$ spectrum (bidirectional $V_{\Delta E}$ spectrum) is used.

\subsection{Comparisons with the nonlinear time-history analysis}

In Section 4.2.1, the nonlinear time-history analysis results using 24 artificial ground motion datasets are compared with the predicted results. In this analysis, $24 \times 4=96$ cases are analyzed for each model: the angle of incidence of the horizontal ground motion $(\psi)$ in Figure 3 is set to $-45^{\circ}, 0^{\circ}, 45^{\circ}$, and $90^{\circ}$ considering the symmetry of the force-deformation relationship assumed in the structural model. Because the characteristics of the two horizontal components are similar, the discussion focuses on comparisons between the envelope of the time-history analysis results and the predicted results.

In Section 4.2.2, the nonlinear time-history analysis results using the four recorded ground motion datasets are compared with the predicted results. In this analysis, $4 \times 12=$ 48 cases are analyzed for each model: the angle of incidence of the horizontal ground motion $(\psi)$ is set to values from $-75^{\circ}$ to $90^{\circ}$ with an interval of $15^{\circ}$.

\subsubsection{Artificial ground motion}

Figures 18 and 19 show the peak relative displacement at $\mathrm{X}_{3 \mathrm{~A}} \mathrm{Y}_{3}$, which is the closest point to the center of the floor mass at each level. In these figures, the nonlinear timehistory analysis results are compared with the results predicted by MABPA (for complex 
damping ratios $(\beta)$ of $0.10,0.20$, and 0.30 ). As shown here, the predicted peaks can approximate the envelope of the time-history analysis results, except in the case of ModelTf34 subjected to the Art-2 series shown in Figure 18(b). In addition, the predicted peak with $\beta=0.10$ is larger than that with $\beta=0.30$. When the models are subjected to the Art-1 series, the predicted peak closest to the envelope of the time-history analysis results is found with $\beta=0.10$ for Model-Tf34 (Figure 18(a)) and with $\beta=0.30$ for Model-Tf44 (Figure 18(b)). Differences in the predicted peaks resulting from the value of the complex damping are small in the case of Model-Tf34 but relatively noticeable in the case of ModelTf44.

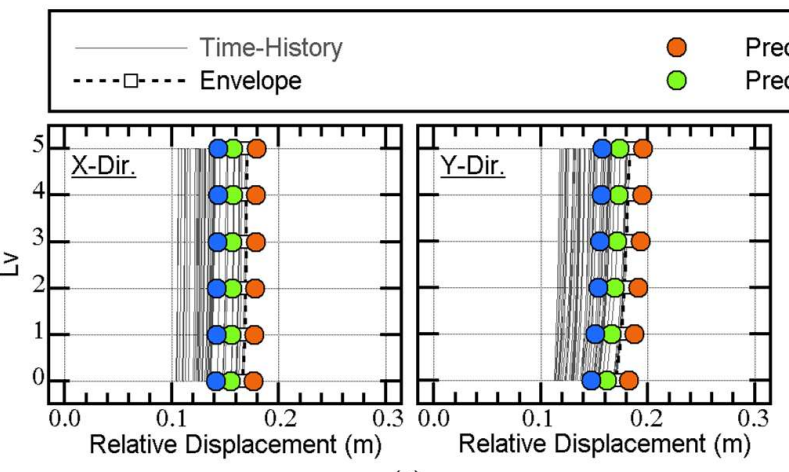

(a)

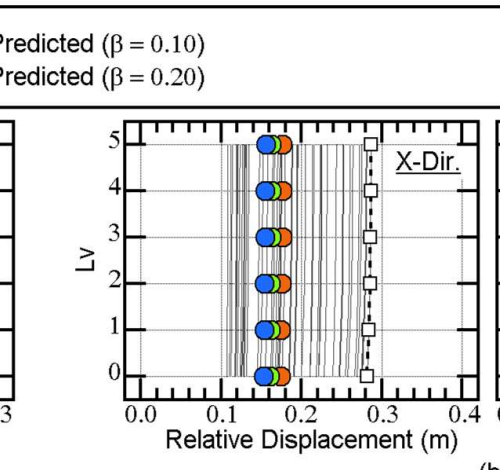

(b)
Predicted $(\beta=0.30)$

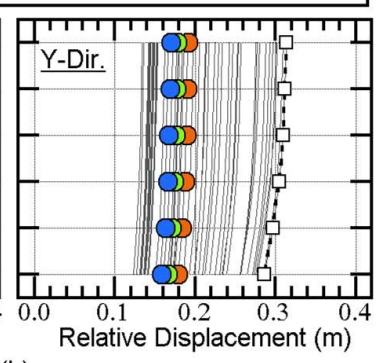

Figure 18. Comparison of the peak relative displacements at $\mathrm{X}_{3 \mathrm{~A}} \mathrm{Y}_{3}$ (Model-Tf34) for the (a) Art-1 and (b) Art-2 series.

\begin{tabular}{|c|c|c|c|c|}
\hline — Time-History & 0 & Predicted $(\beta=0.10)$ & 0 & Predicted $(\beta=0.30)$ \\
\hline -..-- - Envelope & 0 & Predicted $(\beta=0.20)$ & & \\
\hline
\end{tabular}

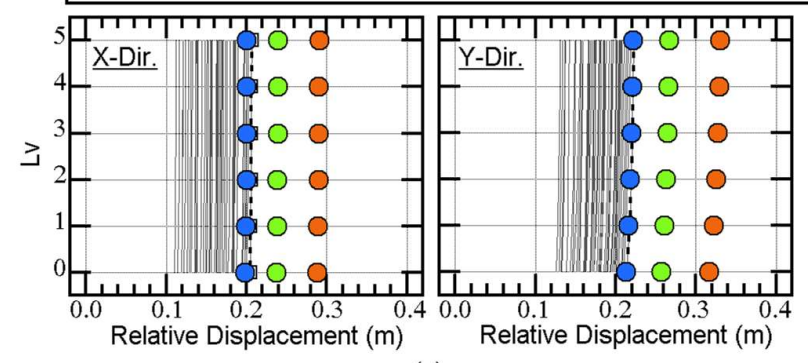

(a)

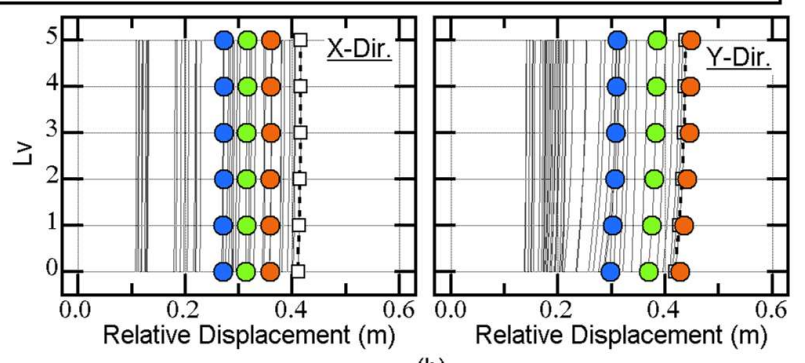

(b)

Figure 19. Comparison of the peak relative displacements at $X_{3 A} Y_{3}$ (Model-Tf44) for the (a) Art-1 and (b) Art-2 series.

Figures 20 and 21 show comparisons of the horizontal distributions of the peak displacement at level 0, which is just above the isolation layer. In Figure 20, the results of Model-Tf34 subjected to the Art-1 series are shown. The predicted peak agrees with the envelope of the time-history analysis results, even though the predicted peak is not conservative at $Y_{1}$ and $Y_{2}$ (the stiff side in the $X$-direction). A similar observation can be made in the case of Model-Tf44 subjected to the Art-1 series, as shown in Figure 21, where the predicted peak with $\beta=0.30$ agrees very well with the envelope of the time-history analysis results, except at $Y_{1}$ and $Y_{2}$. 

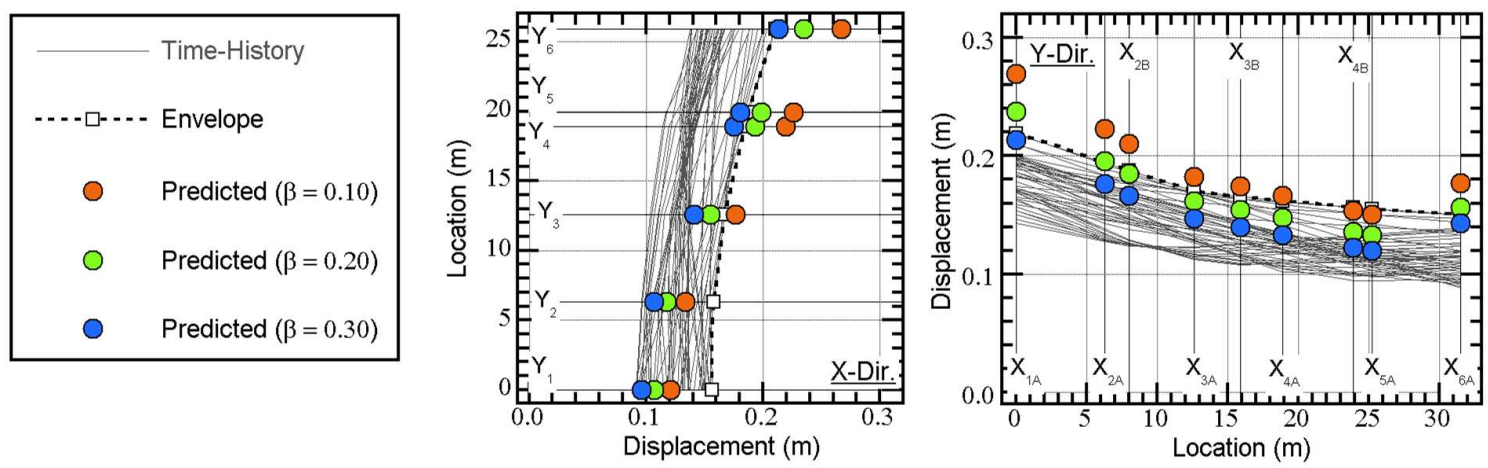

Figure 20. Comparison of the horizontal distributions of the peak displacement at level 0 (model: Model-Tf34, ground motion: Art-1 series).
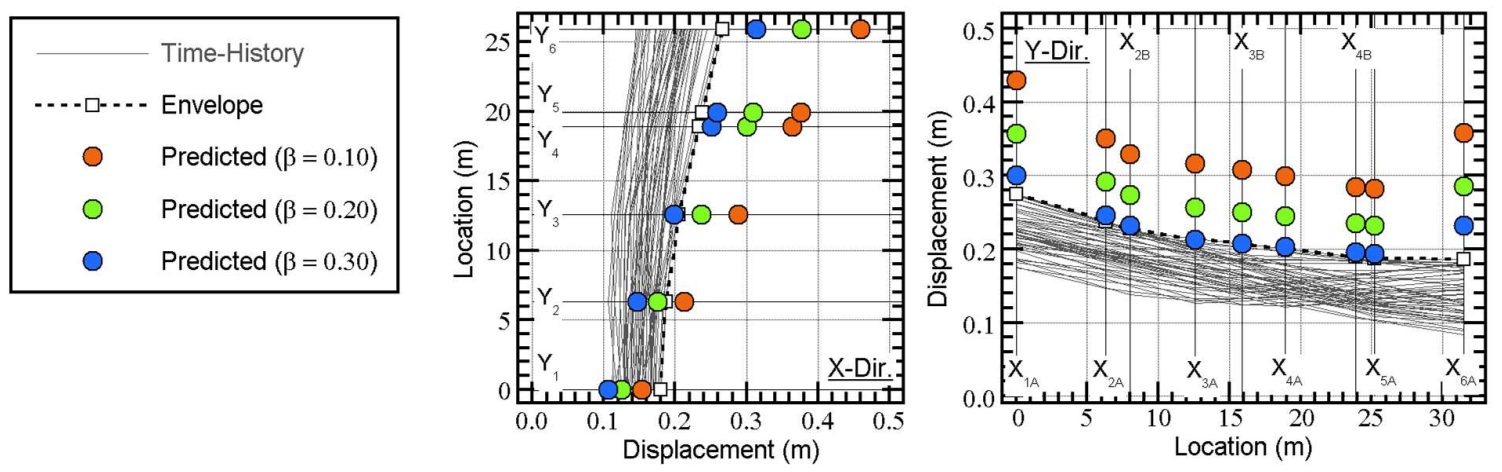

Figure 21. Comparison of the horizontal distributions of the peak displacement at level 0 (model: Model-Tf44, ground motion: Art-1 series).

Based on the above results, the updated MABPA can predict the peak relative displacement at $\mathrm{X}_{3 \mathrm{~A}} \mathrm{Y}_{3}$ and the horizontal distribution of the peak displacement at level 0 for both models according to the artificial ground motion datasets.

\subsubsection{Recorded ground motion}

Figures 22 and 23 show the peak relative displacement at $\mathrm{X}_{3 \mathrm{~A}} \mathrm{Y}_{3}$. The accuracy of the predicted peak displacement is satisfactory: the predicted peak approximates the envelope of the nonlinear time-history analysis results, even though some cases are overestimated (e.g., model: Model-Tf44, ground motion: UTO0416, Figure 23(b)). The variation of the predicted peak due to the assumed complex damping ratio $(\beta)$ depends on the ground motion. In some cases, the largest peak is obtained when $\beta$ is 0.30 (e.g., model: Model-Tf34, ground motion: UTO0416, Figure 22(b)), while in other cases, the largest peak is obtained when $\beta$ is 0.10 (e.g., model: Model-Tf34, ground motion: TCU, Figure 22(c)). 


\begin{tabular}{|llll|}
\hline $\begin{array}{l}\text { Time-History } \\
\text {-..-.-.- Envelope }\end{array}$ & 0 & Predicted $(\beta=0.10)$ & Predicted $(\beta=0.30)$ \\
\hline
\end{tabular}

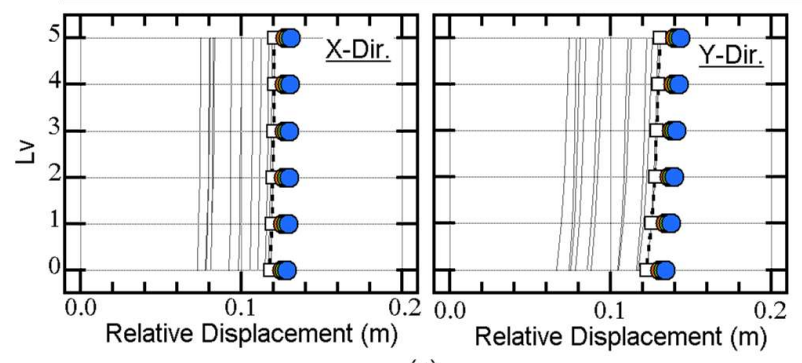

(a)

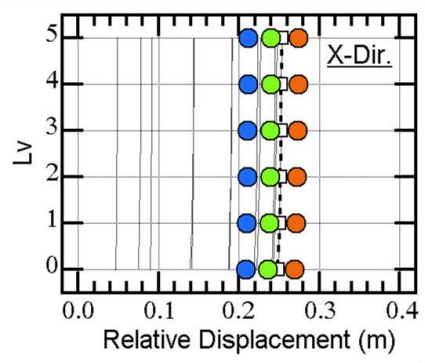

(c)

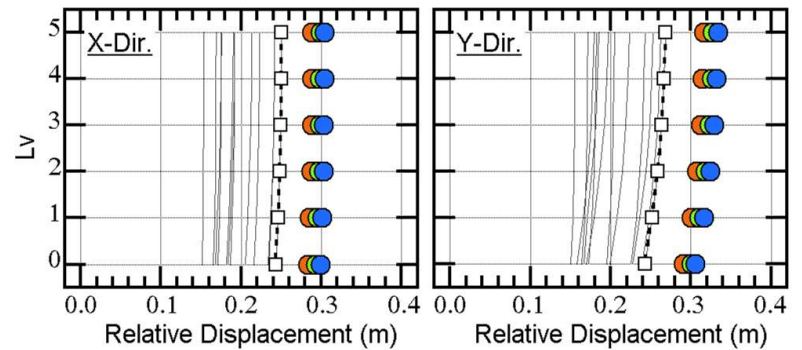

(b)

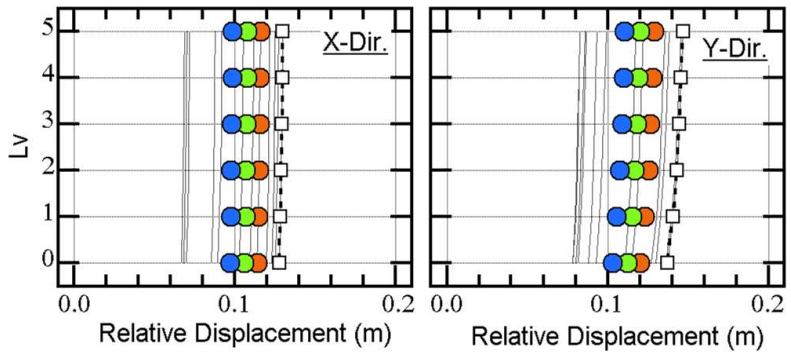

(d)

Figure 22. Comparison of the peak relative displacements at $\mathrm{X}_{3 \mathrm{~A}} \mathrm{Y}_{3}$ (Model-Tf34): (a) UTO0414; (b) UTO0416; (c) TCU; and (d) YPT.

\begin{tabular}{|llll|}
\hline \begin{tabular}{l} 
Time-History \\
\hline$\ldots-$ - - Envelope
\end{tabular} & 0 & Predicted $(\beta=0.10)$ & Predicted $(\beta=0.30)$ \\
\hline
\end{tabular}

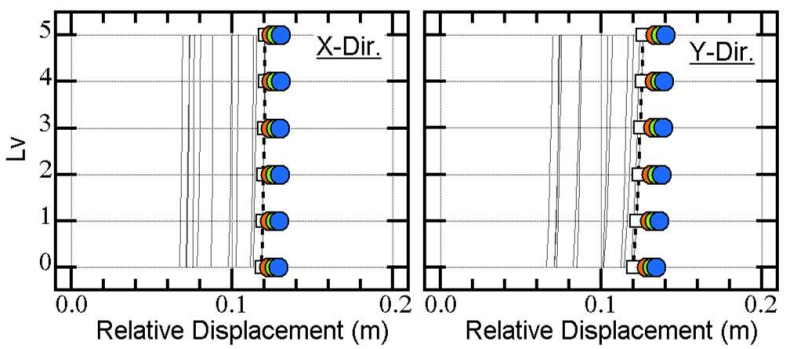

(a)

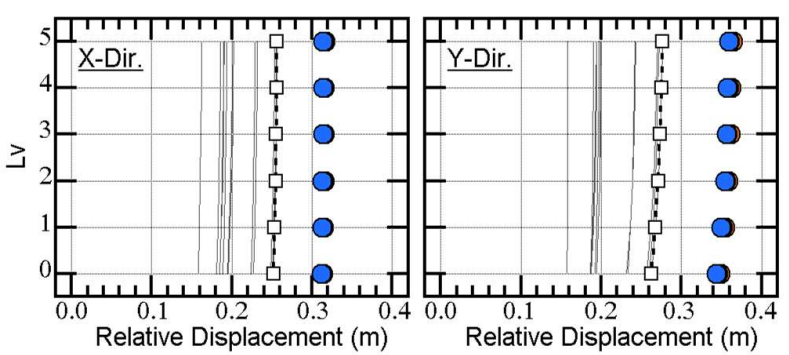

(b)

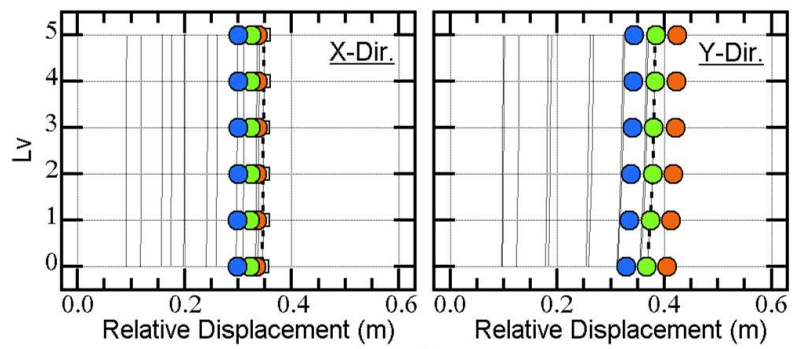

(c)

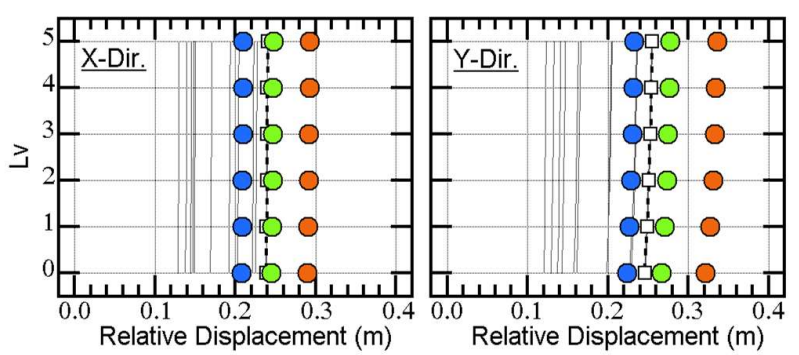

(d)

Figure 23. Comparison of the peak relative displacements at $\mathrm{X}_{3 \mathrm{~A}} \mathrm{Y}_{3}$ (Model-Tf44): (a) UTO0414; (b) UTO0416; (c) TCU; and (d) YPT.

Figure 24 shows comparisons of the horizontal distribution of the peak displacement at level 0 . In this figure, the Model-Tf34 results are shown, with the results for UTO0414 shown in Figure 24(a) and those for TCU shown in Figure 24(b). 

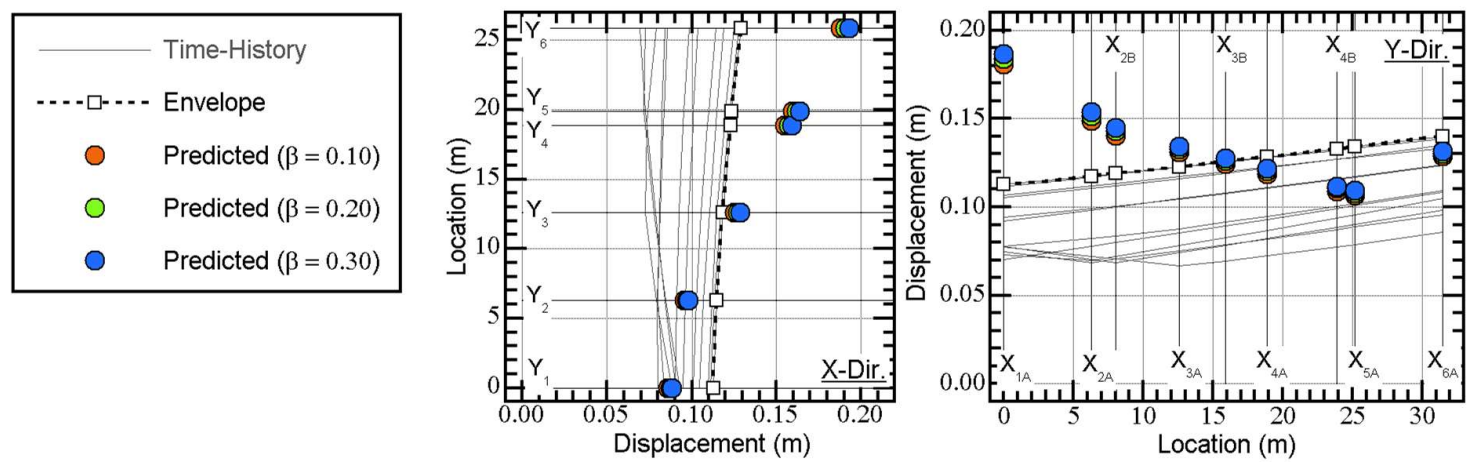

(a)
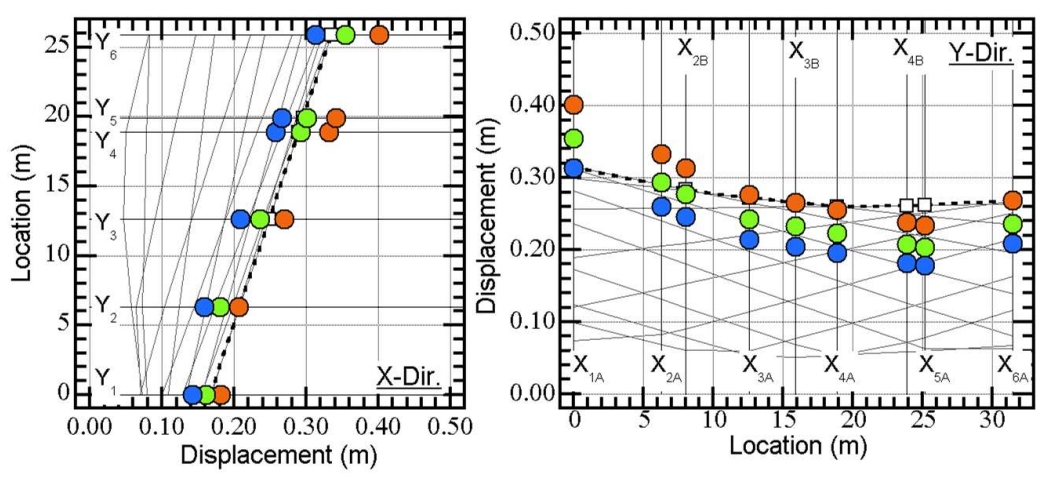

(b)

Figure 24. Comparison of the horizontal distributions of the peak displacement at level 0 (model: Model-Tf34) for (a) UTO0414 and (b) TCU.

The predicted horizontal distribution of the peak displacement in the Y-direction is notably different from the envelope of the time-history analysis in the case of UTO0414, as shown in Figure 24(a). In the predicted distribution, the largest displacement occurs at $\mathrm{X}_{1 \mathrm{~A}}$ (the flexible side in the $\mathrm{Y}$-direction); meanwhile, in the envelope of the time-history analysis results, the displacement at $\mathrm{X}_{1 \mathrm{~A}}$ is the smallest. Conversely, the predicted horizontal distribution of the peak displacement in the Y-direction fits the envelope of the time-history analysis in the case of TCU very well, as shown in Figure 24(b). In the predicted distribution, the largest displacement occurs at $\mathrm{X}_{1 \mathrm{~A}}$, which is consistent with the envelope of the time-history analysis results. The modal displacement responses at $\mathrm{X}_{1 \mathrm{~A}}$ and $\mathrm{X}_{6 \mathrm{~A}}$ (the stiff side in the $\mathrm{Y}$-direction) are compared and discussed further in Section 5.5 .

One of the motivations of this analysis is to evaluate the seismic performance of the retrofitted building models under the recorded motions from the 2016 Kumamoto earthquake. It has already been reported in a previous study [33] that the seismic capacity evaluation of the main building of the former Uto City Hall indicated that the structure was insufficient to withstand the earthquake that occurred on April 14, 2016. Therefore, the drift of the superstructure was examined as follows.

Figure 25 shows comparisons of the peak drift for the three columns in Model-Tf34 in cases with UTO0414 and UTO0416. The peak drifts for the three columns obtained from the nonlinear time-history analysis results are smaller than $0.4 \%$. The largest peak drift occurs for column $\mathrm{A}_{3} \mathrm{~B}_{3}$ on the second story, with a value of $0.12 \%$ in the case of UTO0414 (Figure 25(a)) and a value of $0.30 \%$ in the case of UTO0416 (Figure 25(b)). Therefore, the seismic performance of Model-Tf34 is excellent for the motions recorded during the 2016 Kumamoto earthquake. Figure 26 shows comparisons of the peak drift of Model-Tf44. Similar observations can be made for Model-Tf44. Comparisons of Figures 25 and 26 indicate that the peak drift of Model-Tf44 is smaller than that of Model-Tf34. These figures 
also illustrate that the accuracy of the predicted peak depends on the column, with the accuracy at column $\mathrm{A}_{1} \mathrm{~B}_{1}$ being satisfactory and that at column $\mathrm{A}_{3} \mathrm{~B}_{3}$ being less satisfactory.
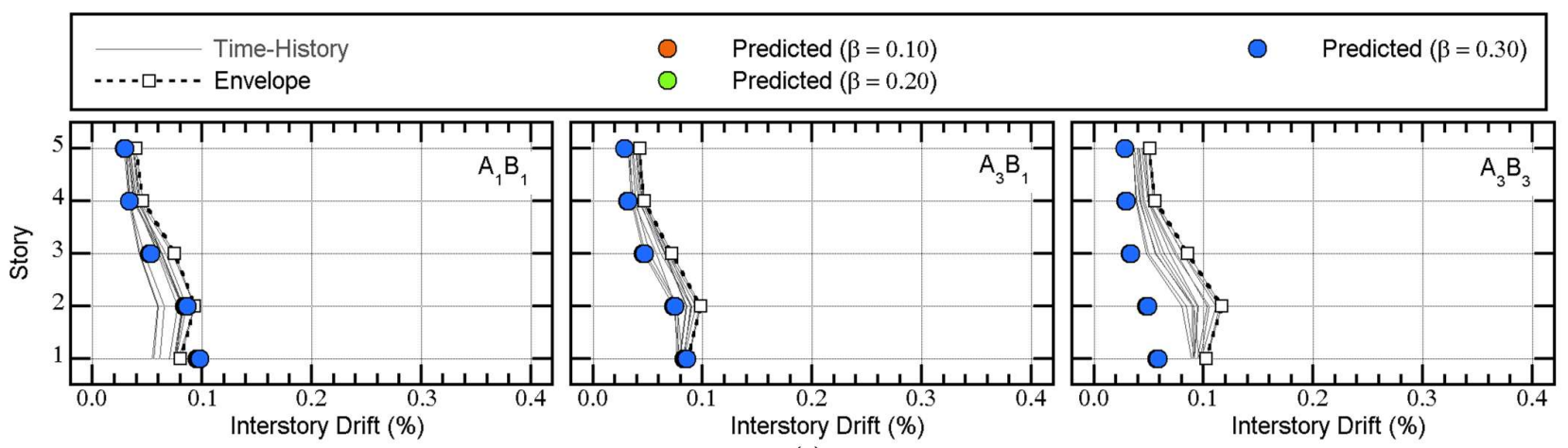

(a)
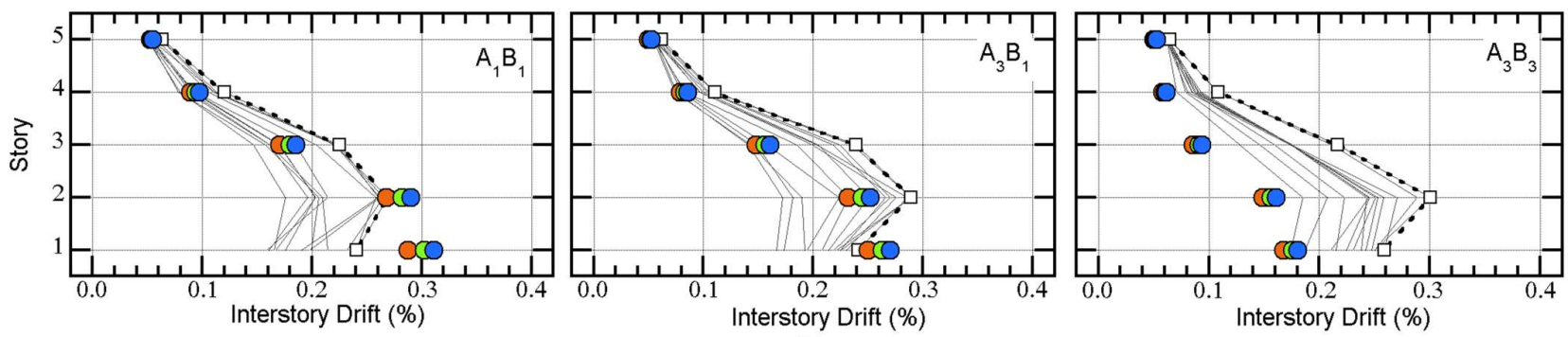

(b)

Figure 25. Comparison of the peak drift for the columns (Model-Tf34) with (a) UTO0414 and (b) UTO0416.

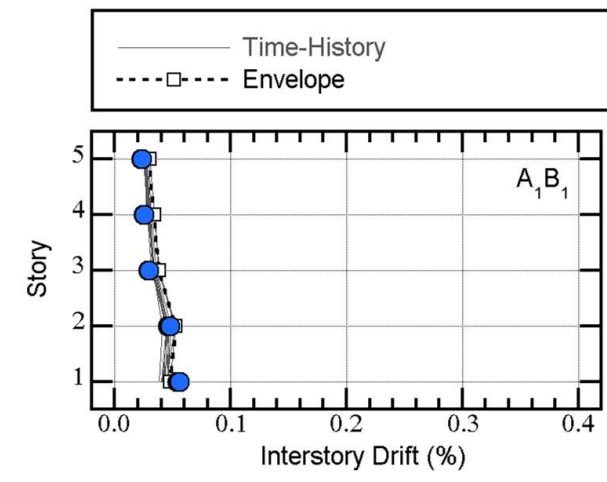

$\begin{array}{ll}\bigcirc & \text { Predicted }(\beta=0.10) \\ \bigcirc & \text { Predicted }(\beta=0.20)\end{array}$
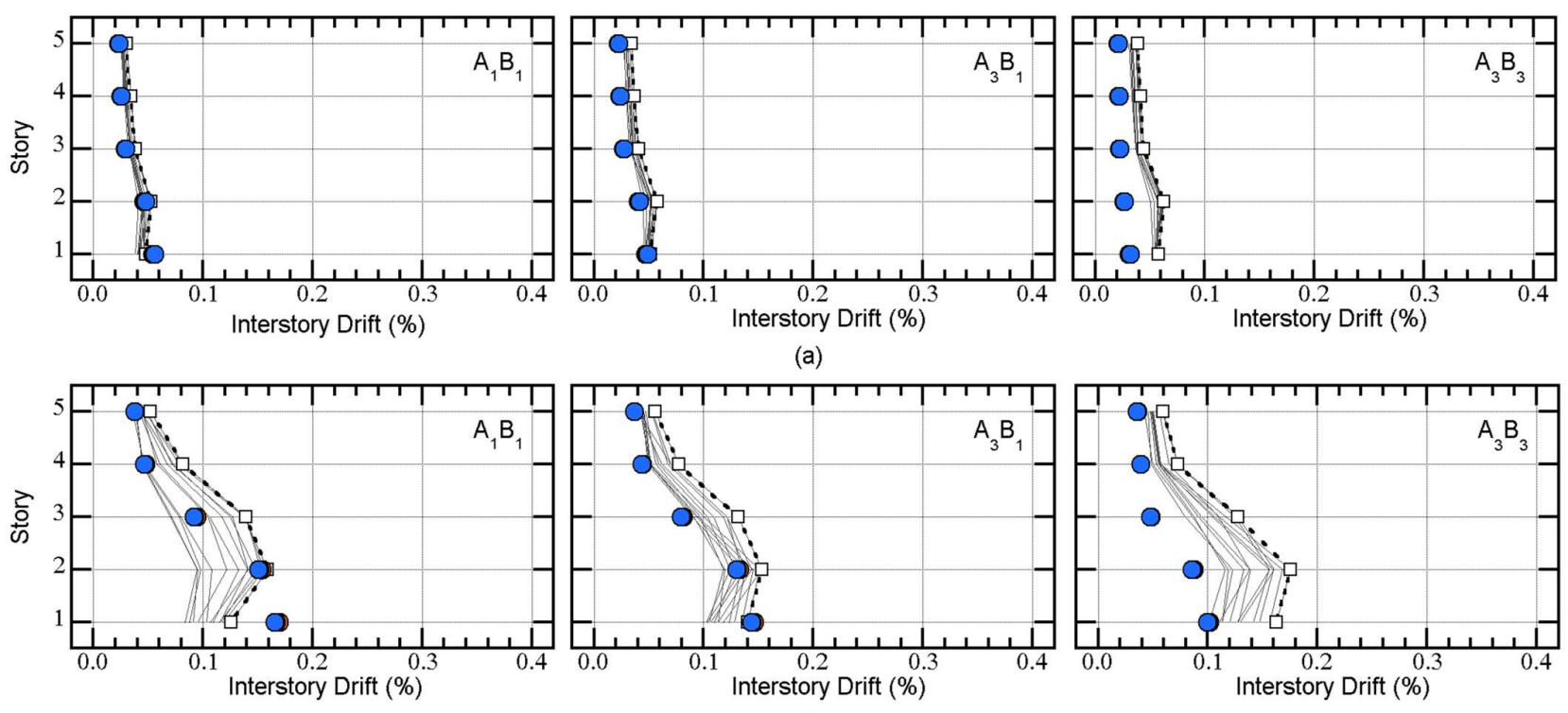

(b)

Figure 26. Comparison of the peak drift for the columns (Model-Tf44) with (a) UTO0414 and (b) UTO0416.

Figures 27 and 28 show the peak displacements at two isolators $\left(\mathrm{X}_{1 \mathrm{~A}} \mathrm{Y}_{6}\right.$ and $\left.\mathrm{X}_{6 \mathrm{~A}} \mathrm{Y}_{1}\right)$ for various angles of incidence of seismic input $(\psi)$. In these figures, the displacement of each isolator is calculated as the absolute (vector) value of the two horizontal directions and 
the predicted peaks are shown by the colored lines. As shown in these figures, the upper bounds of the peak displacement of the isolators can be satisfactorily evaluated using the updated MABPA presented in this study.

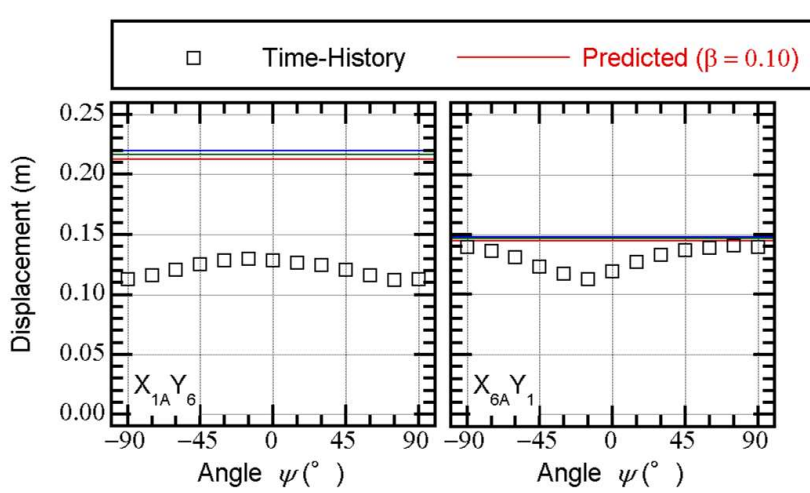

(a)

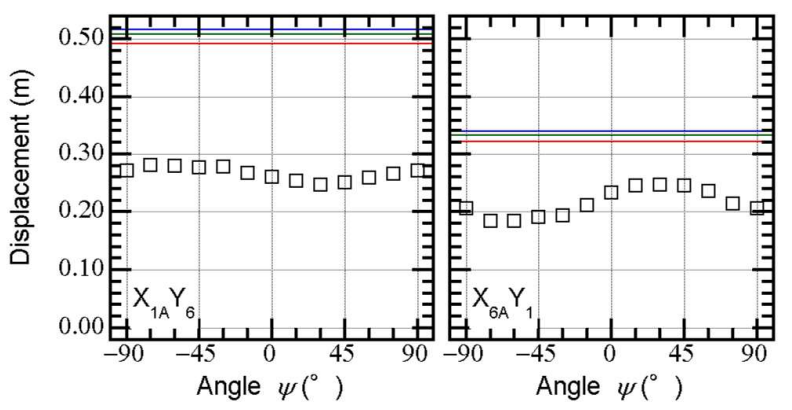

(b)

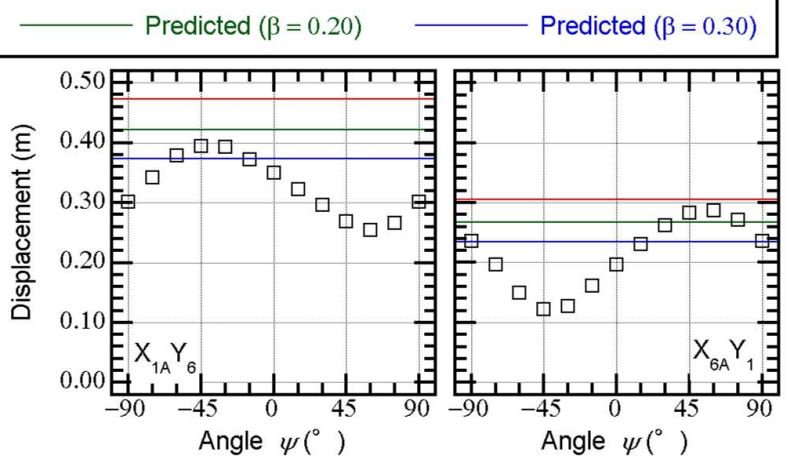

(c)

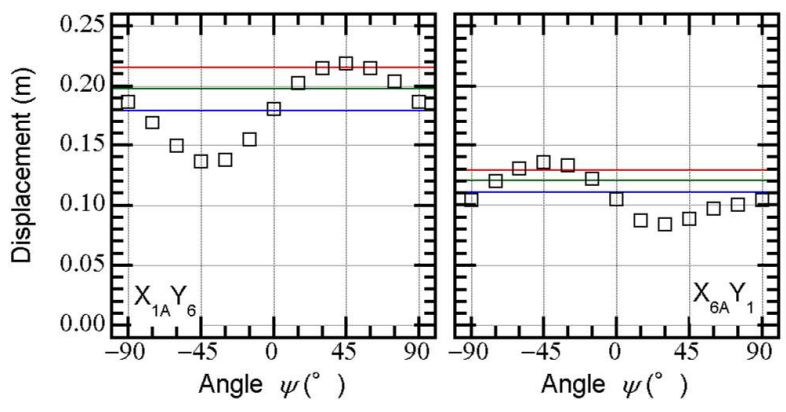

(d)

Figure 27. Peak displacement at isolators for various angles of incidence of seismic input (Model-Tf34): (a) UTO0414; (b) UTO0416; (c) TCU; and (d) YPT. 


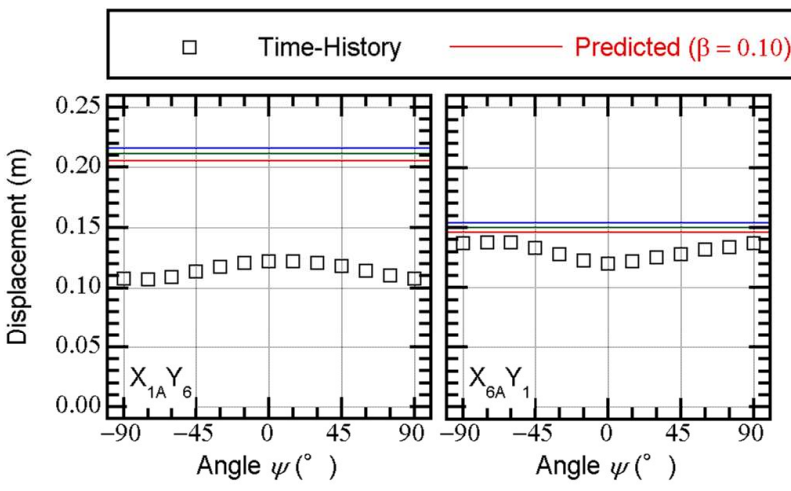

(a)

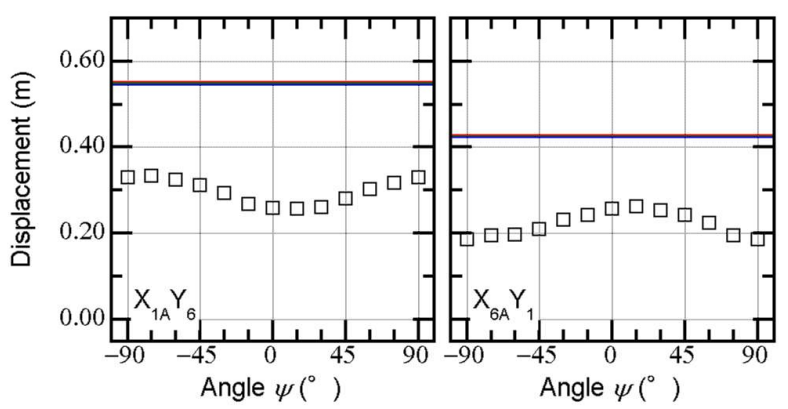

(b)

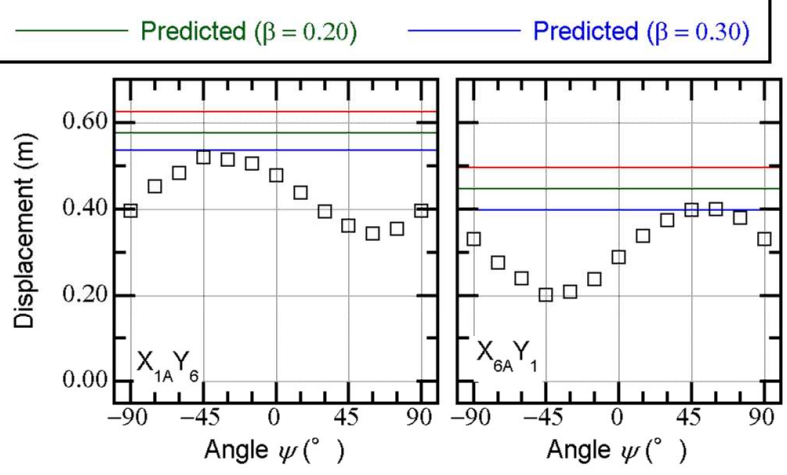

(c)

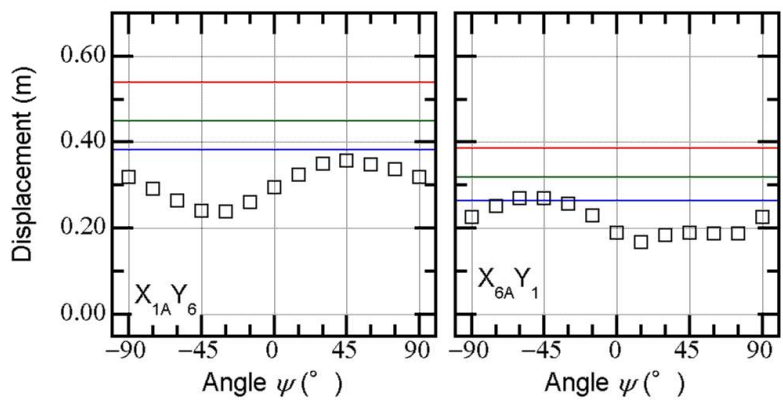

(d)

Figure 28. Peak displacement at isolators for various angles of incidence of seismic input (Model-Tf44): (a) UTO0414; (b) UTO0416; (c) TCU; and (d) YPT.

These figures also indicate that the variation in the peak displacement of the isolators due to the angle of incidence of the seismic input is noticeable, e.g., in the cases of TCU and YPT, for both models. This point is discussed in Section 5.

\section{Discussion}

Here, there are four points of focus: (i) the relationship between the maximum momentary input energy and the peak equivalent displacement of the first modal response and its predictability from the pushover analysis results, (ii) the predictability of the maximum momentary input energy of the first modal response from the bidirectional $V_{\Delta E}$ spectrum, (iii) the accuracy of the predicted peak equivalent displacements of the first and second modal responses, and (iv) the contribution of the higher mode to the displacement response at the edge of level 0.

\subsection{Calculation of the modal responses}

Figure 29 shows the calculation flow for the first and second modal responses from the nonlinear time-history analysis results. This procedure is based on the procedure originally proposed by Kuramoto [49] for analyzing the nonlinear modal response of a nonisolated planer frame structure extended to analyze that of three-dimensional base-isolated structures. 


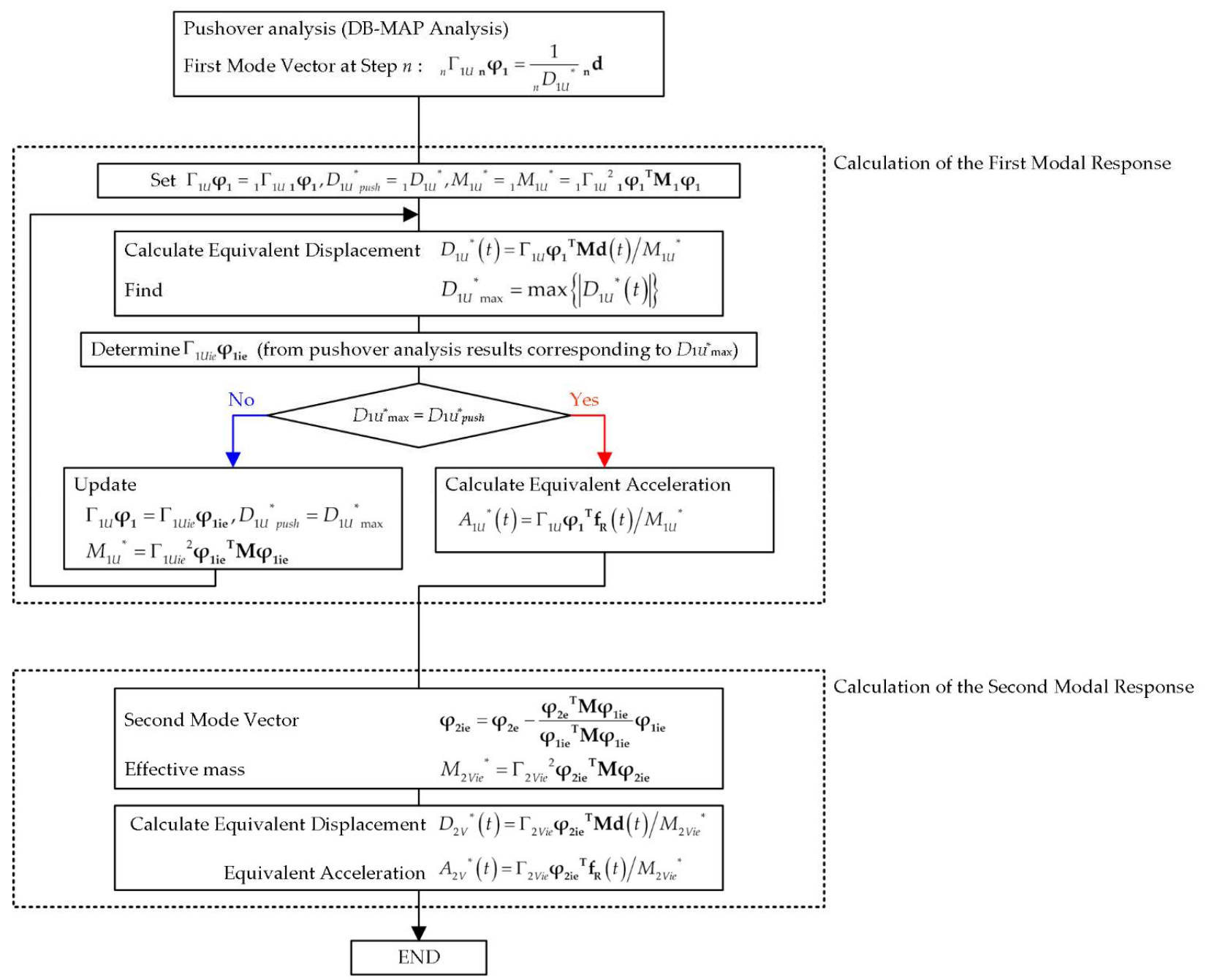

Figure 29. Calculation flow for the first and second modal responses.

Next, the momentary input energy of the first modal response per unit mass was calculated as follows. From the time-history of the equivalent displacement of the first modal response $\left(D_{1 U}{ }^{*}(t)\right)$, the momentary input energy of the first modal response per unit mass is calculated as

$$
\frac{\Delta E_{1 U}{ }^{*}}{M_{1 U}{ }^{*}}=-\int_{t}^{t+\Delta t} \dot{D}_{1 U}{ }^{*}(t) a_{g U}(t) d t .
$$

In Eq. (25), $\dot{D}_{1 U}{ }^{*}(t)$ is the derivative of $D_{1 U}{ }^{*}(t)$ with respect to $t, a_{g u}(t)$ is the ground acceleration component of the U-axis (the principal axis of the first modal response corresponds to $D_{1 U}{ }^{*} \max =\max \left\{\left|D_{1 U}{ }^{*}(t)\right|\right\}$ ), and $\Delta t$ is the duration of a half cycle of the first modal response. The maximum momentary input energy of the first modal response per unit mass $\left(\Delta E_{1 U \max }{ }^{*} / M_{1 U}{ }^{*}\right)$ is the maximum value of $\Delta E_{1 U}{ }^{*} / M_{1 U}{ }^{*}$ calculated by Eq. (25) over the course of the seismic event. Figure 30 shows the definition of the maximum momentary input energy of the first modal response per unit mass. As shown in this figure, the half cycle when the maximum equivalent displacement $\left(D_{1 U \text { max }}{ }^{*}\right)$ occurs corresponds to the half cycle when the maximum momentary energy input occurs. 

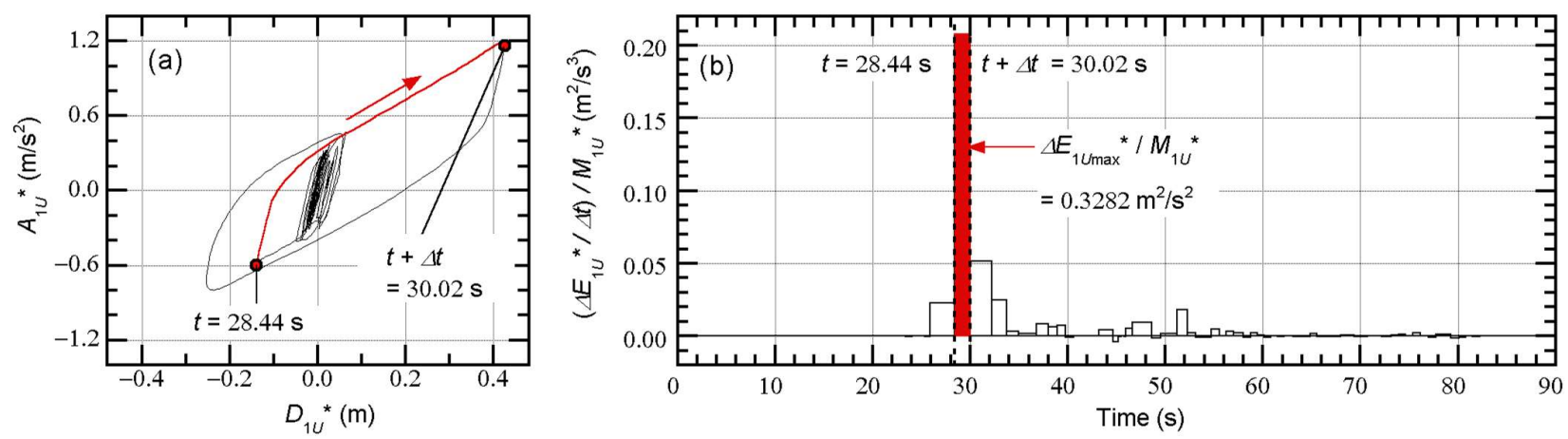

Figure 30. Definition of the maximum momentary input energy of the first modal response per unit mass (structural model: Model-Tf44, ground motion: TCU, angle of incidence of seismic input: $\psi=-30^{\circ}$ ): (a) hysteresis of the first modal response and (b) time-history of the momentary energy input.

The equivalent velocity of the maximum momentary input energy of the first modal response $\left(V_{\triangle E I U}{ }^{*}\right)$ and the response period of the first modal response $\left(T_{1}^{\prime}\right)$ are calculated such that

$$
\begin{gathered}
V_{\Delta E 1 U}{ }^{*}=\sqrt{2 \Delta E_{1 U \max }{ }^{*} / M_{1 U}{ }^{*}}, \\
T_{1}^{\prime}=2 \Delta t .
\end{gathered}
$$

5.2. Relationship between the peak equivalent displacement and the maximum momentary input energy of the first modal response

Figures 31 and 32 show comparisons between the $V_{\triangle E \mu 1 U}{ }^{*}-D_{1 U}{ }^{*}$ curve and the $V_{\triangle E I U}{ }^{*}-D_{1 U}{ }^{*}$ max relationship obtained from the nonlinear time-history analysis, with the results of Models Tf34 and Tf44 shown in Figures 31 and 32, respectively. These figures confirm that the $V_{\triangle E \mu 1 U}{ }^{*}-D_{1 U}{ }^{*}$ curve fits the plots obtained from the time-history analysis results very well. Therefore, the accuracy of the predicted $D_{1 U}{ }^{*}$ max relies on the accuracy of the predicted $V_{\triangle E 1 U}{ }^{*}$, which is discussed in the next subsection. 


\begin{tabular}{|c|c|c|c|c|c|}
\hline & Pushover & 0 & Predicted $(\beta=0.10)$ & 0 & Predicted $(\beta=0.30)$ \\
\hline 口 & Time-History & 0 & Predicted $(\beta=0.20)$ & & \\
\hline
\end{tabular}
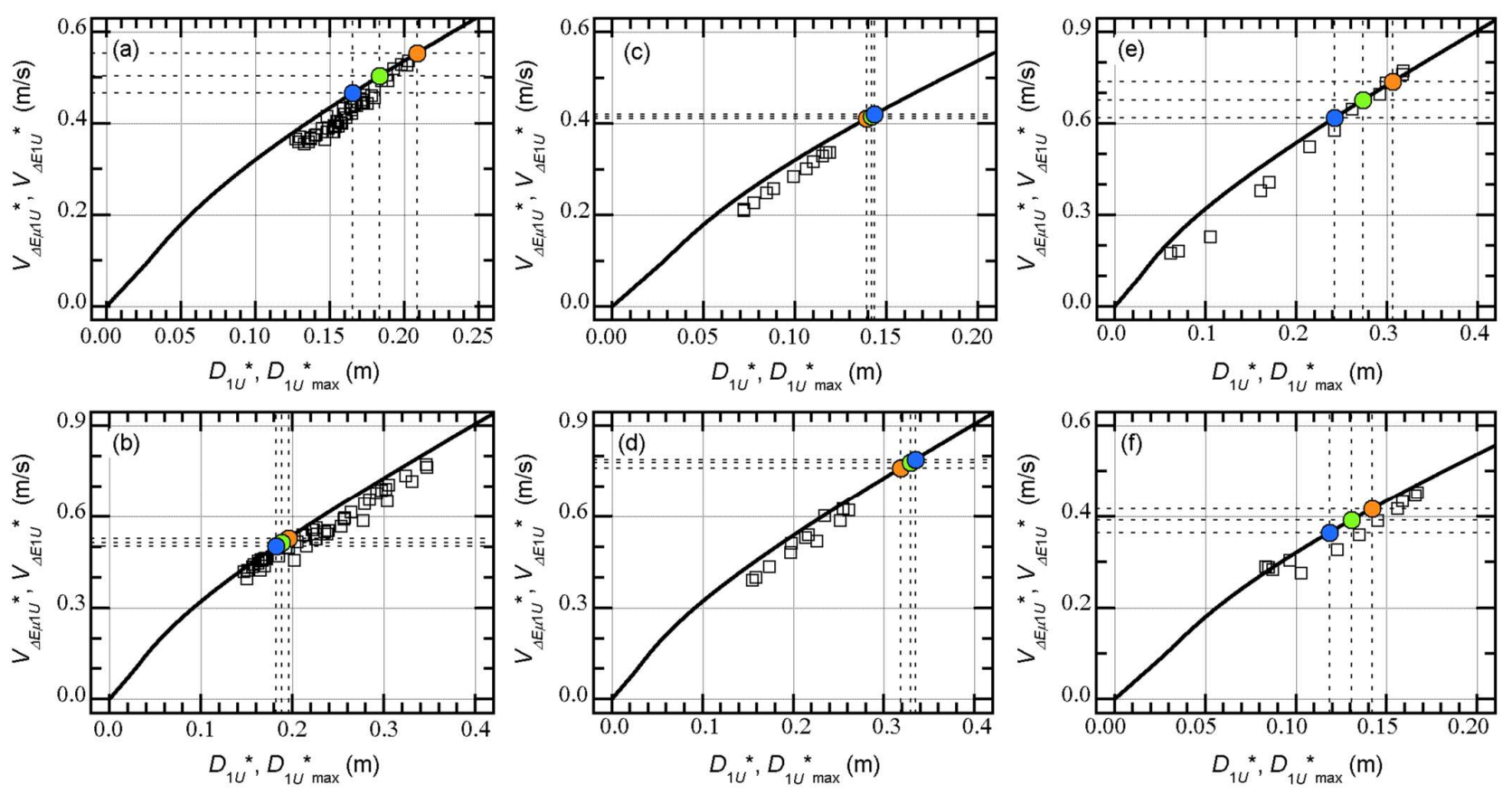

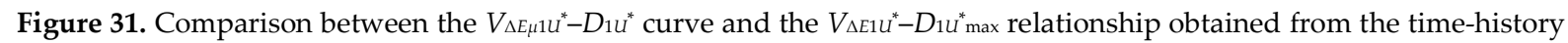
analysis (Model-Tf34): (a) Art-1 series; (b) Art-2 series; (c) UTO0414; (d) UTO0416; (e) TCU; (f) and YPT.
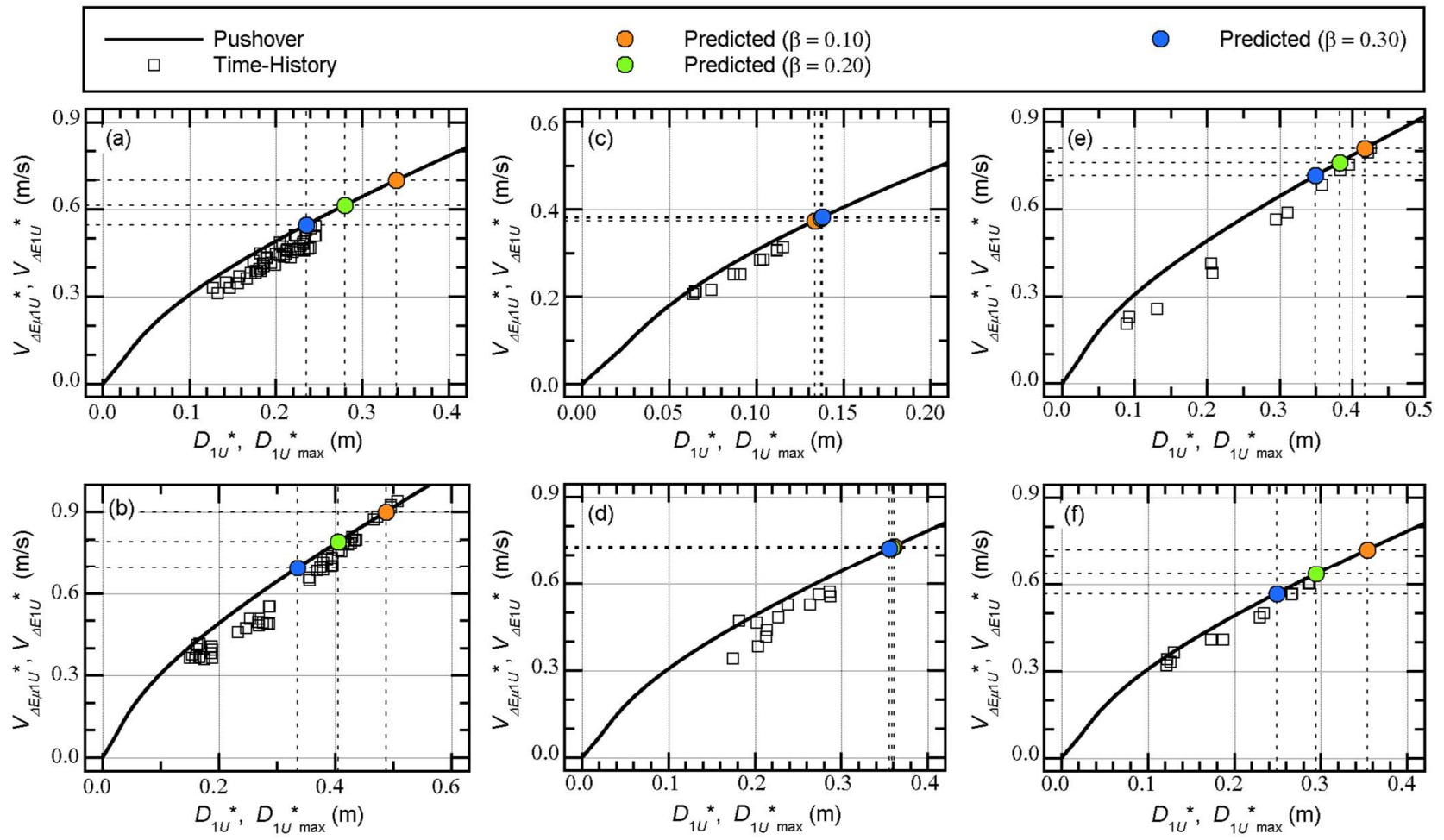

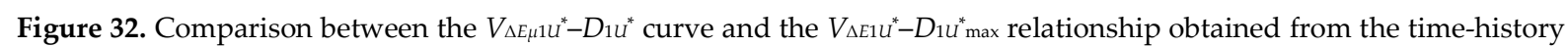
analysis (Model-Tf44): (a) Art-1 series; (b) Art-2 series; (c) UTO0414; (d) UTO0416; (e) TCU; (f) and YPT. 
5.3. Comparison of the maximum momentary input energy and the bidirectional momentary input energy spectrum

Figure 33 shows the prediction of $V_{\triangle E 1 U}{ }^{*}$ from the bidirectional $V_{\Delta E}$ spectrum for Model-Tf34. The plots shown in this figure indicate the nonlinear time-history analysis results.

In most cases, the bidirectional $V_{\Delta E}$ spectrum with complex damping $\beta=0.10$ approximates the upper bound of the plot of the time-history analysis results, as shown in Figures 33(a), 33(b), 33(e), and 33(f). However, in the other cases shown in Figures 33(c) and $33(\mathrm{~d})$, the plots of the time-history analysis results are below those of the bidirectional $V_{\Delta E}$ spectrum.

From the comparisons between the predicted $V_{\Delta E 1 U}{ }^{*}$ and that obtained from the time-history analysis results, the predicted $V_{\Delta E 1 U}{ }^{*}$ provides a conservative estimation, except in the case of the Art-2 series shown in Figure 33(b). This is because the predicted response points correspond to the "valley" of the bidirectional $V_{\Delta E}$ spectrum, therefore making the predicted $V_{\Delta E 1 U}{ }^{*}$ smaller.

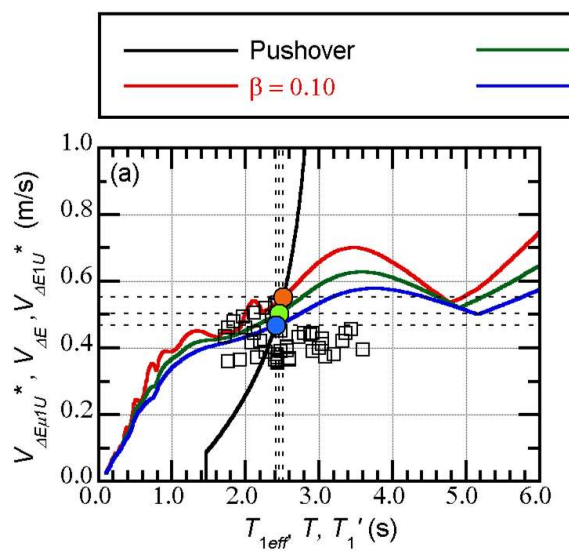

$\begin{array}{lll}\beta=0.20 & \square & \text { Time-History } \\ \beta=0.30 & \bigcirc & \text { Predicted }(\beta=0.10)\end{array}$

$\begin{array}{ll}\bigcirc & \text { Predicted }(\beta=0.20) \\ & \text { Predicted }(\beta=0.30)\end{array}$
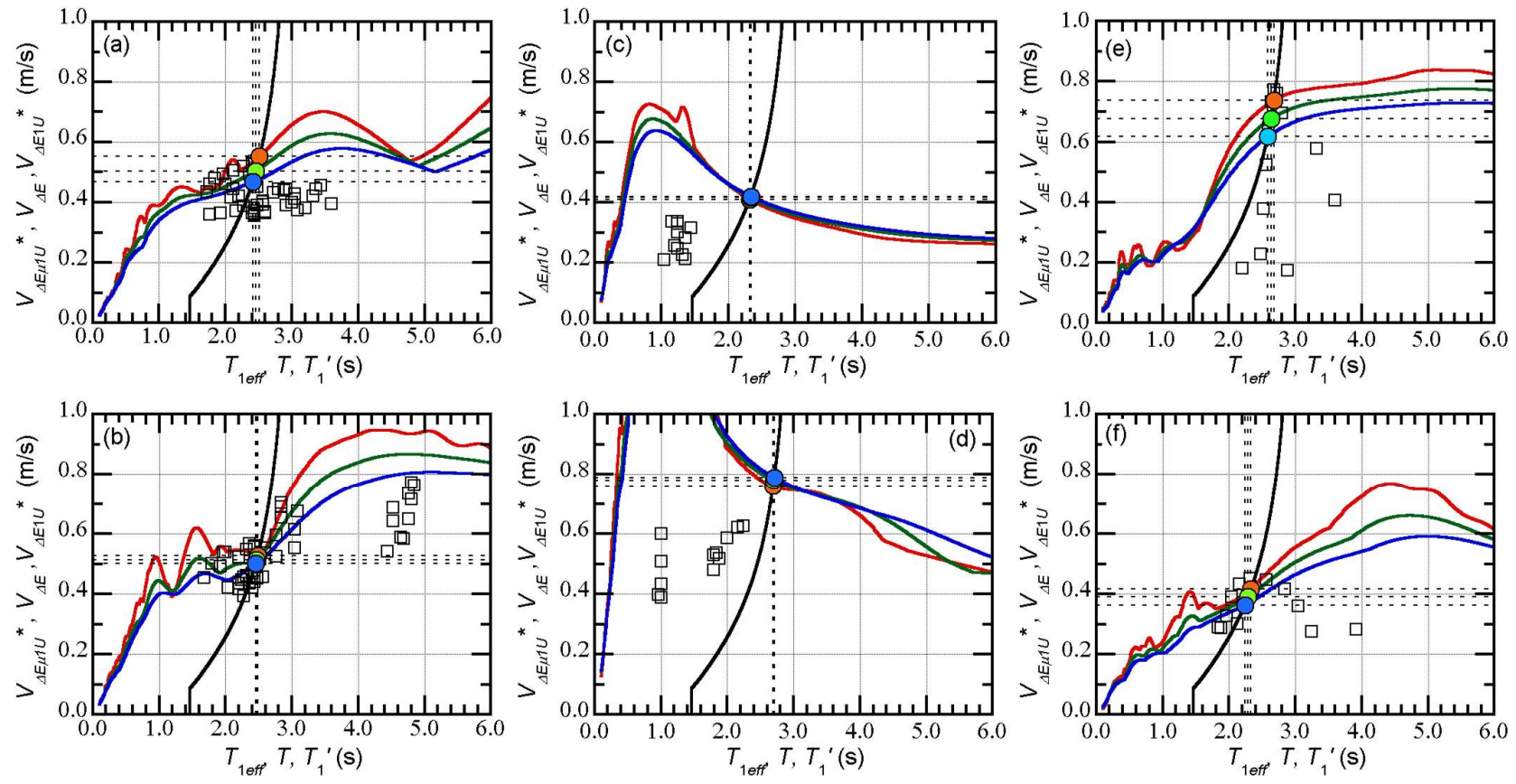

Figure 33. Prediction of $V_{\triangle E 1 U^{*}}$ from the bidirectional $V_{\triangle E}$ spectrum and its accuracy (Model-Tf34): (a) Art-1 series; (b) Art2 series; (c) UTO0414; (d) UTO0416; (e) TCU; and (f) YPT.

Figure 34 shows the prediction of $V_{\triangle E 1 U}$ * from the bidirectional $V_{\Delta E}$ spectrum for Model-Tf44. Similar observations to those made for Model-Tf34 can be made for ModelTf44.

Based on the above results, it can be concluded that that bidirectional $V_{\Delta E}$ spectrum can approximate the upper bound of the equivalent velocity of the maximum momentary input energy of the first mode $V_{\triangle E I U}$ ". Therefore, $V_{\triangle E 1 U}{ }^{*}$ can be properly predicted using the bidirectional $V_{\Delta E}$ spectrum. 


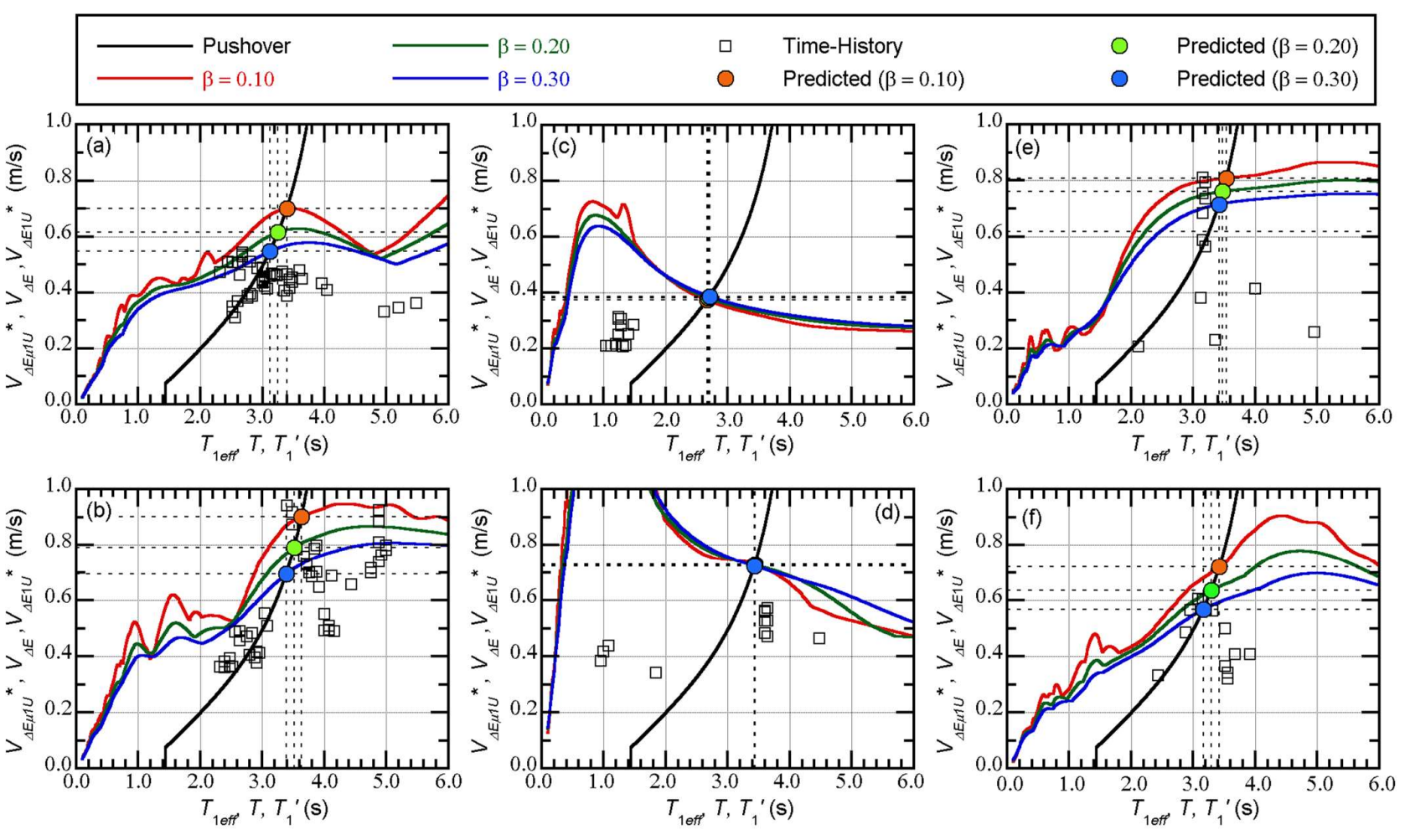

Figure 34. Prediction of $V_{\triangle E 1 U^{*}}$ from the bidirectional $V_{\triangle E}$ spectrum and its accuracy (Model-Tf44): (a) Art-1 series; (b) Art2 series; (c) UTO0414; (d) UTO0416; (e) TCU; and (f) YPT.

5.4. Accuracy of the predicted peak equivalent displacements of the first and second modal responses

Figure 35 shows the accuracy of the predicted peak equivalent displacement of the first and second modal responses, $D_{1 U}{ }^{*}{ }_{\max }$ and $D_{2 V}{ }^{*} \max$, respectively, for Model-Tf34. The predicted peak in the case of complex damping $\beta=0.10$ approximates the upper bound of the time-history analysis results, except when the ground motion dataset is the Art-2 series (Figure 35(b)) or YPT (Figure 35(f)).

Figure 36 shows the accuracy of the predicted $D_{1 U}{ }^{*}{ }_{\max }$ and $D_{2 V}{ }^{*}{ }_{\max }$ for Model-Tf44. The predicted peak in the case of $\beta=0.10$ approximates the upper bound of the timehistory analysis results in all cases.

It is also observed from Figures 35(c)-35(f) and 36(c)-36(f) that the largest $D_{1 U}{ }^{*}{ }^{*}$ ax and $D_{2 V}{ }^{*}{ }_{\max }$ do not occur simultaneously. To understand this phenomena, Figures 37 and 38 show $D_{1 U}{ }^{*}$ max and $D_{2 V}{ }^{*}$ max for varying angles of incidence of the seismic input ( $\psi$ ) for both models. As shown here, the angle where the largest $D_{2 V}{ }^{*}{ }_{\max }$ occurs is different from the angle where the largest $D_{1 U}{ }^{*}$ max occurs, with the difference between the two angles being approximately $90^{\circ}$. This is clearly observed in the cases of TCU and YPT for both models.

Based on the above discussion, the upper bound of the peak equivalent displacements of the first and second modal responses, $D_{1 U}{ }^{*}{ }_{\max }$ and $D_{2 V}{ }^{*}{ }_{\max }$, can be predicted by the updated MABPA. 

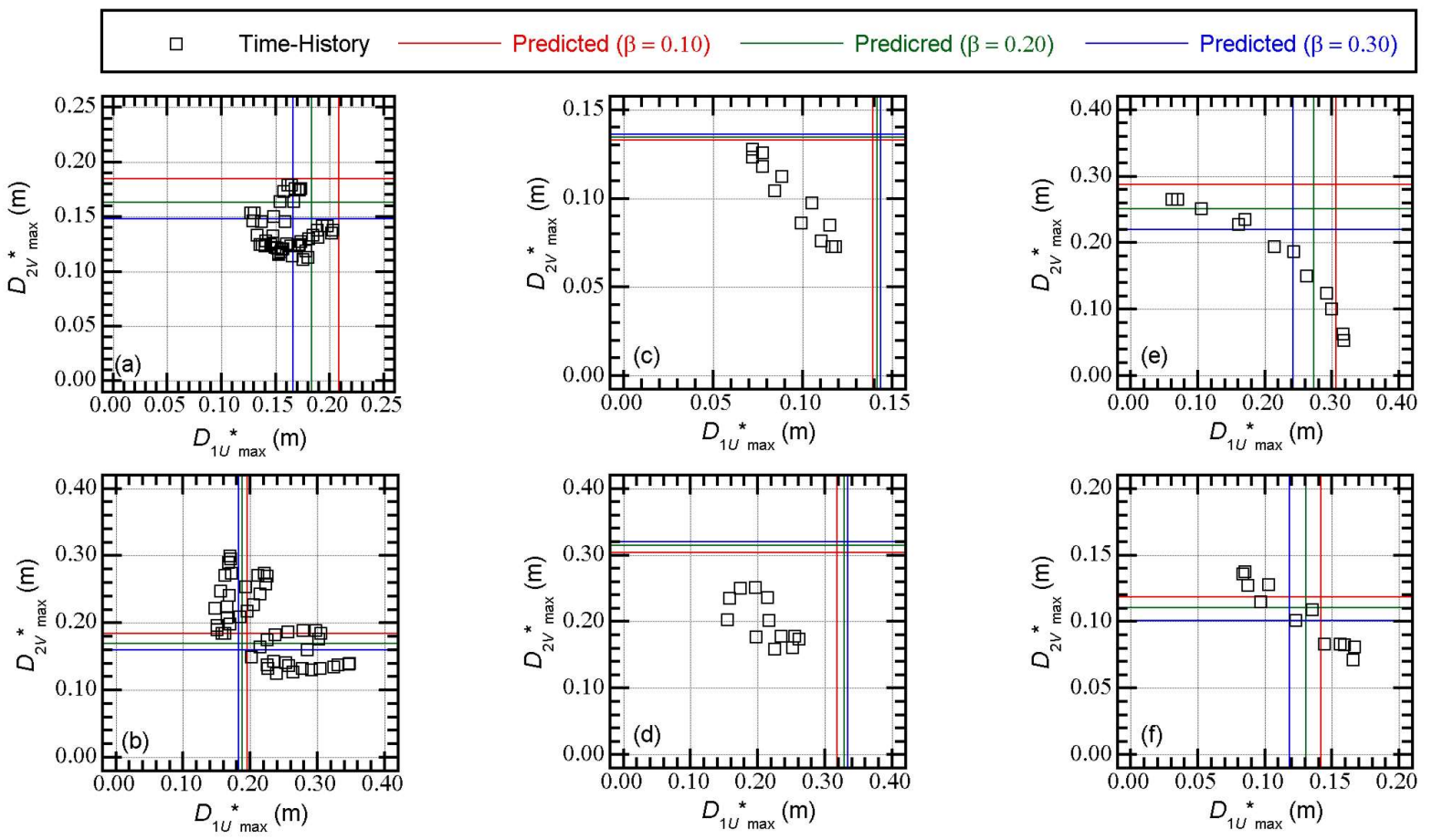

Figure 35. Accuracy of the predicted peak equivalent displacements of the first two modes (Model-Tf34): (a) Art-1 series; (b) Art-2 series; (c) UTO0414; (d) UTO0416; (e) TCU; and (f) YPT.

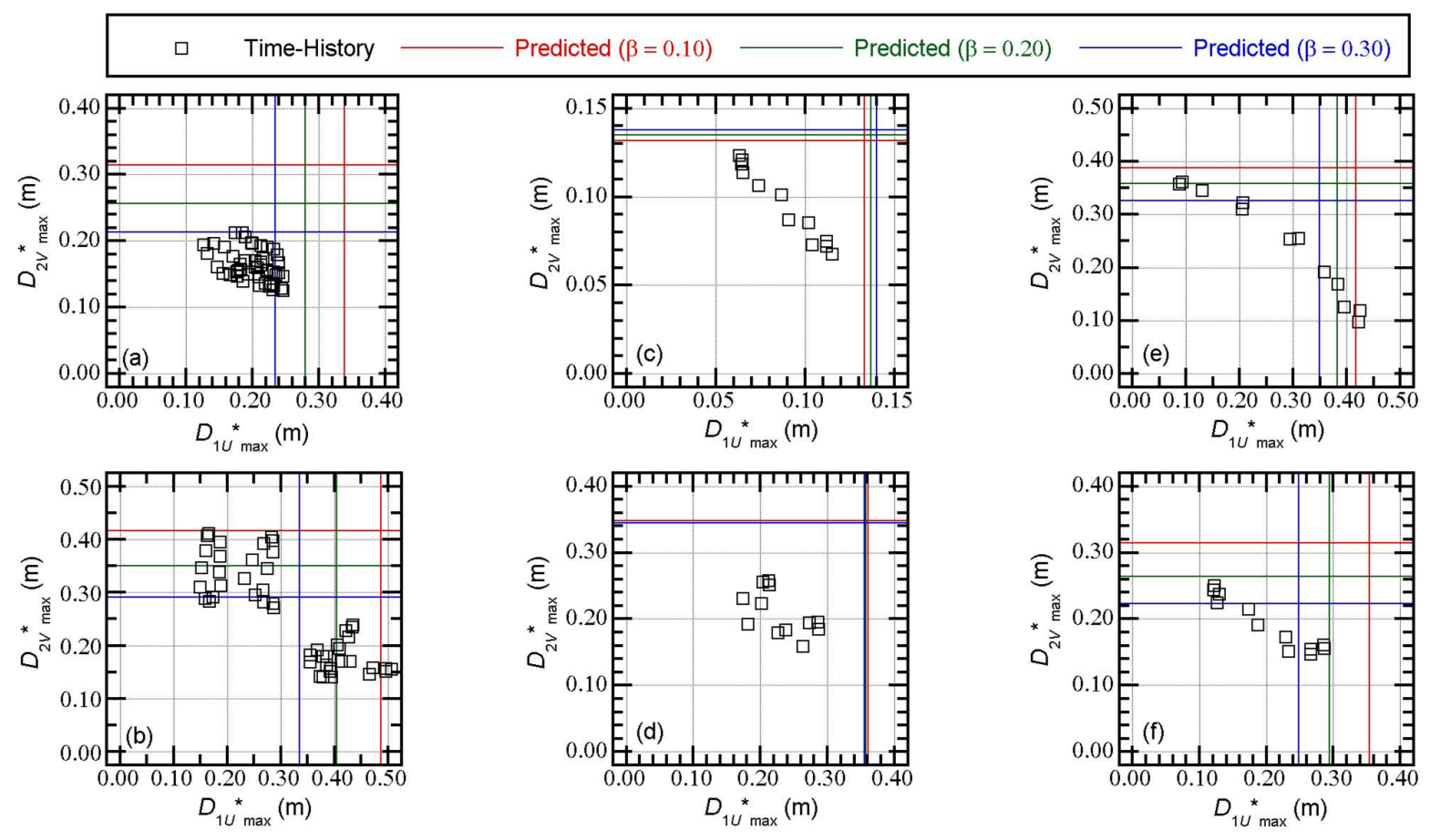

Figure 36. Accuracy of the predicted peak equivalent displacements of the first two modes (Model-Tf44): (a) Art-1 series; (b) Art-2 series; (c) UTO0414; (d) UTO0416; (e) TCU; and (f) YPT. 


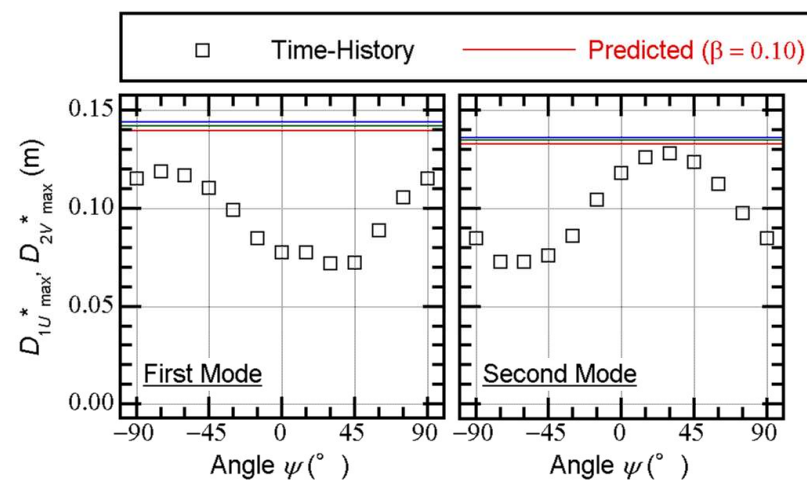

(a)

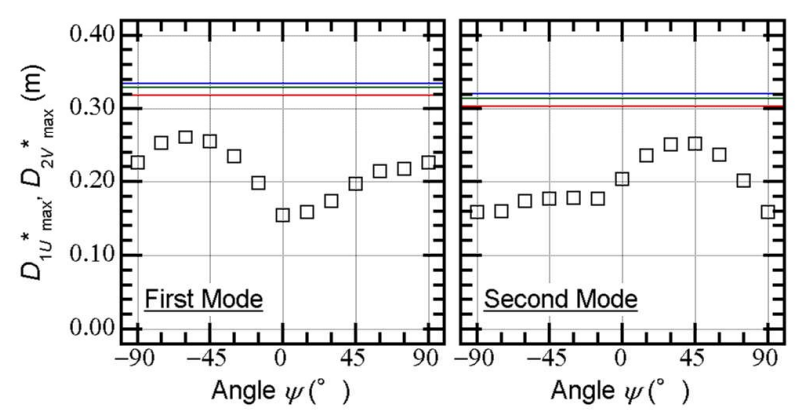

(b)

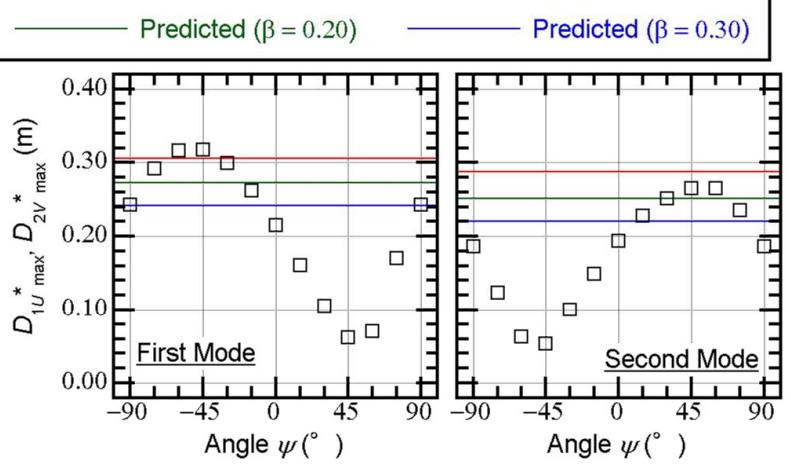

(c)

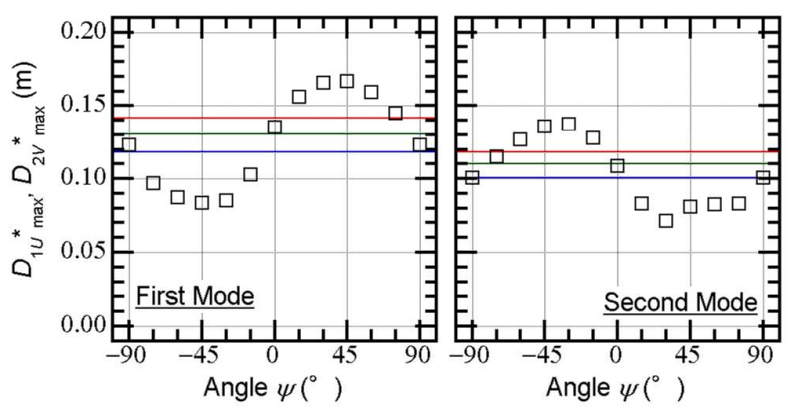

(d)

Figure 37. Peak equivalent displacements of the first two modes for various directions of seismic input (Model-Tf34): (a) UTO0414; (b) UTO0416; (c) TCU; and (d) YPT.

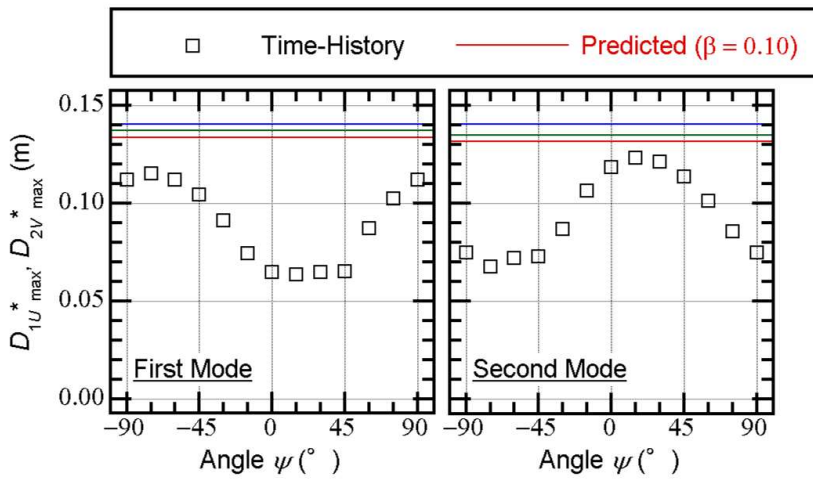

(a)

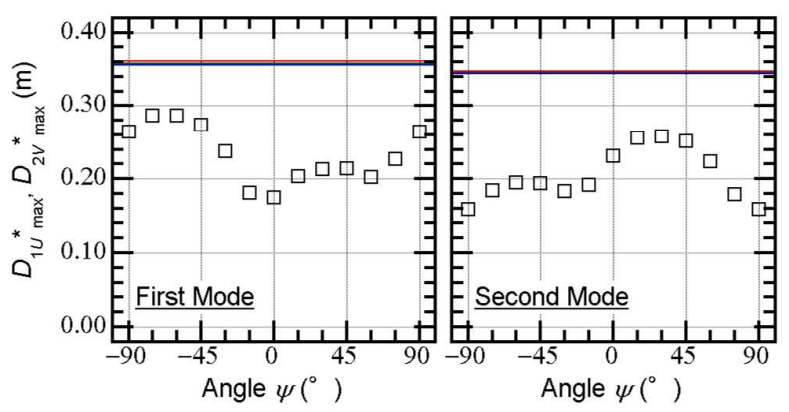

(b)

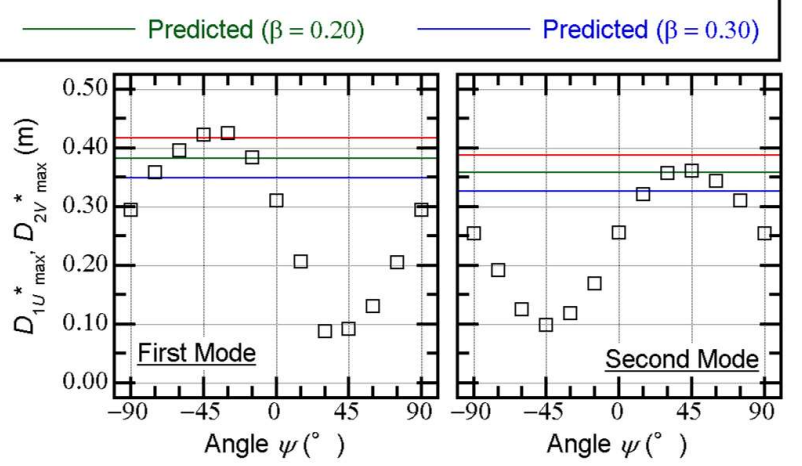

(c)

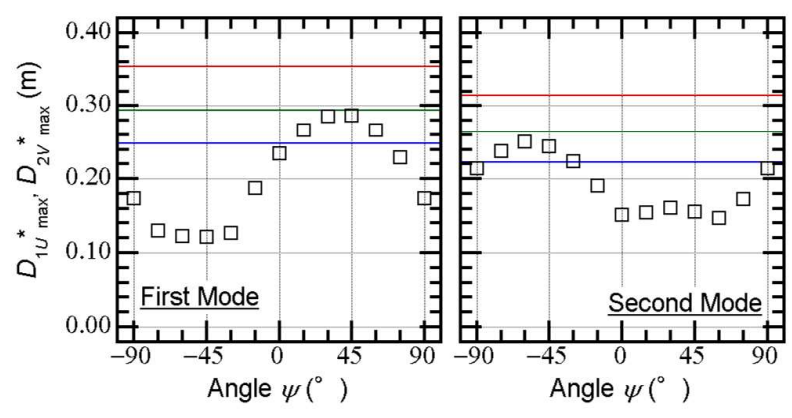

(d)

Figure 38. Peak equivalent displacements of the first two modes for various directions of seismic input (Model-Tf44): (a) UTO0414; (b) UTO0416; (c) TCU; and (d) YPT. 


\subsection{Contribution of the higher mode to the displacement response at the edge of level 0}

As discussed in Section 4.2.2, the accuracy of the predicted horizontal distribution of the peak response at level 0 depends on the ground motion dataset. According to ModelTf34, the predicted largest peak displacement in the Y-direction occurs at $\mathrm{X}_{1 \mathrm{~A}}$ (the flexible side in the Y-direction) while the envelope of the nonlinear time-history analysis results indicates that the largest peak occurs at $\mathrm{X}_{6 \mathrm{~A}}$ (the stiff side in the $\mathrm{Y}$-direction), the opposite side to $\mathrm{X}_{1 \mathrm{~A}}$, in the case of UTO0414, as shown in Figure 24(a). Conversely, in the case of TCU shown in Figure 24(b), the envelope of the time-history analysis results indicates that the largest peak occurs at $\mathrm{X}_{1 \mathrm{~A}}$, which is consistent with the predicted results. In this subsection, the modal response at level 0 is calculated and discussed.

From the time-history of the displacement at the center of mass of level 0 , the horizontal displacement in the Y-direction at point $j$ on level 0 can be calculated as

$$
d_{Y 0 j}(t)=y_{0}(t)-L_{X 0 j} \theta_{0}(t) .
$$

In Eq. (28), $L_{\mathrm{X} 0 j}$ is the location of point $j$ in the X-direction from the center of mass of level 0 . Therefore, the modal response of the horizontal displacement at point $j$ can be calculated as

$$
\begin{aligned}
& d_{Y 0 j 1}(t)=\Gamma_{1 U}\left(\phi_{Y 01}-L_{X 0 j} \phi_{\Theta 01}\right) D_{1 U}{ }^{*}(t), \\
& d_{Y 0 j 2}(t)=\Gamma_{2 V}\left(\phi_{Y 02}-L_{X 0 j} \phi_{\Theta 02}\right) D_{2 V}{ }^{*}(t), \\
& d_{Y 0 j h}(t)=d_{Y 0 j}(t)-\left\{d_{Y 0 j 1}(t)+d_{Y 0 j 2}(t)\right\} .
\end{aligned}
$$

Figure 39 shows comparisons of the modal responses at the edge of level 0 . The structural model shown in this figure is Model-Tf34, the input ground motion dataset is UTO0414, and the angle of incidence of the seismic input $(\psi)$ is $-75^{\circ}$, the angle at which the largest peak response at $\mathrm{X}_{1 \mathrm{~A}}$ occurs. Note that "All modes" is the response originally obtained from the time-history analysis results $\left(d_{\gamma_{0 j}}(t)\right)$, "First mode" and "Second mode" are the first and second modal responses $\left(d_{\gamma_{0 j 1}}(t)\right.$ and $\left.d_{\gamma_{0 j 2}}(t)\right)$, respectively, and "Higher mode" is the higher (residual) modal response calculated from Eq. (31) $\left(d_{\text {Yojh }}(t)\right)$.

In the response of $X_{1 A}$ shown in Figure 39(a), the contribution of the higher modal response is non-negligible, even though the contribution of the first modal response is predominant. In addition, the sign of the higher modal response at the time the peak response occurs at $\mathrm{X}_{1 \mathrm{~A}}$ is opposite to that of the "All mode" response, with the contribution of the higher mode reducing the peak response at $\mathrm{X}_{1 \mathrm{~A}}$.

In the response of $\mathrm{X}_{6 \mathrm{~A}}$ shown in Figure 39(b), the contribution of the first modal response is negligibly small and that of the second and higher modal responses are noticeable. In addition, the sign of the higher modal response at the time the peak response occurs at $\mathrm{X}_{6 \mathrm{~A}}$ is the same as that of the "All mode" response, with the contribution of the higher mode increasing the peak response at $\mathrm{X}_{6 \mathrm{~A}}$.

This indicates that the reason why the largest peak response in the envelope of the time-history analysis results occurs at $\mathrm{X}_{6 \mathrm{~A}}$ (not at $\mathrm{X}_{1 \mathrm{~A}}$ ) in the case of UTO0414 can be explained by the contributions of the higher modal response. In the case of UTO0414, the contribution of the higher modal response is non-negligibly large. 


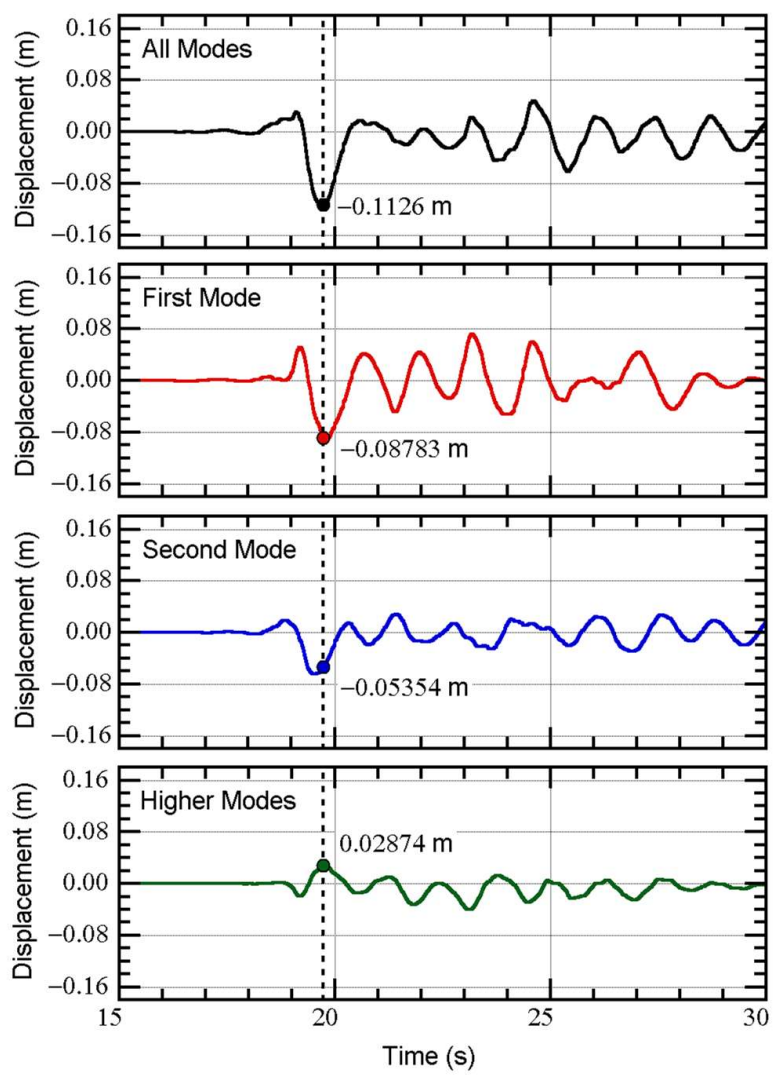

(a)
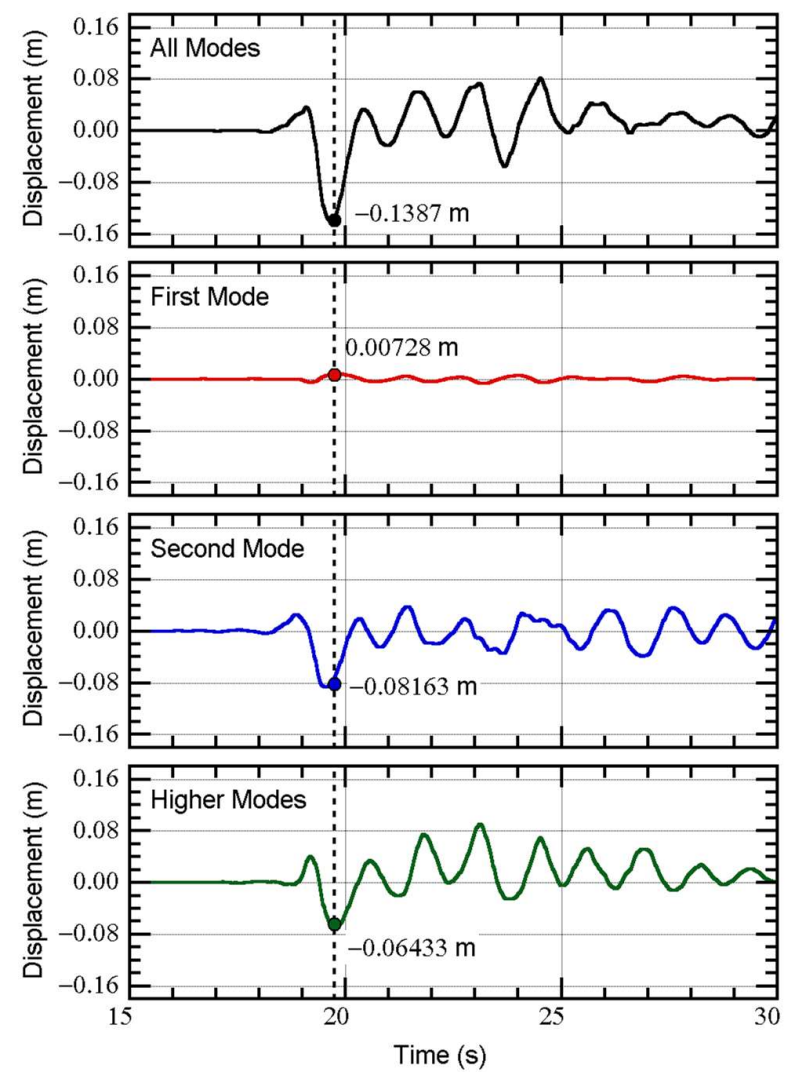

(b)

Figure 39. Comparisons of the modal responses at the edge of level 0 (structural model: Model-Tf34, ground motion: UTO0414, angle of incidence of seismic input: $\left.\psi=-75^{\circ}\right)$ : (a) $\mathrm{X}_{1 \mathrm{~A}}$ and (b) $\mathrm{X}_{6 \mathrm{~A}}$.

Another comparison is made in Figure 40 for the structural model Model-Tf34, the input ground motion dataset TCU, and an angle of incidence of the seismic input $(\psi)$ of $60^{\circ}$, where the angle of the largest peak response at $X_{1 \mathrm{~A}}$ occurs. In the response of $X_{1 \mathrm{~A}}$ shown in Figure 40(a), the contribution of the first modal response is predominant while that of the higher modal response is small. Meanwhile, in the response of $\mathrm{X}_{6 \mathrm{~A}}$ shown in Figure 40(b), the contribution of the first modal response is negligibly small and that of the second and higher modal responses are noticeable.

Therefore, the accuracy of the predicted horizontal distribution of the peak response at level 0 relies on the contribution of the higher modal response. The envelope of the time-history analysis results is notably different from the predicted results in the case of UTO0414 because the contribution of the higher modal response is significant. Meanwhile, the predicted results are close to the envelope of the time-history analysis results in the case of TCU because the contribution of the higher modal response is small. To confirm this, Table 6 lists the equivalent velocities of the maximum momentary input energy predicted from the bidirectional $V_{\Delta E}$ spectrum (complex damping ratio $(\beta)$ of 0.10 ) for the two cases. In this table, the values of the first and second modal responses are those predicted using MABPA, while the value of the third mode is predicted assuming that the effective period ( $\left.T_{3 e f f}\right)$ equals the natural period in the elastic range $\left(T_{3 e}\right)$. This table confirms that the contribution of the third mode may be noticeable in the case of UTO0414, while it may be small in the case of TCU.

In the MABPA prediction, only the contributions of the first and second modal responses are considered. Therefore, a discrepancy of the predicted results from the time- 
history analysis may occur because of the lack of a contribution from the higher modal responses.
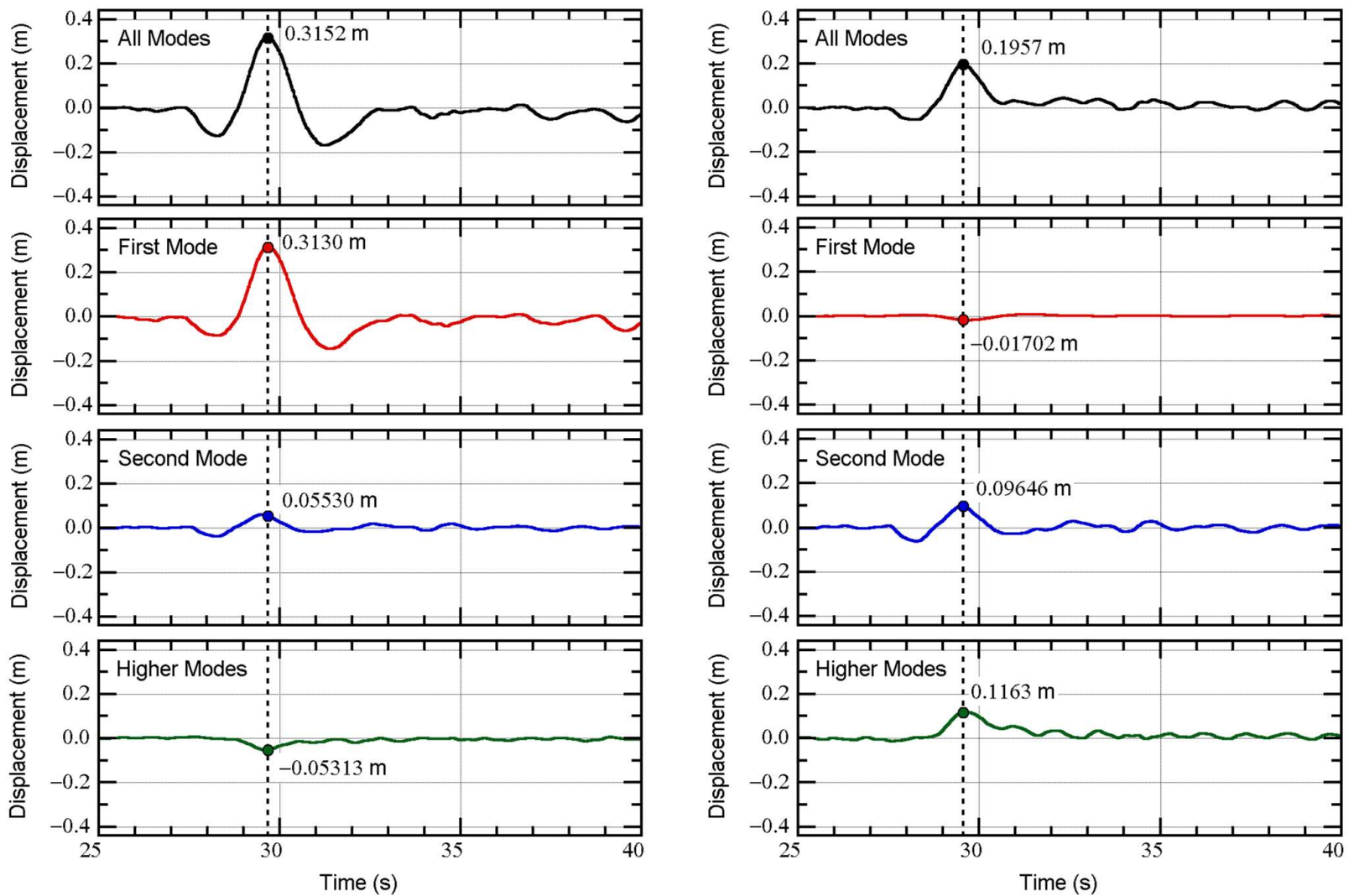

(a)

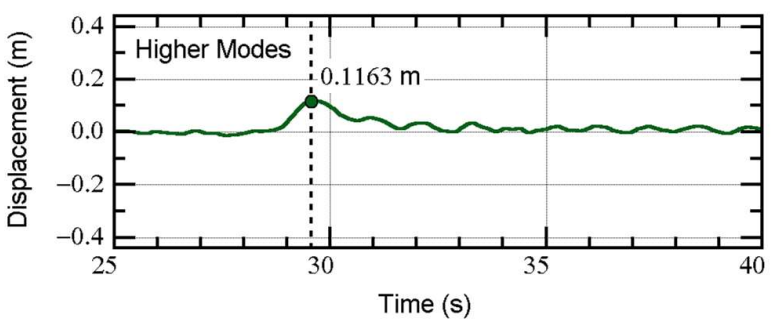

(b)

Figure 40. Comparisons of the modal responses at the edge of level 0 (structural model: Model-Tf34, ground motion: TCU, angle of incidence of seismic input: $\psi=60^{\circ}$ ): (a) $\mathrm{X}_{1 \mathrm{~A}}$ and (b) $\mathrm{X}_{6 \mathrm{~A}}$.

Table 6. Equivalent velocities of the maximum momentary input energy predicted from the bidirectional $V_{\Delta E}$ spectrum $(\beta=0.100)$.

\begin{tabular}{|c|c|c|c|c|c|}
\hline $\begin{array}{l}\text { Ground } \\
\text { motion set }\end{array}$ & $\begin{array}{c}\text { First Mode } \\
V_{\Delta E}\left(T_{1 e f f}\right) \\
(\mathrm{m} / \mathrm{s})\end{array}$ & $\begin{array}{c}\text { Second Mode } \\
V_{\Delta E}\left(T_{2 e f f}\right) \\
(\mathrm{m} / \mathrm{s})\end{array}$ & $\begin{array}{c}\text { Third Mode } \\
V_{\Delta E}\left(T_{3 e}\right) \\
(\mathrm{m} / \mathrm{s})\end{array}$ & $\begin{array}{c}\text { Ratio } \\
\text { (2nd / 1st) }\end{array}$ & $\begin{array}{c}\text { Ratio } \\
\text { (3rd / 1st) }\end{array}$ \\
\hline UTO0414 & 0.4108 & 0.4232 & 0.7151 & 1.030 & 1.741 \\
\hline TCU & 0.7575 & 0.7319 & 0.2519 & 0.9662 & 0.3325 \\
\hline
\end{tabular}

\section{Conclusions}

In this study, the main building of the former Uto City Hall was investigated as a case study of the retrofitting of an irregular reinforced concrete building using the baseisolation technique. The nonlinear peak responses of two retrofitted building models subjected to horizontal bidirectional ground motions were predicted by MABPA, and the accuracy of the method was evaluated. The main conclusions and results are as follows.

- $\quad$ The predicted peak response according to the updated MABPA agrees satisfactorily with the envelope of the time-history analysis results. The peak relative displacement at $\mathrm{X}_{3 \mathrm{~A}} \mathrm{Y}_{3}$ at each floor can be satisfactorily predicted. The predicted distribution of the peak displacement at level 0 (just above the isolation layer) approximates the envelope of the nonlinear time-history analysis results, even though in some cases the 
predicted distributions differ from the envelope of the nonlinear time-history analysis.

- The relationship between the equivalent velocity of the maximum momentary input energy of the first modal response $\left(V_{\Delta E 1 U}{ }^{*}\right)$ and the peak equivalent displacement of the first modal response $\left(D_{1 U}{ }^{*}{ }_{\max }\right)$ can be properly evaluated from the pushover analysis results. The plots obtained from the nonlinear time-history analysis results fit the evaluated curve from the pushover analysis results well.

- The upper bound of the peak equivalent displacements of the first two modal responses can be predicted using the bidirectional $V_{\Delta E}$ spectrum [41]. Comparisons between the predicted peak equivalent displacements and those calculated from the nonlinear time-history analysis results show that the predicted peak approximates the upper bound of the nonlinear time-history analysis results. The upper bound of $V_{\triangle E 1 U}{ }^{*}$ can be approximated by the bidirectional $V_{\Delta E}$ spectrum.

Based on the above findings, the updated MABPA appears to predict the peak responses of irregular base-isolated buildings with accuracy. However, MABPA still has two shortcomings. The first shortcoming is the limitation of the applicability of MABPA. As discussed in a previous study [32], the application of MABPA is limited to buildings classified as torsionally stiff buildings. The current (updated) MABPA has the same restriction. This limitation can be avoided if the torsional resistance of the isolation layer is sufficiently provided, as shown in this study. The second shortcoming involves the contributions of the higher modal responses. In the original MABPA for non-isolated buildings, only the first two modes were considered for the prediction. Therefore, the prediction was less accurate for cases when the response in the stiff-side perimeter was larger than that in the flexible-side perimeter. The contributions of the third and higher modal responses need to be investigated.

Another aspect of this study to be emphasized is the application of the bidirectional $V_{\Delta E}$ spectrum for the prediction of the peak response of a base-isolated building. The results shown in this study imply that the bidirectional $V_{\Delta E}$ spectrum [41] is a promising candidate for a seismic intensity parameter for the peak response. As discussed in a previous study [42], one of the biggest advantages of the bidirectional momentary input energy is that it can be directly calculated from the Fourier amplitude and phase angle of the ground motion components using a time-varying function of the momentary energy input, without knowing the time-history of the ground motion. This means that researchers can eliminate otherwise unavoidable fluctuations from the nonlinear time-history analysis results. Therefore, the pushover analysis and the bidirectional $V_{\triangle E}$ spectrum are an optimal combination to understand the fundamental characteristics of both base-isolated and nonisolated asymmetric buildings.

The optimal distribution of the hysteresis dampers according to the design of the isolation layer needed to minimize the torsional response is not discussed in this study. However, the updated MABPA presented here can help in the optimization of the damper distribution. By carrying out the pushover analysis and calculating the torsional index of the first three modes in each step, as shown in previous studies [31, 32], the contribution of the torsional response in each modal response can be monitored. Based on this, the damper distributions can be optimized. This is one of the issues that will be investigated in subsequent studies.

Author Contributions: Conceptualization, Kenji Fujii and Takumi Masuda; Data curation, Kenji Fujii and Takumi Masuda; Formal analysis, Kenji Fujii and Takumi Masuda; Funding acquisition, Kenji Fujii; Investigation, Kenji Fujii and Takumi Masuda; Methodology, Kenji Fujii; Project administration, Kenji Fujii; Resources, Kenji Fujii and Takumi Masuda; Software, Kenji Fujii; Supervision, Kenji Fujii; Validation, Kenji Fujii; Visualization, Kenji Fujii; Writing - original draft, Kenji Fujii; 
Writing - review \& editing, Kenji Fujii. All authors have read and agreed to the published version of the manuscript.

Funding: This research received no external funding.

Data Availability Statement: The data presented in this study are available on request from the corresponding author. The data are not publicly available because they are not part of ongoing research.

Acknowledgments: The ground motions used in this study were obtained from the website of the National Research Institute for Earth Science and Disaster Resilience (NIED) (http://www.kyoshin.bosai.go.jp/kyoshin/, last accessed on December 14, 2019) and the Pacific Earthquake Engineering Research Center (PEER) (https://ngawest2.berkeley.edu/, last accessed on December 14, 2019). The contributions during the beginning stage of this study made by Ami Obikata, a former undergraduate student at the Chiba Institute of Technology, are greatly appreciated.

Conflicts of Interest: The authors declare no conflict of interest.

\section{Appendix: Time-histories of the recorded ground motions used in this study}

Table A1 shows the date of event, magnitude (Meteorological Agency Magnitude $M_{J}$, or moment magnitude $\left.M_{W}\right)$, location of epicenter, distance, and station name of each record. Figures A1-A4 show the time-histories and orbits of the original ground motion records.

Table A1. Event date, magnitude, location of epicenter, distance, and station name of each record.

\begin{tabular}{|c|c|c|c|c|c|c|}
\hline \multirow{2}{*}{ ID } & \multirow{2}{*}{ Event date } & Magnitude & Distance & Station name & \multicolumn{2}{|c|}{ Direction of components } \\
\cline { 5 - 7 } UTO0414 & $2016 / 04 / 14$ & $M_{J}=6.5$ & $15 \mathrm{~km}$ & K-Net UTO (KMM008) & EW & NS \\
UTO0416 & $2016 / 04 / 16$ & $M_{J}=7.3$ & $12 \mathrm{~km}$ & K-Net UTO (KMM008) & EW & NS \\
TCU & $1999 / 09 / 20$ & $M_{W}=7.6$ & $0.89 \mathrm{~km}^{*}$ & TCU075 & major $^{* *}$ & minor \\
YPT & $1999 / 08 / 17$ & $M_{W}=7.5$ & $4.83 \mathrm{~km}^{*}$ & Yarimca & major $^{* *}$ & minor $^{* *}$ \\
\hline
\end{tabular}

* This distance is the closest distance from the rupture plane defined in the Pacific Earthquake Engineering Research Center (PEER) database, while those from the Japanese database are the epicentral distances.

** Horizontal major and minor axes are determined following the work done by Arias [50] and Penzien and Watabe [51].
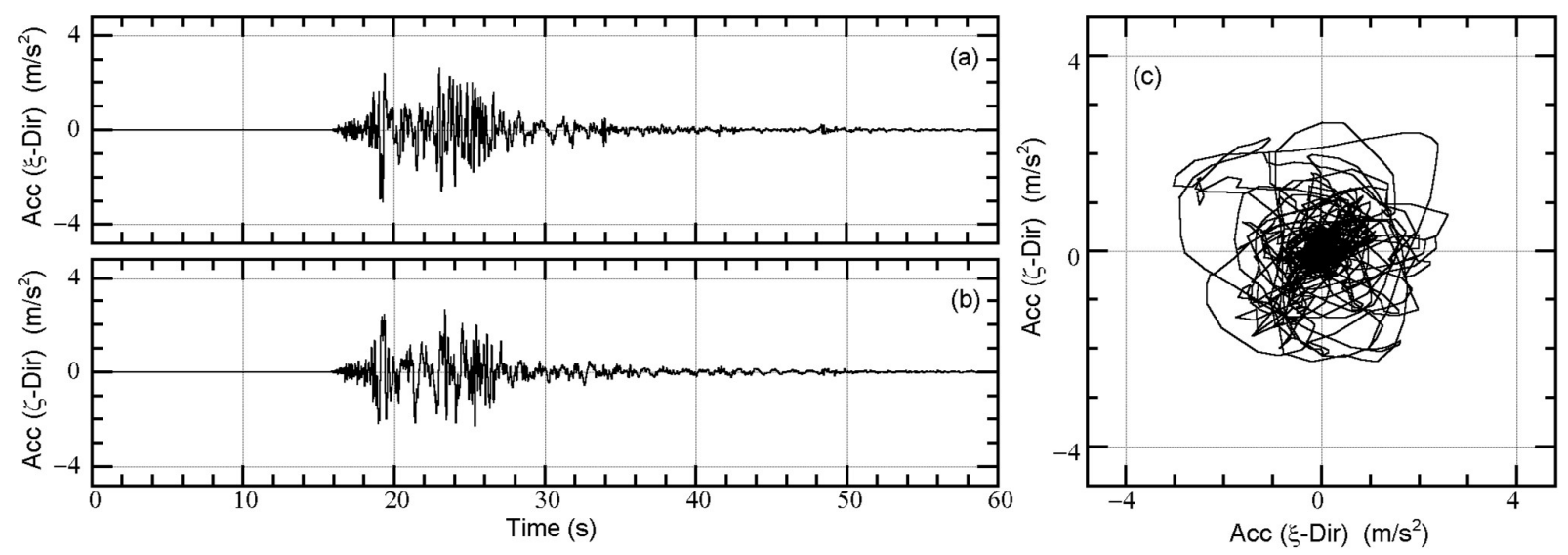

Figure A1. Two components of the generated artificial ground motion (UTO0414): (a) $\xi$-direction; (b) $\zeta$-direction; and (c) orbit. 

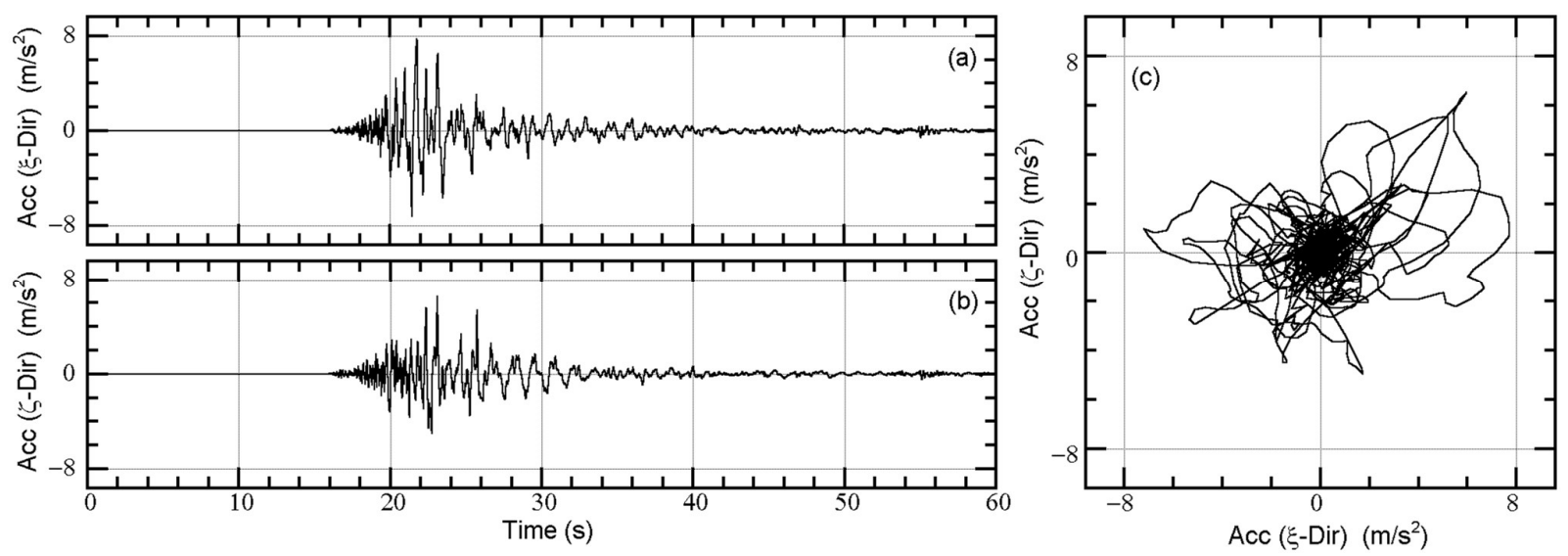

Figure A2. Two components of the generated artificial ground motion (UTO0416): (a) $\xi$-direction; (b) $\zeta$-direction; and (c) orbit.
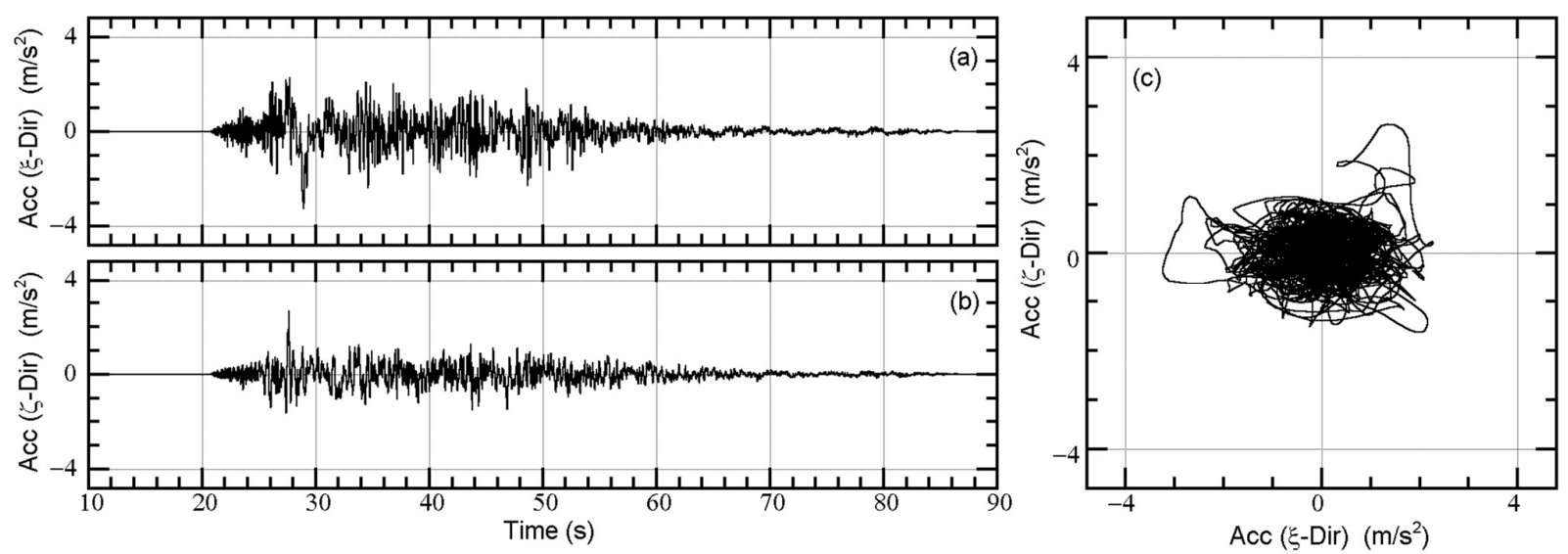

Figure A3. Two components of the generated artificial ground motion (TCU): (a) $\xi$-direction; (b) $\zeta$-direction; and (c) orbit.
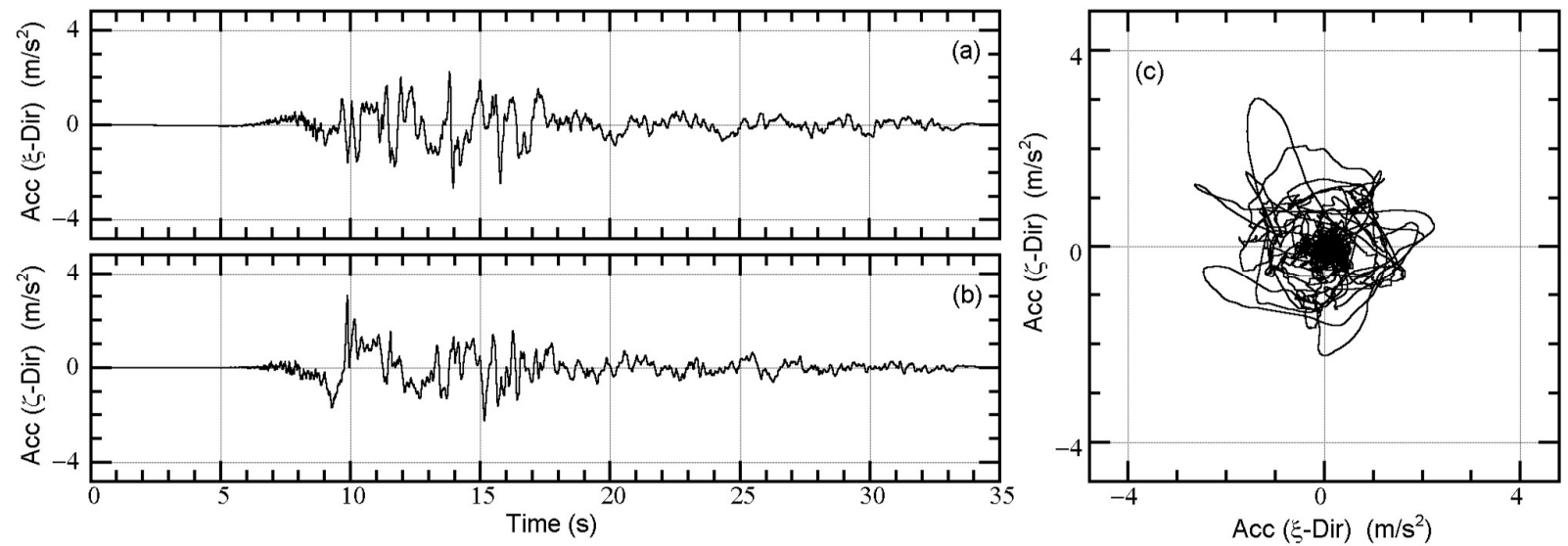

Figure A4. Two components of the generated artificial ground motion (YPT): (a) $\xi$-direction; (b) $\zeta$-direction; and (c) orbit.

\section{References}

1. Charleson, A.; Guisasola, A. Seismic isolation for architects; Routledge: London and New York, the United Kingdom and the United States, 2017. 
2. Architectural Institute of JAPAN (AIJ). Design recommendations for seismically isolated buildings; Architectural Institute of Japan: Tokyo, Japan, 2016.

3. ASCE. Seismic Evaluation and Retrofit of Existing Buildings; ASCE standard, ASCE/SEI41-17; American Society of Civil Engineering: Reston, VA, USA, 2017.

4. Seki M.; Miyazaki M.; Tsuneki Y.; Kataoka K. A Masonry school building retrofitted by base isolation technology, Proceedings of the 12th World Conference on Earthquake Engineering, Auckland, New Zealand, 30 January - 4 February 2000.

5. Clemente P.; De Stefano A. Application of seismic isolation in the retrofit of historical buildings. Earthquake Resistant Engineering Structures VIII, WIT Transactions on The Built Environment 2011, 120, 41-52.

6. SJ Gilani A.; Kit Miyamoto H. Base isolation retrofit challenges in a historical monumental building in Romania, Proceedings of the 15th World Conference on Earthquake Engineering, Lisbon, Portugal, 24 - 28 September 2012.

7. Nakamura H.; Ninomiya T.; Sakaguchi T.; Nakano Y.; Konagai K.; Hisada Y.; Seki M.; Ota T.; Yamazaki Y.; Mochizuki S.; Yanagi T.; Ohishi T.; Takahashi A. Seismic isolation retrofit of Susano City Hall situated above lava tubes, Proceedings of the 15th World Conference on Earthquake Engineering, Lisbon, Portugal, 24 - 28 September 2012.

8. Sorace S.; Gloria Terenzi G. A viable base isolation strategy for the advanced seismic retrofit of an r/c building. Contemporary Engineering Sciences 2014, 7, 817-834.

9. Terenzi G.; Fuso E.; Sorace S.; and Costoli I. Enhanced seismic retrofit of a reinforced concrete building of architectural interest. Buildings 2020, 10, 211. https://doi.org/10.3390/buildings10110211

10. Vailati M.; Monti G.; Bianco V. Integrated solution-base isolation and repositioning-for the seismic rehabilitation of a preserved strategic building. Buildings 2021, 11, 164. https://doi.org/10.3390/buildings11040164

11. Usta P. Investigation of a base-isolator system's effects on the seismic behavior of a historical structure. Buildings 2021, 11, 217. https://doi.org/10.3390/buildings11050217

12. Nagarajaiah S.; Reinhorn AM.; C. Constantinou MC. Torsion in base-isolated structures with elastomeric isolation systems. Journal of Structural Engineering, ASCE 1992, 119 (10), 2932-2951.

13. Tena-Colunga A.; Gómez-Soberón L. Torsional response of base-isolated structures due to asymmetries in the superstructure. Engineering Structures 2002, 24, 1587-1599.

14. Tena-Colunga A.; Zambrana-Rojas C. Dynamic torsional amplifications of base-isolated structures with an eccentric isolation system. Engineering Structures 2006, 28, 72-83.

15. Tena-Colunga A.; Escamilla-Cruz JL. Torsional amplifications in asymmetric base-isolated structures. Engineering Structures 2008, 29, 237-247.

16. Seguín CE.; De La Llera JC.; Almazán JL. Base-structure interaction of linearly isolated structures with lateral-torsional coupling. Engineering Structures 2008, 30, 110-125.

17. Di Sarno L.; Chioccarelli E.; Cosenza E. Seismic response analysis of an irregular base isolated building. Bulletin of Earthquake Engineering 2011, 9, 1673-1702.

18. Mazza F.; Mazza M. Nonlinear seismic analysis of irregular r.c. framed buildings base-isolated with friction pendulum system under near-fault excitations. Soil Dynamics and Earthquake Engineering 2016, 90, 299-312.

19. Cancellara D.; De Angelis F. Assessment and dynamic nonlinear analysis of different base isolation systems for a multi-storey rc building irregular in plan. Computers and Structures 2017, 180, 74-88.

20. Mazza F. Seismic demand of base-isolated irregular structures subjected to pulse-type earthquakes. Soil Dynamics and Earthquake Engineering 2018, 108, 111-129.

21. Volcev R.; Postolov N.; Todorov K.; Lazarov L. Base isolation as an effective tool for plan irregularity reduction. In Seismic Behaviour and Design of Irregular and Complex Civil Structures III; Köber, D., De Stefano M., Zembaty Z. Eds.; Springer Nature Switzerland: Cham, Switzerland, 2020; pp. 377-389.

22. Köber D.; Semrau P.; Weber F. Design approach for an irregular hospital building in Bucharest, Proceedings of the 9th European Workshop on the Seismic Behaviour of Irregular and Complex Structures, Online, 15 - 16, December 2020.

23. Reyes JC. Seismic behaviour of torsionally-weak buildings with and without base isolators, Proceedings of the 9th European Workshop on the Seismic Behaviour of Irregular and Complex Structures, Online, 15 - 16, December 2020.

24. Koren, D.; Kilar, V. Seismic behaviour of asymmetric base isolated structures with various distributions of isolators. Engineering Structures 2009, 31, 910-921.

25. Koren, D.; Kilar, V. The applicability of the N2 method to the estimation of torsional effects in asymmetric base-isolated buildings. Earthquake Engineering \& Structural Dynamics 2011, 40, 867-886.

26. Peruś I.; Fajfar P. On the inelastic torsional response of single-storey structures under bi-axial excitation. Earthquake Engineering and Structural Dynamics 2005, 34(8), 931-941.

27. Fajfar P.; Marušić D.; Peruś I. Torsional effects in the pushover-based seismic analysis of buildings. Journal of Earthquake Engineering 2005, 9(6), 831-854.

28. Fujii, K. Nonlinear static procedure for multi-story asymmetric frame buildings considering bi-directional excitation. Journal of Earthquake Engineering 2011, 15, 245-273.

29. Fujii, K. Prediction of the largest peak nonlinear seismic response of asymmetric buildings under bi-directional excitation using pushover analyses. Bulletin of Earthquake Engineering 2014, 12, 909-938. 
30. Fujii, K. Application of the pushover-based procedure to predict the largest peak response of asymmetric buildings with buckling-restrained braces, Proceedings of the 5th ECCOMAS Thematic Conference on Computational Methods in Structural Dynamics and Earthquake Engineering (COMPDYN), Crete Island, Greece, 25-27 May 2015.

31. Fujii, K. Assessment of pushover-based method to a building with bidirectional setback. Earthquakes and Structures 2016, 11(3), 421-443.

32. Fujii, K. Prediction of the peak seismic response of asymmetric buildings under bidirectional horizontal ground motion using equivalent SDOF model. Japan. Architectural Review 2018, 1, 29-43.

33. Fujii, K. Pushover-based seismic capacity evaluation of Uto City Hall damaged by the 2016 Kumamoto Earthquake. Buildings 2019, 9, 140. https://doi.org/10.3390/buildings9060140

34. Building Center of Japan (BCJ). The building standard law of Japan on CD-ROM; The Building Center of Japan: Tokyo, Japan, 2016.

35. Güneş N.; Ulucan ZÇ. Nonlinear dynamic response of a tall building to near-fault pulse-like ground motions, Bulletin of Earthquake Engineering 2019, 17, (6): pp. 2989-3013.

36. Akiyama H. Earthquake-resistant limit-state design for buildings. University of Tokyo Press, Tokyo, Japan, 1985.

37. Nakamura T.; Hori N.; Inoue N. Evaluation of damaging properties of ground motions and estimation of maximum displacement based on momentary input energy, Journal of Structural and Construction Engineering, Transactions of the AIJ 1998, 513, pp. 65-72. (in Japanese)

38. Inoue N.; Wenliuhan H.; Kanno H.; Hori N.; Ogawa J. Shaking Table Tests of Reinforced Concrete Columns Subjected to Simulated Input Motions with Different Time Durations, Proceedings of the 12th World Conference on Earthquake Engineering, Auckland, New Zealand, 30 January - 4 February 2000.

39. Hori N.; Inoue N. Damaging properties of ground motion and prediction of maximum response of structures based on momentary energy input. Earthquake Engineering \& Structural Dynamics 2002, 31 (9), pp. 1657-1679.

40. Fujii K.; Kanno H.; Nishida T. Formulation of the time-varying function of momentary energy input to a SDOF system by Fourier series, Journal of Japan Association for Earthquake Engineering 2019, 19 (5), 247-266. (in Japanese).

41. Fujii K.; Murakami Y. Bidirectional momentary energy input to a one-mass two-DOF system, Proceedings of the 17th World Conference on Earthquake Engineering, Sendai, Japan, 13 - 18 September 2020. (Conference postponed to 2021)

42. Fujii, K. Bidirectional seismic energy input to an isotropic nonlinear one-mass two-degree-of-freedom system. Buildings 2021, 11, 143. https://doi.org/10.3390/buildings11040143

43. Bridgestone Corporation. Seismic isolation product line-up version 2017 vol. 1. https://www.bridgestone.com/products/diversified/antiseismic_rubber/pdf/catalog_201710.pdf (accessed on 7th September 2021).

44. Bridgestone Corporation. Kenchiku-Menshin-yo Sekisou-Gomu-Seihin Shiyou-Ichiran (Seismic isolation product line-up) version 2021 vol. 1. https://www.bridgestone.co.jp/products/dp/antiseismic_rubber/product/pdf/product_catalog_202106.pdf (accessed on 7th September 2021).

45. Nippon Steel Engineering Co. Ltd. Men-shin NSU damper line-up. https://www.eng.nipponsteel.com/steelstructures/product/base_isolation/damper_u/lineup_du/ (accessed on 3rd August 2019, in Japanese).

46. Fujii, K. Prediction of the Maximum Seismic Member Force in a Superstructure of a Base-Isolated Frame Building by Using Pushover Analysis. Buildings 2019, 9, 201. https://doi.org/10.3390/buildings9090201

47. Wada, A.; Hirose K. Elasto-plastic dynamic behaviors of the building frames subjected to bi-directional earthquake motions. Journal of Structural and Construction Engineering. AIJ, 1989, 399, 37-47 (in Japanese).

48. Ordaz, M.; Huerta, B., Reinoso, E.: Exact Computation of Input-Energy Spectra from Fourier Amplitude Spectra, Earthquake Engineering \& Structural Dynamics 2003, 32 (4): pp.597-605.

49. Kuramoto, H. Earthquake response characteristics of equivalent SDOF system reduced from multi-story buildings and prediction of higher mode responses, Journal of Structural and Construction Engineering. AIJ, 2004, 580, 61-68 (in Japanese).

50. Arias, A. A measure of seismic intensity. In Seismic Design for Nuclear Power Plant; MIT Press: Cambridge, MA, USA, 1970; pp. 438-483.

51. Penzien, J.; Watabe, M. Characteristics of 3-dimensional earthquake ground motions. Earthquake Engineering E Structural Dynamics. 1975, 3, 365-373. 